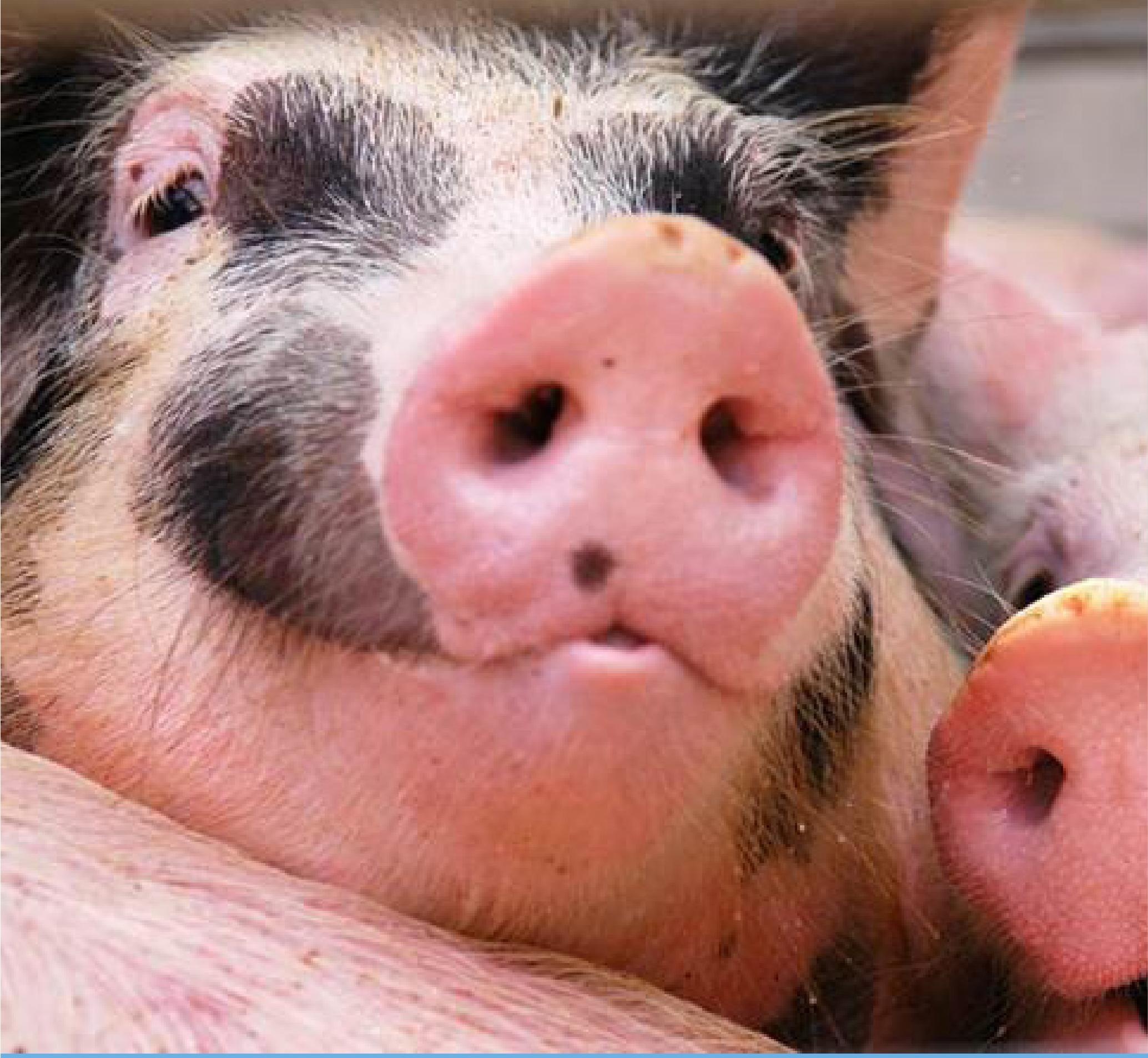

Amino acid requirements in relation to health status in growing and finishing pigs

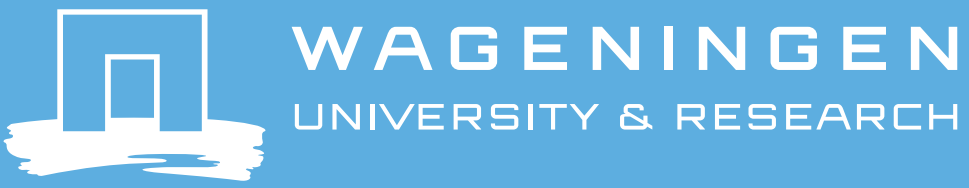





\section{Amino acid requirements in relation to health status in growing and finishing pigs}

C.M.C. van der Peet-Schwering, S.J. Koopmans, A.J.M. Jansman

Wageningen Livestock Research

This research was conducted by Wageningen Livestock Research as part of the Public Private Partnership "Feed4Foodure" (TKI-AF-16123), and funded by Vereniging Diervoederonderzoek Nederland (VDN) and the Ministry of Agriculture, Nature and Food Quality (LNV).

Wageningen Livestock Research

Wageningen, May 2019

Report 1168 
C.M.C. van der Peet-Schwering, S.J. Koopmans and A.J.M. Jansman, 2019. Amino acid requirements in relation to health status in growing and finishing pigs. Wageningen Livestock Research, Report 1168.

This report can be downloaded for free at https://doi.org/10.18174/477671 or at www.wur.nl/livestock-research (under Wageningen Livestock Research publications).

(C) 2019 Wageningen Livestock Research

P.O. Box 338, 6700 AH Wageningen, The Netherlands, T +31 (0)317 483953 ,

E info.livestockresearch@wur.nl, www.wur.nl/livestock-research. Wageningen Livestock Research is part of Wageningen University \& Research.

All rights reserved. No part of this publication may be reproduced and/or made public, whether by print, photocopy, microfilm or any other means, without the prior permission of the publisher or author.

Wageningen Livestock Research is NEN-EN-ISO 9001:2015 certified.

All our research commissions are in line with the Terms and Conditions of the Animal Sciences Group. These are filed with the District Court of Zwolle. 


\section{Table of contents}

$\begin{array}{ll}\text { Foreword } & 5\end{array}$

$\begin{array}{ll}\text { Summary } & 7\end{array}$

1

$\begin{array}{ll}\text { Introduction } & 9\end{array}$

2

$\begin{array}{ll}\text { Definition of health status } & 11\end{array}$

2.1 Health and immune status $\quad 11$

2.2 Experimental methods to activate the immune system 12

Immune system activation in relation to amino acid requirements $\quad 15$

$\begin{array}{lll}3.1 & \text { Feed intake } & 15\end{array}$

3.2 Digestibility of protein, amino acids and energy 18

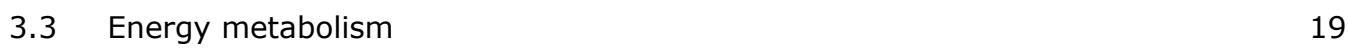

3.3.1 Maintenance requirement for energy 19

3.3.2 Efficiency of energy use for protein and fat deposition 20

$\begin{array}{lll}3.4 & \text { Protein and amino acid metabolism } & 21\end{array}$

3.4.1 Maintenance requirements for amino acids $\quad 21$

$\begin{array}{ll}3.4 .2 \text { Efficiency of protein deposition } & 22\end{array}$

3.4.3 Maximum protein deposition $\quad 25$

3.4.4 Amino acids costs for an activated immune system 26

3.4.5 Nutrient metabolism during and after LPS challenge using the amino acid $\begin{array}{ll}\text { and glucose clamp technique } & 31\end{array}$

3.4.6 Whole body protein turnover in pigs during LPS challenge 39

3.4.7 Immune system activation and changes in glucose and amino acid
metabolism in humans with an activated immune system

3.4.8 Beneficial effects of supplementing dietary BCAA on performance of pigs with an activated immune system. 41

3.5 Effects of amino acid supplementation on performance of pigs 42

Consequences of health status for amino acid and energy requirements at the level of the diet

4.1 Model to calculate effects of health status on amino acid and energy requirements and consequences for dietary levels of amino acids and energy 46

$\begin{array}{lll}4.2 & \text { Results } & 49\end{array}$

$\begin{array}{lll}4.3 & \text { Discussion } & 57\end{array}$

$\begin{array}{ll}\text { References } & 61\end{array}$

$\begin{array}{ll}\text { Appendix } 1 & 68\end{array}$

$\begin{array}{lr}\text { Appendix } 2 & 69\end{array}$

$\begin{array}{ll}\text { Appendix } 3 & \mathbf{7 0}\end{array}$

$\begin{array}{ll}\text { Appendix } 4 & \mathbf{7 1}\end{array}$

$\begin{array}{ll}\text { Appendix } 5 & \mathbf{7 2}\end{array}$

$\begin{array}{ll}\text { Appendix } 6 & 73\end{array}$ 



\section{Foreword}

Feed4Foodure is a public-private partnership between the Dutch Ministry of Agriculture, Nature and Food Quality, a consortium of various organizations within the animal production chain and Wageningen Livestock Research. Feed4Foodure aims to contribute to sustainable and healthy livestock farming in the Netherlands, simultaneously strengthening its competitive position on the global market.

In the Feed4Foodure program line "Improvement of the utilization of nitrogen in pigs" research is conducted to improve resource and protein efficiency in pigs. This report presents results of a review of the literature and results of research performed by Wageningen Livestock Research on the effects of health status on the amino acid and energy requirements in pigs and consequences for optimal amino acid and energy levels in the diet.

The authors thank the industry partners of the Feed4Foodure consortium for their valuable input in the study.

Alfons Jansman, project leader 


\section{Summary}

The present study provides an overview based on literature reports and studies performed by Wageningen Livestock Research on quantitative information related to changes in amino acid and energy metabolism and requirements of growing/finishing pigs as affected by health status and degree of immune system activation. Results of studies using challenges targeting gut health as well as studies focussed on systemic health were considered. The data were used to calculate the consequences for the quantitative changes at the level of the diet for requirements of amino acids and energy of pigs differing in health status using a factorial model to calculate protein deposition in a pig of $50 \mathrm{~kg}$.

Stimulation of the immune system using different challenge models with live pathogens (different pathogens and challenge levels) that lead to subclinical disease in pigs can reduce feed intake in the range of 3 to $25 \%$. Systemic immune system activation may decrease the digestibility of protein and amino acids in pigs mildly with up to 1 to $2 \%$, while the digestibility of energy seems hardly affected by systemic immune system activation. Immune system activation due to a sanitary challenge may reduce the ileal or faecal digestibility of protein and amino acids with 1 to $7 \%$ and the faecal digestibility of energy with about 3\%. Especially, when the health status of the gastrointestinal tract is compromised, digestibility of protein, amino acids and energy is reduced.

Systemic immune system activation by a non-pathogenic challenge may increase the maintenance requirement for energy with 10 to $30 \%$. Immune system activation due to a sanitary challenge may increase the maintenance requirement for energy with 7 to $12 \%$. As far as studied, no effect of immune system activation on the efficiency of use of metabolisable energy in the diet for retention of energy in body protein and fat was observed.

The maintenance requirement for individual amino acids may increase with 0 to $30 \%$ in pigs with an activated immune system. A low number of available studies showed that the maintenance requirement of lysine, methionine + cysteine, threonine may increase with up to 15, 23, and $5 \%$, respectively, or were not affected for tryptophan and arginine. No information is available whether the maintenance requirements of other essential amino acids are increased by immune system activation. Immune system activation has no effect on the post-absorptive utilization of lysine, methionine + cysteine, threonine and arginine for protein deposition. However, it may reduce the efficiency of tryptophan utilization for protein deposition in pigs with by $7 \%$. The efficiency of utilization of other essential amino acids for protein deposition as influenced by immune system activation is hardly studied.

Systemic immune system activation via a challenge with e.g. LPS or Complete Freund adjuvans decreases the maximum protein deposition in pigs with 4 to $12 \%$. Systemic immune system activation by a pathogenic challenge (PRRSV) decreases the maximum protein deposition in pigs with up to $35 \%$. Immune system activation due to a sanitary challenge can decrease maximum protein deposition with 10 to $25 \%$. Activation of the immune system may increase the amino acid requirements due to the production of immune proteins such as acute phase proteins and immunoglobulins. Total amino acid requirements, however, may decrease because of a reduced protein retention in the body, related to enhanced body protein degradation during immune challenge. Because the amino acid composition of acute phase proteins and immunoglobulins differ from the amino acid composition in muscle protein, the amino acid requirements and the ratio between amino acids required may change in pigs with an activated immune system. Immune system stimulation increases the metabolism and requirements of at least methionine + cysteine, tryptophan and threonine. It was concluded that additional dietary supplementation of methionine + cysteine, threonine and tryptophan, in addition to provision of amino acids for covering requirements for protein deposition, might be beneficial in pigs with an activated immune system.

Branched chain amino acids (BCAA; valine, leucine and isoleucine) were shown to play an important role in immune function and in the protection against skeletal muscle degradation during conditions of (strong) immune system activation. Immune system stimulation via a systemic challenge with LPS increased the net metabolic utilisation (NMU) for the branched chain amino acids with on average $30 \%$, suggesting an enhanced requirement for these amino acids under these conditions. Changes in requirements for BCAA are related to the recovery after skeletal muscle degradation during immune 
system activation, independent on the nature of the immune system. BCAA may therefore serve a more general purpose during immune system activation to support or maintain the growth performance of pigs.

Using the aforementioned information of the literature review, five scenario were selected for which model calculations were made, representing different conditions of health challenge considering gut and systemic challenges, both in acute and chronic form and a scenario called "low sanitary conditions". With the calculations, using a factorial model for calculating protein and energy deposition, the effects of the challenges on the amino acid and energy requirements at the level of the diet were estimated. In addition, calculations were made for the required increase in dietary levels of essential amino acids and in dietary energy density to compensate for the increased amino acid and energy requirements and the reduced feed intake under conditions of health challenge. For all scenario evaluated, the required increase in absolute levels of dietary essential amino acids was higher than the changes in the ratio relative to Lys. Relative to other essential amino acids, Trp and Thr seem to become first limiting under conditions of low health of pigs when their diet would not be changed. Our calculations showed that the supply of dietary energy can also limit protein deposition in most health scenario related to a lower feed (and energy) intake, a lower digestibility of dietary energy and increased maintenance requirements for energy under suboptimal health conditions. This indicates that increasing only dietary levels of (SID) amino acids without considering energy density of the diet will not result in maximum support of protein deposition under conditions of compromised health.

Results of the present study can be used by the feed industry to develop tailored diets with regard to amino acid composition and energy density for pigs on farms with a different health status. Application of this knowledge contributes to further optimize nitrogen and protein (resource) efficiency in pig production. 


\section{Introduction}

There is growing interest in understanding background of variation in the performance of growingfinisher pigs. This interest is based on the large consequences variation in the growth performance of pigs under practical conditions have in terms of impact on economy, environment, and resource and nutrient (nitrogen $(N)$, phosphorus $(P)$, energy) efficiency. Over 2016, it has been shown, that the gross margin per pig per farm in The Netherlands varies between $€ 65$ and $€ 115$ (20 and 80\% medians) (http://www.agrimatie.nl). Variation in growth performance and feed efficiency is related to characteristics of the animals (genotype, sex, health status), environmental factors (housing, climate, sanitary conditions, diet composition, feeding strategy and other management factors) and their interactions (Moloney and McGee, 2017; Patience et al., 2015). Some of the factors seem rather controlled, while others are rather uncontrolled and difficult to measure objectively. The latter complicates largely our ability to predict the performance of pigs under practical conditions.

The health status of pigs is supposed to be an important factor contributing to the large variation in pig performance (Van der Peet-Schwering and Jansman, 2007; Pastorelli et al., 2012b). The health status of pigs on farms in the EU has obtained large attention over the past decade related to the pressure to increase general health status of farm animals. The former is related to the pressure to reduce the use of therapeutic antibiotics and to the relationship between animal health on the one hand and animal performance and welfare on the other hand.

In commercial farms pigs are continuously exposed to both pathogenic and non-pathogenic agents, which can activate the immune system. During immune system activation, nutrients are redistributed from anabolic and maintenance processes towards processes involved in immunity (Klasing and Johnstone, 1991; Spurlock, 1997; Colditz, 2002). As a consequence, growth performance may reduce and amino acid (AA) requirements may change both in absolute as well as in relative terms after immune system activation.

Quantitative information on the effects of immune system activation on the AA requirements of pigs was rather limited up to more recently. Therefore, over the past 5-10 years increasing attention has been paid to the evaluation of the effects of health status and immune system activation on quantitative changes in nutrient and AA metabolism and requirements. In these studies, mostly effects on performance indicators, such as feed intake and body weight gain, or a limited number of specific (immune related) responses are measured in pigs under challenged and non-challenged conditions. The nature of the health and immune challenges applied in these studies differ widely and can be considered as very specific (e.g. challenge with a defined pathogen via a predefined route) to rather general/multifactorial (e.g. exposure to low sanitary status). Some challenges applied, focus on influencing gut health and immunity, while others target on influencing systemic health or e.g. lung health. Measured response parameters in such studies also vary widely in nature, which complicates the translation of results to changes in quantitative nutrient requirements of the pig under these conditions.

Meanwhile, it should be noted that classical AA requirement studies (dose - response titration studies), of which the results form the basis for our current recommendations for AA requirements, are often performed with pigs housed in a rather controlled environment with low pathogen pressure. These studies do in most cases not consider health status as a factor contributing to variation in AA requirements. This lack of knowledge hampers feed manufacturers in their ability to optimize pig diets in relation to variation in health status of pigs, and thereby contributing to further improving pig performance. Apart from the influence of immune system activation on AA requirements, there is increasing evidence that the dietary protein or AA supply can affect inflammatory responses per se during a period of immune system activation (Grimble et al., 1992; Jahoor et al., 1999; Li et al., 1999; Grimble, 2001; Li et al., 2007; Le Floc'h et al., 2008; Le Floc'h et al., 2009; Calder and Yaqoob, 2012), and thereby influence the capacity of the animal to cope with the challenge. 
It is hypothesized that feeding diets that are, in terms of nutrient composition, adjusted to variation in health status of pigs may improve overall nutrient utilization, production performance, and consequently reduce $\mathrm{N}$ excretion into the environment, while maintaining appropriate functioning of the immune system. In turn, feeding such tailored diets may also support the pig's capacity to cope with challenges of the immune system and the animal's health.

\section{Objective of the study}

The present study provides a state of the art overview of quantitative information related to changes in amino acid and energy metabolism and requirements of growing/finishing pigs as affected by health status and degree of immune system activation. Results of studies using challenges targeting gut health as well as studies focussed on systemic health were considered. Subsequently, these data were used to calculate the consequences for the quantitative AA and energy requirements of pigs differing in health status. The resulting information can be used by the feed industry to develop tailored diets with regard to AA composition for pigs on farms with a different health status. Application of this knowledge contributes to further optimize $\mathrm{N}$ and protein resource efficiency in pig production. 


\section{Definition of health status}

\section{$2.1 \quad$ Health and immune status}

Stimulation of the immune system triggers a series of responses of the animal, such as a reduction in feed intake, increases in energy expenditure, body protein catabolism and body temperature (Black, 1999), production of cytokines and acute phase proteins and fever (Heegaard et al., 2011). During immune system activation, nutrients are redistributed from anabolic and maintenance processes towards processes involved in immunity (Klasing and Johnstone, 1991; Spurlock, 1997; Colditz, 2002). A cascade of cytokine induced metabolic alterations occur, including reduced feed intake, increased breakdown and decreased synthesis of skeletal muscle protein, increased hepatic synthesis of acute phase proteins, and increased deamination of glucogenic amino acids among which the essential amino acids methionine, cysteine, threonine, tryptophan, isoleucine, valine, histidine and phenylalanine (Klasing and Johnstone, 1991; Lochmiller and Deerenberg, 2000; Le Floc'h et al., 2004). In pigs, immune system activation decreased feed intake, body weight (BW) gain, and $\mathrm{N}$ retention (Williams et al., 1997b; Daiwen et al., 2008; Le Floc'h et al., 2008). Moreover, nutrient partitioning can be altered away from body protein accretion towards metabolic responses in support of immune function (Klasing and Johnstone, 1991; Johnson, 1997; Spurlock, 1997). A schematic presentation of the impact of challenge by pathogens or other antigens on protein and AA metabolism is presented in Figure 1 (Kampman-van de Hoek, 2015). Exposure to pathogens or antigens activate the immune system and can reduce feed intake, intestinal absorption of AA, and body protein synthesis for body protein retention and growth. Invasion of pathogens or antigens may also stimulate endogenous protein and $A A$ losses in the gastrointestinal tract, protein synthesis for immune functioning, protein breakdown, and AA oxidation in organs and tissues. As a consequence, growth performance may reduce and AA requirements may change both in absolute as well as in relative terms.

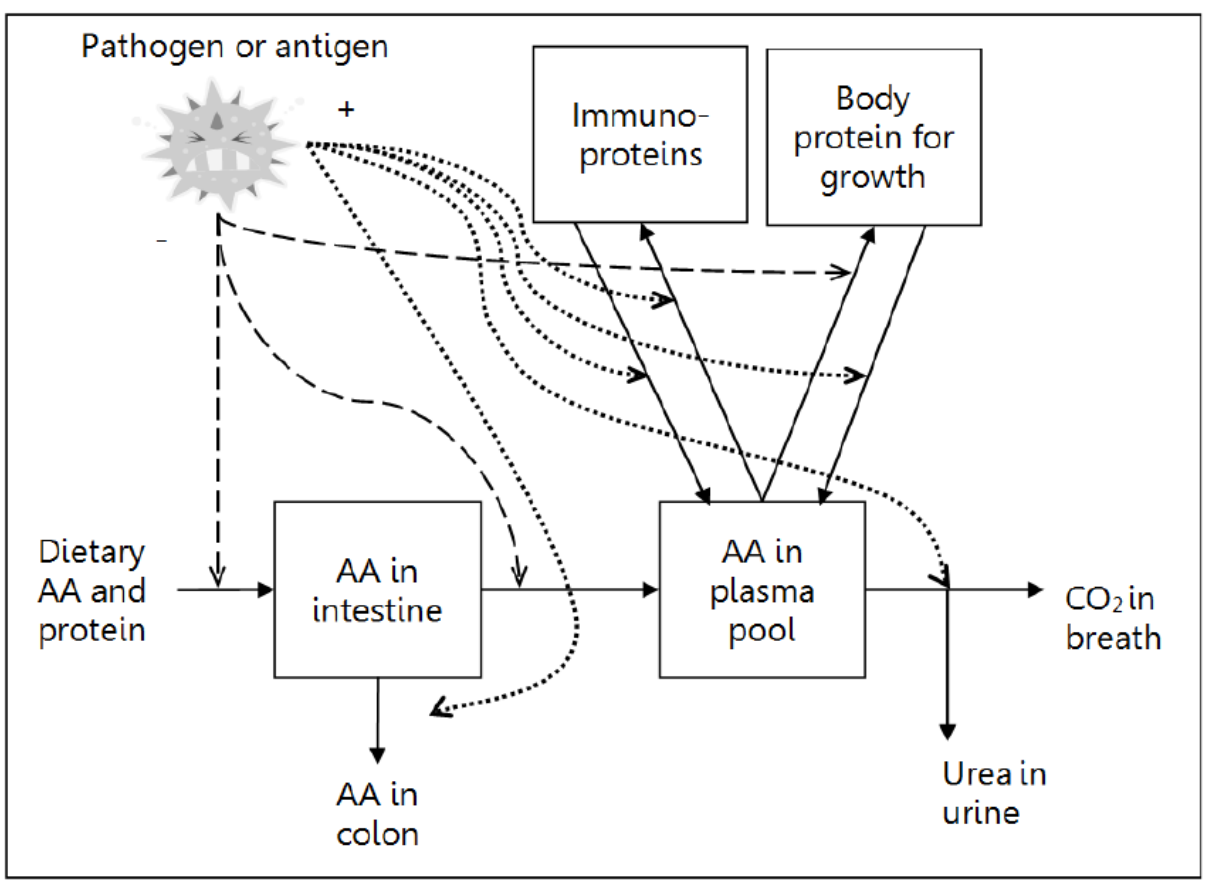

Figure 1 Impact of challenge with pathogens or antigens on protein and AA metabolism. Black solid arrows indicate nutrient fluxes. Black dotted arrows indicate stimulating effects, dashed arrows indicate inhibiting effects (Kampman-van de Hoek, 2015).

Animal health can be defined as the absence of disease as determined by clinical examinations in combination with various diagnostics tests (Petersen et al., 2004). Pigs, however, can suffer from 
clinical and subclinical infections and both can stimulate the immune system. Subclinical infections may be difficult to detect by clinical examinations (Stark, 2000) but may decrease performance of the pigs (Le Floc'h et al., 2004). Classifying the health status of pigs is important in applying targeted feeding strategies (Kampman-van de Hoek, 2015). Kampman-van de Hoek (2015) developed a concept for classification of the health status of growing-finishing pigs farms, based on commonly recorded data in the Netherlands. Six traits were incorporated into a health status web, being average daily gain (ADG), energy conversion ratio (ECR), mortality, incidence of pleuritis, and percentage rejected lungs and livers at slaughter over a period of one year (Figure 2). Each of the traits were assumed to be directly or indirectly related to the health status of pigs on farms.
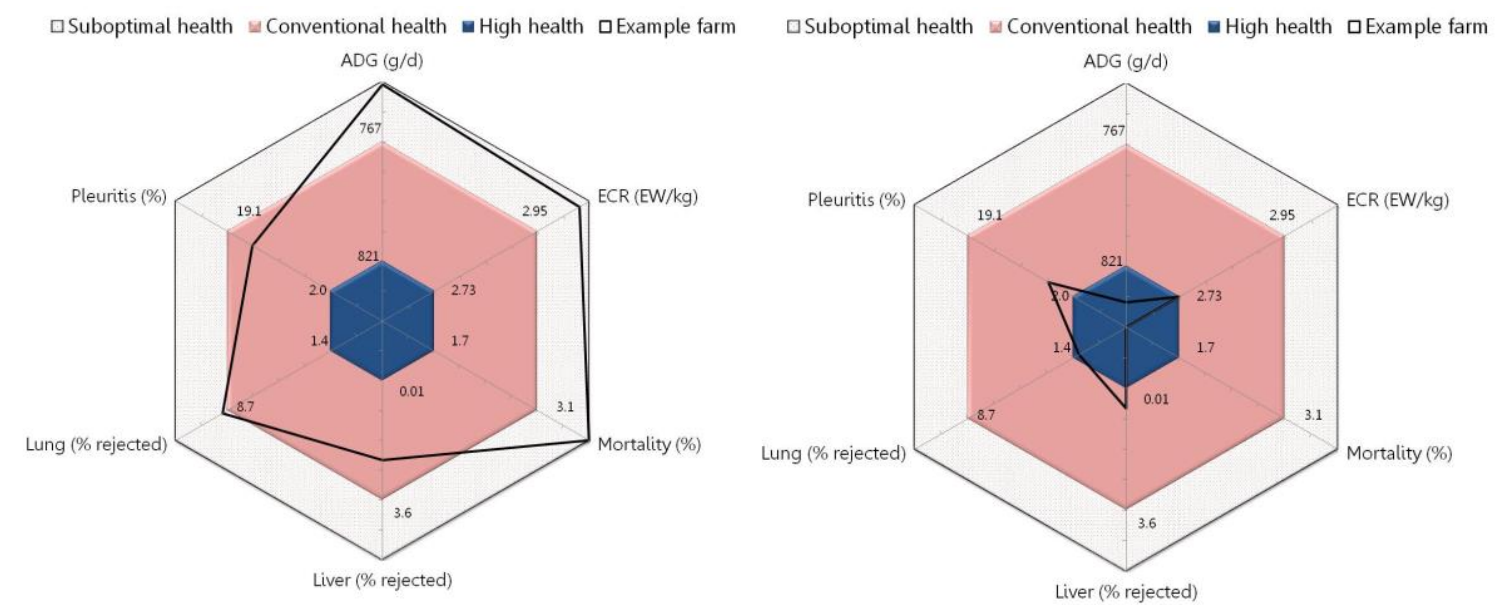

Figure 2 Graphical representation of the health status web of a farm characterized as having a low health status (left health status web) or a high health status (right health status web) according to the farm health status classification web. The 25th and 75th percentiles for each trait of the Dutch growing-finishing pig population in 2012 are displayed (Kampman-van de Hoek, 2015).

The health status web, that incorporates traits which are registered at farm level, are generally readily available and are collectively directly or indirectly related to (sub)clinical disease, and can be used to monitor medium to long term changes in health status of farms provided that the data of the six underlying farm traits of the growing-finishing population are updated each year. In addition, it can be used by feed companies to categorize farms on the basis of their health status and to develop farm specific diets taking into account their health status (Kampman-van de Hoek, 2015).

\subsection{Experimental methods to activate the immune system}

Different concepts and approaches have been developed to represent the effect of disease on feed intake and growth in pigs (Black et al., 1999; Sandberg et al., 2006; Kyriazakis and Doeschl-Wilson, 2009). Most studies in pigs evaluating the relationship between immune system stimulation and nutrient requirements use specific experimental challenge models. Both non-pathogenic agents such as LPS, Complete Freund's Adjuvant (CFA) and turpentine oil (TO) and live pathogenic bacteria such as Escherichia coli, PRRSv, Actinobacillus pleuropneumonia and Streptococcus suis bacteria are used to stimulate the immune system after administration via different routes. In addition, also sanitation challenge models are used to stimulate the immune system of pigs.

Administration of a single i.v. dose of LPS or a single challenge with LPS intraperitoneally (i.p.)leads to an acute short stimulation of the immune system of about 6 hours (Williams et al., 2009; De Greeff et al., 2016). By repeating the administration of LPS every two days the immune system can be stimulated for a period of about 7-10 days (Rakhshandeh and De Lange, 2012; de Ridder et al., 2012; Kim et al., 2012; Campos et al., 2014). Pigs develop, however, rapidly tolerance to LPS. To maintain a similar immune stimulating effect, an increased dosage of 12 or $15 \%$ relative to the previous dosage 
should be given at each subsequent injection (van der Meer, 2017). A LPS challenge is often administered systemically (e.g. intravenous (i.v.) or i.p.). It leads to an increase in pro-inflammatory cytokines, acute phase proteins in blood and body temperature (Williams et al., 2009; De Greeff et al., 2016).

I.v. administration of CFA in pigs will develop a chronic lung inflammation and an increase in acute phase proteins in blood (Le Floc'h et al., 2008; Kampman-van de Hoek et al., 2015). S.c. administration of TO is a systemic challenge which also results in an increased production of acute phase proteins (Kampman-van de Hoek et al., 2011) and an increase in body temperature (Rakhshandeh and de Lange, 2012) over a period of several days.

An oral challenge with a live pathogenic $E$. coli is frequently used to induce an intestinal infection leading to diarrhoea in piglets. An aerosol challenge with A. pleuropneumoniae induces a lung inflammation, and a subcutaneous injection with S. suis might lead to clinical signs of illness, such as lameness and meningitis (van der Meer, 2017). It is difficult to estimate in advance how long the immune system remains stimulated after such bacterial challenges, as in many studies pigs were dissected before response parameters were back to baseline. Based on a review of van der Meer (2017), the effects of a challenge with E. coli last at least several days ( \pm 4 days; McLamb et al., 2013) and a challenge with A. pleuropneumoniae and $S$. suis can result in a stimulated immune system up to 20 days (Heegaard et al., 2011).

In general, models with agents such as LPS, CFA, and TO and living pathogens are suitable for studies evaluating nutritional costs of disease or mechanistic relationships between immune stimulation and nutrition (van der Meer, 2017). Evidence for effects on AA requirements is obtained in studies in which pigs were challenged with LPS (Kim et al., 2012; de Ridder et al., 2012; Rakhshandeh et al., 2010), Complete Freund's Adjuvant (Le Floc'h et al., 2008; Kampman-van de Hoek et al., 2015), turpentine oil (Kampman-van de Hoek et al., 2011), PRRSv (Stuart et al., 2015; Rakhshandeh, 2015), E. coli (Kahindi et al., 2018) or Porcine circovirus type 2 (Parra et al., 2006). The results of studies using such challenge models, however, are difficult to translate to an on farm situation (van der Meer, 2017). The models using live pathogens are associated with variable responses, e.g. high mortality rate and extreme loss of BW, depending on the nature and pathogenicity of the micro-organism used (Wichterman et al., 1980). Models with non-pathogenic agents such as LPS, CFA and TO are sterile models which can be more easily controlled and can induce more reproducible responses (van der Meer, 2017). Administering these agents in a high concentration single dose, however, might lead to severe clinical responses and it is not unusual that some of the challenged pigs die (Williams et al., 2009). Reduction of the concentration per dose generally induces less severe responses, however, also shortens the recovery time to several hours. In addition, repeated or continuous administration of LPS as model challenge leads to tolerance tolerance meaning that responses to the challenge are weakening in time. This limits the possibility to perform measurements on responses of the immune system in steady state conditions.

Several researchers used sanitation challenge models to stimulate the immune system for a longer period (Williams et al., 1997a,b,c; Le Floch et al., 2009; van der Meer et al., 2016; van der Meer, 2017; Kahindi et al., 2017). Poor sanitary conditions (i.e., low-quality hygiene) decrease daily feed intake and growth performance, increase the occurrence of diarrhoea (Williams et al., 1997; Le Floc'h et al., 2009), and limit the ability of pigs to cope with stressful events (Pastorelli et al., 2012a). A sanitary challenge can be considered as a systemic challenge as it increases e.g. the production of acute phase proteins but it also can induce intestinal challenge and infection and negatively affect the digestibility of nutrients. Pigs housed in sub-optimal conditions in practice have an increased frequency of exposure to antigens resulting in a stimulation of their immune system without inducing severe clinical signs of disease or mortality (e.g. Williams et al. (1997), van der Meer et al. (2017)). Van der Meer (2017) suggested that studies with a more practical approach, mimicking farm situations, are needed to quantify the nutrient costs of suboptimal conditions. This approach generally does not focus on acute challenges and clinical infections but on factors that are encountered on farms in practice and influence the immune system of the pig without inducing severe clinical signs of disease or mortality. In this approach a low-grade contrast in immune system stimulation can be created by exposing pigs to different sanitary status, medication strategies, degree of ventilation, and to differences in animal density. Use of such a model has the advantage that translation of the results to farm condition is 
more easy than when using models inducing severe clinical infections. However, the challenge with the use of sanitation models might be the difficulty in standardizing unsanitary conditions and determine with certainty the causative agent for any immunological response observed (Adewole et al., 2016). This makes it difficult to reproduce the model over time and among trials.

In the literature review in chapter 3 of the present report, the effects of both experimental challenge models and poor sanitary conditions on immune system activation, feed intake, energy and amino acids metabolism and amino acid requirements were considered. 


\section{Immune system activation in relation to amino acid requirements}

Stimulation of the immune system triggers a series of responses in the animal, including a reduction in feed intake and increases in energy expenditure, body protein synthesis and catabolism and body temperature (Black, 2009). In this section an overview of results in literature on the effects of immune system (IS) activation on feed intake, nutrient digestibility and energy and protein metabolism is given.

\subsection{Feed intake}

Chronic activation of the immune system (IS) will reduce feed intake of growing-finishing pigs (e.g. Williams et al., 1997c; Le Floc'h et al., 2009; Le Floc'h et al., 2014; Pastorelli et al., 2012b; van der Meer, 2017). Williams et al. (1997c) compared growing pigs with a low or a high level of chronic IS activation. The low IS pigs were weaned at $12 \mathrm{~d}$ of age and placed into a sanitized nursery facility physically isolated from major vectors of antigen transmission. Upon reaching a BW of $27 \mathrm{~kg}$, pigs were transported to a sanitized grower facility also isolated from other pigs. The high IS pigs were weaned at $19 \mathrm{~d}$ of age and placed in a non-sanitized nursery facility and grower pig facility. The units had been previously occupied and were not washed via high pressure spraying between batches of pig. Daily feed intake and daily gain were reduced with 11 and $18 \%$, respectively, in the high IS pigs compared to the non-challenged control groups. Pastorelli et al. (2012b) carried out a meta-analysis on 122 published experiments to quantify the feed intake and growth responses of growing pigs after a sanitary challenge. A total of six different challenges were considered (Figure 3).

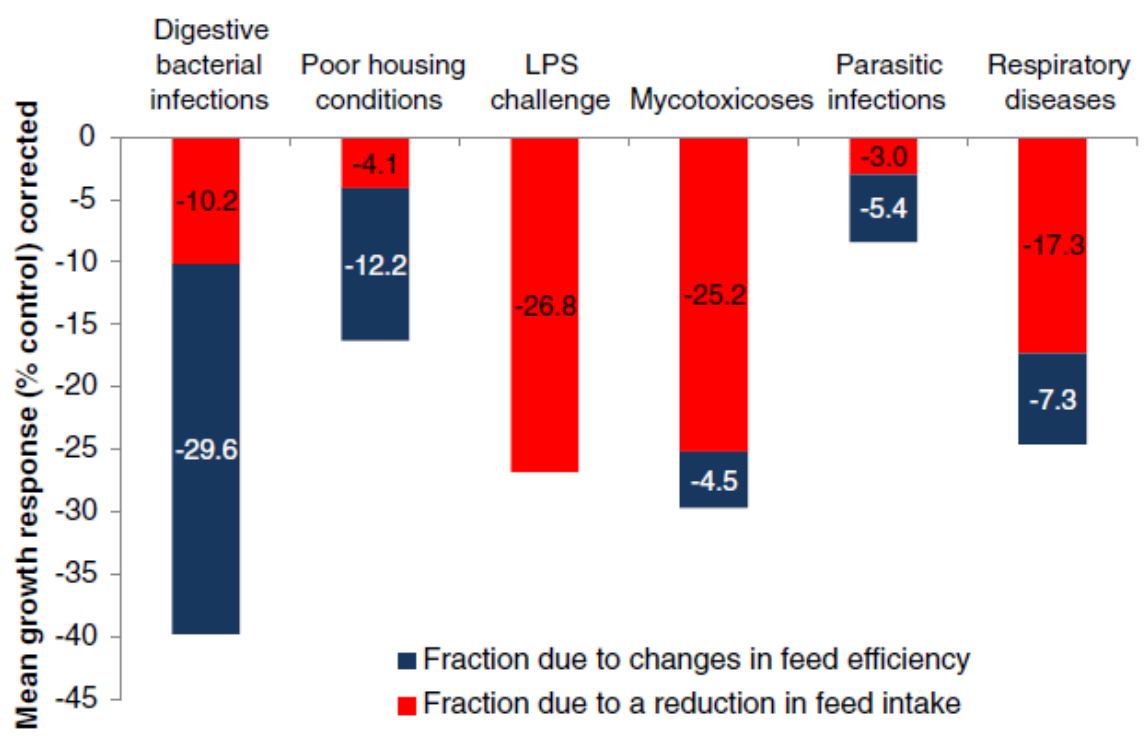

Figure 3 Consequences of an activated immune system for feed intake growth in pigs. Partitioning of the reduction in mean growth responses following different immune challenges between the fraction related to reductions in feed intake and feed efficiency (a poorer feed conversion ratio due to an increase in maintenance requirements for nutrients or a lower nutrient efficiency) (Goodband et al. (2014) adapted from Pastorelli et al. (2012b)).

Bacterial infections (29 studies) directed to the GI tract corresponded to experimental challenge studies of pigs, with mainly E. coli administered orally or intragastrically. Poor housing conditions (20 studies) corresponded to pigs raised under suboptimal conditions including poor hygiene conditions, 
exposure to extreme temperature (heat or cold stress), and limiting space allowance. LPS challenges (12 studies) corresponded to experimental inflammation of pigs with LPS from E. coli. Pigs received intramuscularly single or multiple injections of $200 \mathrm{mg}$ LPS/ $\mathrm{kg} \mathrm{BW.} \mathrm{Mycotoxicoses} \mathrm{(39} \mathrm{studies)}$ corresponded to dietary intoxications with a single mycotoxin or combinations of two or three mycotoxins. Parasitic infections corresponded mainly to single experimental infections with different species of parasites in the GI tract or with parasites in either the blood, kidney or on the skin. Respiratory diseases (10 studies) corresponded either to single experimental infections with the PRRSV virus, single experimental infections with respiratory bacteria (e.g. Mycoplasma hyopneumoniae or Pasteurella multocida) or experimental infections with both PRRSV virus and respiratory bacteria. Pigs were infected once intranasally at the beginning of the experiment.

The results in Figure 3 show that the reduction in growth is partly due to a reduction in feed intake and partly due to a reduced feed efficiency (poorer feed conversion ratio) (Pastorelli et al., 2012b). For mycotoxicoses, LPS challenge and respiratory diseases, more than $70 \%$ of the reduction in average daily gain could be explained by a reduction in feed intake. For digestive bacterial infections and poor housing conditions, about one third of the reduction in daily gain was due to a reduced feed intake and two third was due to a poorer feed conversion ratio (increase in maintenance requirements for nutrients and/or lower growth efficiency).

Recently, van der Meer et al. (2016) and van der Meer (2017) studied the performance in growingfinishing pigs under low (LSC) or high sanitary conditions (HSC). HSC pigs received vaccinations during the first nine weeks of age, an injection with antibiotics at the start of the study and the rooms were intensively cleaned prior to stocking. The LSC pig did not receive vaccinations and antibiotics and the rooms were not cleaned prior to stocking. In the first study (van der Meer et al., 2016) daily gain and gain to feed ratio were $55 \mathrm{~g} / \mathrm{d}(6 \%)$ and $0.013(3 \%)$ higher, respectively, in HSC pigs. Feed intake, however, was not influenced significantly by sanitary condition. In the second study (van der Meer, 2017), feed intake, daily gain and G:F were on average 9, 22\% and $10 \%$ higher in HSC pigs compared with LSC pigs. The lower body weight, lower feed intake, lower daily gain and greater haptoglobin levels in LSC pigs indicate a contrast in subclinical health between LSC and HSC pigs slightly more severe than in the first experiment using a similar model of ISS (van der Meer et al., 2016). In an experiment of Le Floc'h et al. (2009), LSC weaned piglets had a 5 to $9 \%$ lower feed intake than HSC piglets. In an experiment of Le Floc'h et al. (2014) with growing pigs, pigs housed in poor hygiene conditions ate $10 \%$ less than pigs housed in good hygiene conditions. Poor hygiene conditions were created by housing pigs in a room previously occupied by non-experimental pigs. The room was neither cleaned nor disinfected before and during the experimental period. Additionally, non-experimental pigs were also housed in the same room to increase the microbial pressure. In good hygiene conditions, pigs were housed in a room that was cleaned and disinfected before and daily throughout the experimental period. There was no mixing with non-experimental pigs and the staff put on clean boots and clothes before entering the room (Le Floc'h et al., 2014).

Sandberg et al. (2006) developed a model to predict the effects of subclinical pathogen challenges of different doses and virulence on the relative feed intake (RFI) of animals. The RFI was defined as the feed intake (FI, kg/d) of the animal challenged by a pathogen divided by its FI in the same state when it would have not been challenged. The RFI was assumed to be affected only when animals were naïve to a particular pathogen, i.e. had not previously experienced it, and when the challenge dose was above a predetermined threshold. The way in which RFI changes with time is described in 4 steps (see Figure 4): 1) Lag time (L) is the delay from a pathogen challenge until an effect on RFI is seen; 2 ) Reduction time (R) describes the time it takes for the lowest value of RFI $(\lambda)$ to be achieved; 3 ) Duration time (D) describes the time that $\lambda$ is maintained; 4$) \rho$ describes the rate of recovery of RFI until RFI $=1$. 


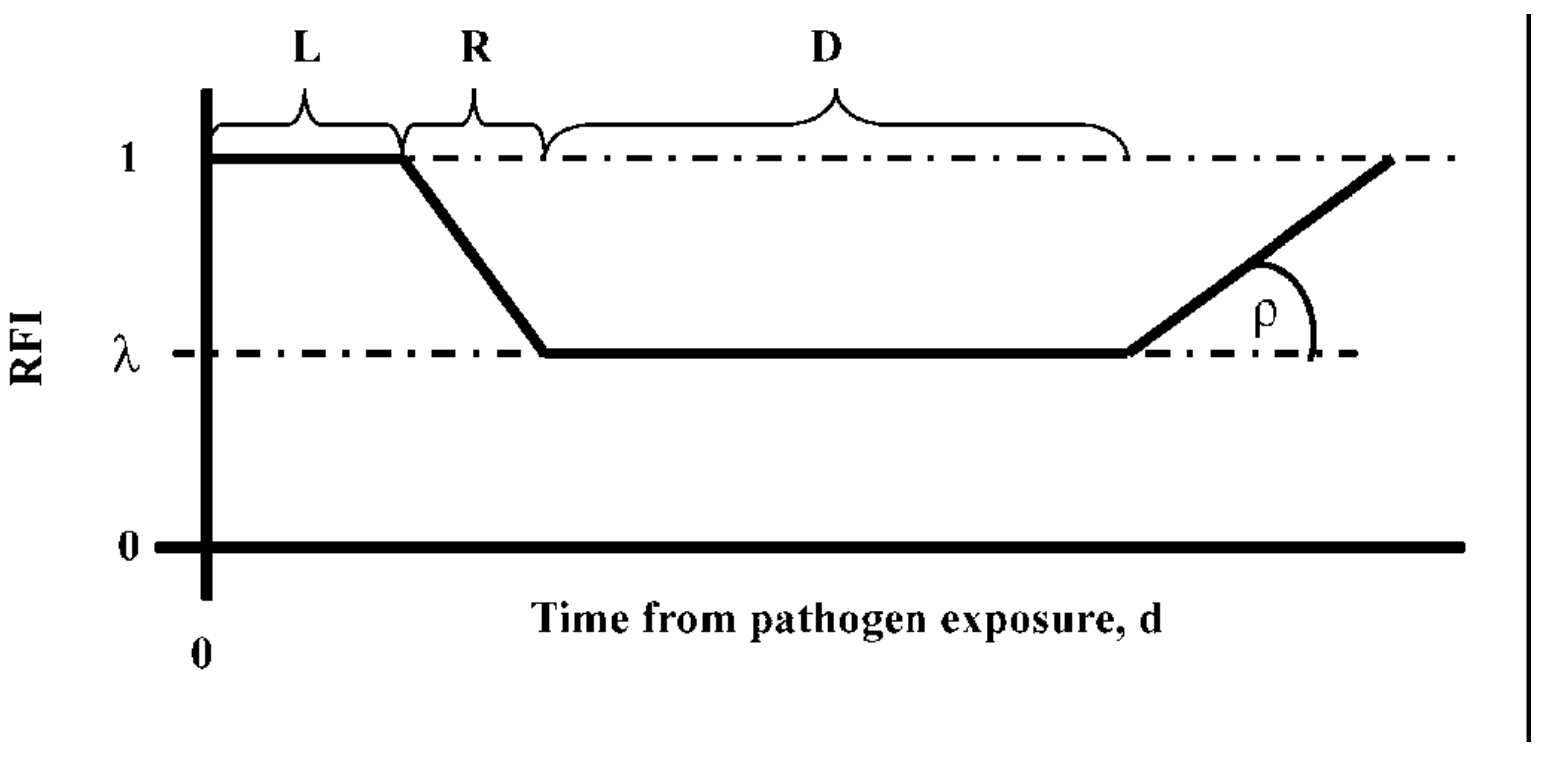

Figure 4 The response in relative feed intake (RFI) to time of pathogen exposure, indicating five parameters: lag time $(L)$, reduction time $(R)$, reduction in relative feed intake $(\lambda)$, duration of the reduction $(D)$, and the rate of recovery of relative feed intake $(\rho)$ (Sandberg et al., 2006).

The value of $L$ is specific to the kind of pathogen (Sandberg et al., 2006). Bacterial and viral challenges can have a lag time of a few hours (Greiner et al., 2000; Balaji et al., 2002), whereas parasites may take several weeks to have an effect (Kyriazakis et al., 1994, 1996). The value of the parameter $\lambda$ describes the lowest RFI during a pathogen challenge and is affected by the level of pathogen challenge (Symons et al., 1981; Coop et al., 1982; Houdijk et al., 2005). Reduction time (R) describes the time it takes for $\lambda$ to be achieved. The value of $R$ depends on the type of pathogen and is independent of the level of pathogen challenge (Sandberg et al., 2006). The value of $\mathrm{R}$ has been estimated to be 1 to 2 days for bacterial and viral pathogen challenges (Greiner et al., 2000; Houdijk et al., 2005) and 40 days for a parasite challenge (Kyriazakis et al., 1996). Duration time (D) reflects the time taken by the immune system to begin controlling and subsequently expelling the pathogens. The value of $D$ depends on the type of pathogen challenge but is independent of the level of pathogen challenge (Sandberg et al., 2006). The recovery rate reflects the reduction of pathogen load in the host once immunity has been acquired and begins to become expressed (van Houtert et al., 1995). The value of $\rho$ is proposed to be pathogen specific, as the recovery is much faster for bacterial (Balaji et al., 2000) and viral (Greiner et al., 2000) than for parasitic (Steel et al., 1980; Kyriazakis et al., 1996) challenges.

The mechanism underlying the reduction in feed intake during pathogen challenges is not fully clear (Sandberg et al., 2006). Johnson (1997) indicated that pathogens reduce the feed intake, by inducing cells of the immune system to produce cytokines. Alternatively the potential for maximum protein deposition may be reduced, which leads to reduced nutrient requirements and consequently a reduced feed intake (Schinckel et al., 2003).

It can be concluded that stimulation of the immune system using different challenge models (different pathogens and doses) that lead to subclinical diseases in a naïve host can reduce feed intake in the range of 3 to $25 \%$. When pigs develop clinical signs after pathogen exposure, a more significant decrease in feed intake and even complete cessation of eating can occur (Kyriazakis and Houdijk, 2007). The intensity and duration of feed intake reduction may differ between challenges and is related to the nature and dose of the challenge (Kyriazakis and Houdijk, 2007). The response, however, is also influenced by the ability of the pig to cope with challenges (Sandberg et al., 2007; Kyriazakis and Doeschl-Wilson, 2009). According to the meta-analysis of Pastorelli et al., (2012b), it seems that chronic activation of the immune system induced by low sanitary conditions reduces the feed intake in growing pigs over studies with $4 \pm 10 \%$. Activation of the immune system by a systemic LPS challenge can reduce the feed intake with $10 \pm 13 \%$. Bacterial challenges towards the 
digestive tract reduce the feed intake with $8 \pm 12 \%$ and challenges of the respiratory system reduce the feed intake with $16 \pm 15 \%$.

\subsection{Digestibility of protein, amino acids and energy}

In general, systemic challenges do not seem to impair the digestibility of dietary nutrients because they do not affect the ability of the gastrointestinal tract to hydrolyse and absorb nutrients (Sandberg et al., 2007). This is confirmed in several trials. Labussière et al. (2015) concluded that the digestibility of the main dietary nutrients is not affected in $20 \mathrm{~kg}$ pigs after intravenous challenge with CFA. Moreover, Kampman-van de Hoek et al. (2015) concluded that a similar challenge with CFA does not affect faecal $\mathrm{N}$ digestibility in growing pigs. Rakhshandeh et al. (2014) investigated in two trials with growing pigs the effect of immune system activation by an intramuscular LPS injection every 48 hours for 7 days on AID of energy and SID of protein and amino acids (Table 1). They did no show significant effects of immune system stimulation on the AID of energy nor on the SID of crude protein, lysine, methionine, methionine + cysteine, threonine, arginine, isoleucine and leucine.

Table 1 Impact of immune system stimulation (ISS) via LPS administered i.m. on the apparent ileal digestibility (\%, AID) of energy and standardised ileal digestibility (\%, SID) of crude protein and amino acids (Least-square means with their standard errors) in growing pigs (Rakhshandeh et al., 2014).

\begin{tabular}{|c|c|c|c|c|c|c|}
\hline & \multicolumn{3}{|c|}{ Experiment 1} & \multicolumn{3}{|c|}{ Experiment 2} \\
\hline & ISS- & ISS+ & SE & ISS- & ISS+ & SE \\
\hline Energy & 83.6 & 83.5 & 1.74 & - & - & - \\
\hline Lysine & 86.8 & 83.7 & 2.26 & 89.1 & 88.0 & 1.75 \\
\hline Methionine & 87.8 & 86.0 & 1.81 & 87.8 & 88.1 & 3.42 \\
\hline Threonine & 83.3 & 77.8 & 3.35 & 79.0 & 76.6 & 5.17 \\
\hline Arginine & 88.4 & 87.7 & 3.02 & 91.6 & 90.5 & 1.60 \\
\hline Isoleucine & 87.6 & 84.4 & 2.35 & 85.7 & 86.0 & 3.07 \\
\hline Leucine & 86.2 & 83.1 & 1.24 & 83.0 & 83.6 & 3.86 \\
\hline
\end{tabular}

Rakhshandeh and De Lange (2011) reviewed the impact of systemic immune system activation on the physiology and productivity of growing pigs including the effect on nutrient digestibility. They concluded that observations in the literature suggest that the digestive and absorptive function of the gastrointestinal tract is compromised during a systemic inflammation. Physiological alterations in the gastro intestinal tract during systemic inflammation include changes in gut motility, permeability, mucin production, microflora, expression of digestive enzymes, and epithelial transport systems. However, they also concluded that little solid information is available about the impact of inflammation induced physiological changes in the gastrointestinal tract on overall digestive capacity of the animal. Based on their literature review and on their own research (Rakhshandeh et al., 2014), they finally concluded that the effects of systemic immune system stimulation on the digestibility of energy, protein and AA are rather small.

When the gut is the target of a bacterial, viral or model challenge, health status and functionality of the gastrointestinal tract is compromised and nutrient digestibility can be reduced as a result of a reduced secretion or activity of digestive enzymes, an increased secretion of endogenous protein or a reduced recycling of endogenous protein (van der Klis and Jansman, 2002). In several studies in which the immune system in growing pigs was activated by a sanitary challenge the apparent digestibility of dietary $\mathrm{N}$ was decreased with about 1 to $2 \%$ (Williams et al., 1997a; van der Meer et al., 2016), 3 to 4\% (Kampman-van de Hoek et al., 2016) or 6 to 7\% (Le Floc'h et al., 2014; van der Meer et al., 2017). Energy digestibility may be reduced with 3\% (van der Meer et al., 2017). The reduced digestibility for protein might be due to intestinal pathogens involved in this multifactorial 
challenge model resulting in intestinal damage, greater endogenous protein losses or an increased digesta passage rate (Williams et al., 1997a; Sandberg et al., 2006; Pastorelli et al., 2012b).

Overall, it can be concluded that systemic immune system activation may decrease the digestibility of protein and amino acids in pigs with 1 to $2 \%$. The digestibility of energy seems hardly affected by systemic immune system activation. Immune system activation due to a sanitary challenge may reduce the ileal or faecal digestibility of protein and amino acids with 1 to $7 \%$ and the faecal digestibility of energy with about 3\%. Especially, when the health status of the gastrointestinal tract is compromised by a challenge, digestibility of protein, amino acids and energy will be reduced.

\subsection{Energy metabolism}

\subsubsection{Maintenance requirement for energy}

A pathogen challenge may increase the energy requirement due to the production of immune proteins (e.g. for acute phase proteins and immunoglobulins), and due to the expression of fever (Baracos et al., 1987; Sandberg et al., 2007). Moreover, the presence of antigens/pathogens in the intestinal lumen induced local responses which require protein (amino acids) and energy that in good sanitary conditions could have been used for muscle protein deposition (Kim et al., 2012). Several experiments (reviewed by Sandberg et al., 2007) were carried out in which total energy expenditure was measured using indirect calorimetry through measurements of oxygen consumption during challenges with nonpathogenic antigens (Table 2). Difference in energy expenditure was estimated from the rate of oxygen consumption (20.1 kJ/l O2; Eraud et al. (2005)) between challenged and non-challenged adult mice and different species of birds.

Table 2 The relative change in maintenance energy expenditure ( $R C E$, challenged/controls) and energetic cost ( $E_{\text {antibody, }}$ challenged energy expenditure - control energy expenditure) due to antibody production, as measured by changes in oxygen consumption of adult mice and birds challenged with non-pathogenic antigens (Sandberg et al., 2007).

\begin{tabular}{|c|c|c|c|c|c|}
\hline Host & Body weight (g) & $\mathrm{RCE}$ & $E_{\text {antibody }}(\mathrm{ks} / \mathrm{kg}$ BW per day) & $\begin{array}{l}\text { RCE proportional } \\
\text { to antibody production }\end{array}$ & Source \\
\hline Mice $^{t}$ & 360 & $1: 55$ & 230. & Yes. & Demas et al: (1997) \\
\hline Blue tits & $10.0^{\ddagger}$ & 1.10 & 275 & Yes & Svenssion et al. (1998) \\
\hline Great tits & 18.6 & $1: 09$ & 148 & - & Ots et al: (2001) \\
\hline House sparrows & 28.4 & 1.29 & 148 & - & Martin et al. (2002) \\
\hline Collared doves & 130. & 1,09 & 36 & Yes & Eraud et al (2005) \\
\hline
\end{tabular}

† The antigen for IS stimulation was keyhole limpet hemocyanin, an immune stimulant glycoprotein, in all other studies presented in the Table sheep red blood cells were used for IS stimulation.

₹ Estimated from their age.

Sandberg et al. (2007) concluded that the increase in maintenance energy expenditure in animals and birds challenged with non-pathogenic antigens ranges between 10 and 30\% except for the study of Demas et al. (1997) who found an increase in energy expenditure of 55\%. This may be explained by the use of a different antigen for IS stimulation, which induced an increase $\left(>1^{\circ} \mathrm{C}\right)$ in colonic temperature (Sandberg et al., 2007). Moreover, they concluded that the energy costs of an immune response is strongly related to the level of the immune response, with the greatest energetic cost occurring for pathogen or antigen challenges that lead to fever. Baracos et al. (1987) reviewed the energy requirements caused by fever and concluded that a $1^{\circ} \mathrm{C}$ increase in body temperature due to fever, increased the energy requirement with 10\%. Lochmiller and Deerenberg (2000) also concluded that fever usually elicits a $10-15 \%$ elevation in basal metabolic rate for each $1^{\circ} \mathrm{C}$ rise in body temperature in humans. Moreover, they concluded that challenges inducing infections can increase the resting metabolic rate with about $25 \%$ because of the elevated energetic costs of protein synthesis by the immune system (e.g. for acute-phase inflammatory proteins and antibodies). 
Williams et al (1997a) conducted an experiment to determine the effect of the level of chronic immune system activation due to a sanitary challenge on the maintenance requirement for ME and on the efficiency of utilization of dietary ME for body protein and fat accretion in pigs from 6 to $27 \mathrm{~kg} \mathrm{BW}$. The maintenance requirement for ME was numerically, but not significant, increased with $12 \%(0.483 \mathrm{MJ}$ $\mathrm{ME} / \mathrm{BW}^{0.75}$ versus $0.428 \mathrm{MJ} \mathrm{ME} / \mathrm{BW}^{0.75}$ ) in pigs with a high level of chronic immune system activation compared to pigs subjected to a low degree of chronic immune system activation (high and low degree of IS stimulation is described in chapter 3.1).

Van der Meer (2017) studied the difference in fasting heat production as a proxy for maintenance energy expenditure in clinically healthy growing pigs kept under low or high sanitary conditions. Low sanitary conditions increased the fasting heat production with $8 \%$ (from 696 to $750 \mathrm{~kJ} /\left(\mathrm{kg} \mathrm{BW}^{0.6} . \mathrm{d}\right.$ )). The higher fasting heat production for pigs under low sanitary conditions compared with pigs under high sanitary conditions reflects a lower energetic efficiency for pigs under low sanitary conditions due to an increased energy expenditure for maintenance purposes, of which functioning of the immune system is part of. From fasting heat production, van der Meer (2017) estimated the energy requirement for maintenance (MEm) by using the method of Labussière et al. (2011). The MEm was $7 \%$ greater for pigs under low sanitary conditions using this method.

Overall, it can be concluded that systemic immune system activation by a non-pathogenic challenge may increase the maintenance requirement for energy with 10 to $30 \%$. Immune system activation due to a sanitary challenge may increase the maintenance requirement for energy with 7 to $12 \%$.

\subsubsection{Efficiency of energy use for protein and fat deposition}

Only a few experiments were conducted to investigate the effects of immune system activation on the utilization of dietary energy for protein and fat deposition. Williams et al. (1997a) conducted an experiment to determine the effect of the level of chronic immune system activation (low vs high IS activation) due to a sanitary challenge on the efficiency of utilization of dietary ME for body protein and fat accretion in pigs from 6 to $27 \mathrm{~kg} \mathrm{BW}$. The energetic efficiency of ME utilization for body protein $\left(\mathrm{k}_{\mathrm{p}}\right)$ and lipid accretion $\left(\mathrm{k}_{\mathrm{f}}\right)$ were similar among the two IS groups. The values of $\mathrm{k}_{\mathrm{p}}$ in the low and high IS pigs were estimated to be .47 and .49 , respectively, and the values for $k_{f}$ were estimated to be .67 and .70 , respectively.

Van der Meer (2017) measured the ME intake, energy requirement for maintenance (MEm), total energy retention and energy retention in protein and in fat in growing pigs kept under a high or a low sanitary status. Based on the published data we calculated the energetic efficiency of ME for total energy retention and for protein and fat retention. The energetic efficiencies were similar in growing pigs with a high or a low sanitary status and were about $0.60,0.49$ and 0.70 for total energy retention, energy retention in protein and energy retention in fat, respectively.

Labussière et al. (2015) determined the effects of an inflammatory challenge via an intravenous administration of complete Freund's adjuvant (CFA) in $20 \mathrm{~kg}$ pigs from two lines of pigs divergently selected for a low (RFI-) or a high (RFI+) residual feed intake (RFI; difference between actual feed intake and theoretical feed requirements). They measured the ME intake, energy requirement for maintenance and total energy retention in pigs of $20 \mathrm{~kg}$ body weight (six and seven from RFI+ and RFI- line, respectively) from 3 days before to 3 days after CFA challenge. Based on the published data, we calculated the energetic efficiency of ME for total energy retention. The energetic efficiencies were similar in RFI- and RFI+ pigs and were similar before and after CFA challenge in both RFI- and RFI+ pigs.

Pastorelli et al. (2012b) showed in a meta-analysis using results of 122 studies that the reduction in daily gain in growing pigs with an activated immune system is partly due to a reduced feed efficiency. The reduced feed efficiency is due to an increase in maintenance requirements for nutrients or due to a lower nutrient efficiency. However, it is not known which part can be explained by an increase in maintenance requirement and which part by a lower nutrient efficiency.

Overall, it seems that there is no effect of immune system activation on the energetic efficiency of the use of dietary ME for total energy retention or for retention of energy in body protein and fat. Based on a literature review, Sandberg et al. (2007) concluded that energy partitioning in the body during 
pathogen challenges is unaffected, with any effects of pathogen challenges on energy requirements being included as part of requirements for maintenance.

\subsection{Protein and amino acid metabolism}

\subsubsection{Maintenance requirements for amino acids}

Pigs may produce significant amounts of nitrogenous compounds and proteins such as cytokines, antibodies, acute phase proteins or specific immune cells during pathogen challenges which may increase the maintenance requirements for amino acids. According to a review of Sandberg et al. (2007), the maintenance requirement for amino acids in challenged animals (e.g. via sanitary challenge, bacterial antigen challenge or challenge with parasites) varied from 1 to 1.3 times of that in healthy, non-challenged animals. The increase in amino acids requirement may differ between the individual different amino acids.

Webel et al. $(1998 a, b)$ found that LPS challenged chickens (chickens were for 9 d daily or every two days i.p. injected with LPS) had a $15 \%$ higher maintenance requirement for lysine than control chickens (Figure 6), while the maintenance requirement for threonine tended to increase ( $5 \%$ increase). There was no effect of an LPS challenge on the maintenance requirement for arginine. The observed different effects on maintenance requirement of individual amino acids suggest that amino acid requirements for maintenance were affected to different extents (Webel et al., 1998a). LPS stimulates an acute phase response, including the production of acute phase proteins, which have a different amino acid composition compared to body protein and muscle protein retained in healthy animals (Reeds et al.,1994; Conde-Aguilera et al., 2010); Figure 5 and Table 3). The contents of phenylalanine, tyrosine, tryptophan and threonine are higher in acute phase proteins than in body and muscle protein. In immunoglobulins, in general tryptophan, leucine, valine, cysteine, threonine and serine are higher than in body and muscle protein. The balance between the decrease in amino acid requirements for lean tissue deposition and the increase in amino acids requirements to fuel the immune system determines the impact of immunological stress on the overall amino acid requirements (Webel et al., 1998b) and on the ratio between the different individual essential amino acids. The experiments of Webel et al. $(1998 a, b)$ in broilers suggest that it is necessary to consider the requirements of individual amino acids to fully account for a reduction in growth performance during periods of IS stimulation.

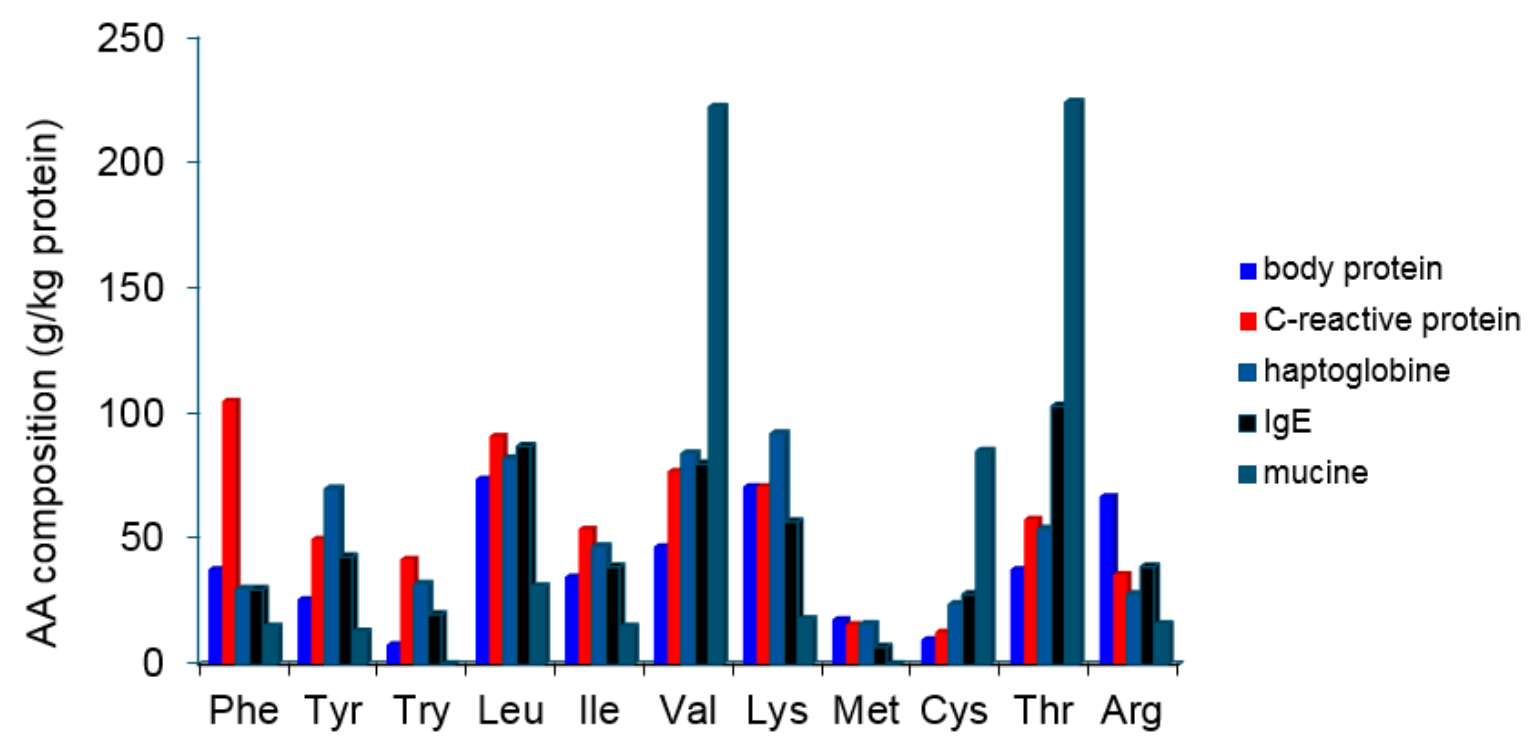

Figure 5 Amino acid composition of different proteins that are associated with the immune system and their responses and of body protein in pigs (data from Kyriazakis et al. (1993), Reeds et al. (1994) and Houdijk and Athanasiadou (2003)). 
Table 3 Amino acid composition of body and muscle protein in pigs and proteins related to the immune system.

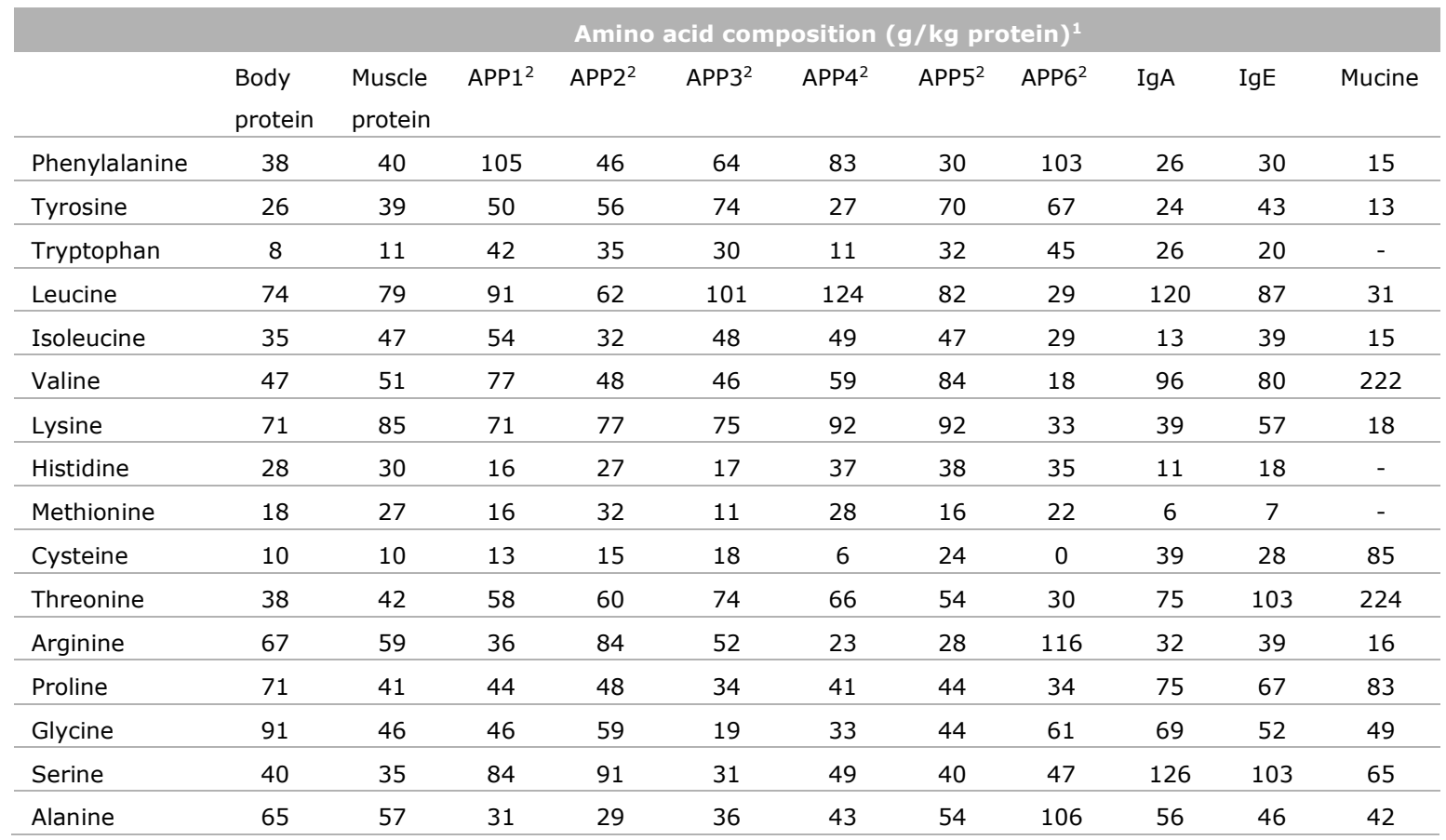

1 Amino acid composition of body protein (Kyriazakis et al., 1993), of acute phase proteins (Reeds et al., 1994), of IgA, IgE and mucine (Houdijk and Athanasiadou, 2003) and muscle protein (Conde-Aguilera et al., 2010) in pigs.

2 APP (1 to 6) acute phase proteins: (1) C-reactive protein, (2) fibrinogen, (3) alpha-1-glycoprotein, (4) alpha-1-antitrypsin, (5) haptoglobine and (6) amyloid $A$.

Rakhshandeh et al. (2014) conducted two experiments in growing pigs of about $20 \mathrm{~kg}$ to determine the effects of chronic ISS by repeated intramuscular injections of increasing amounts of LPS on ileal nutrient digestibility and utilisation of sulphur amino acids (SAA: Methionine + Cysteine) intake for whole-body protein deposition. ISS increased the SAA maintenance requirements with about $23 \%$. They supposed that the increase in SAA maintenance requirements in the ISS+ pigs can be attributed largely to increased SAA utilisation for the synthesis of non-protein compounds that are involved in the immune response, such as glutathione.

De Ridder et al. (2012) examined the effect of ISS on $\mathrm{N}$ retention in growing pigs fed diets limiting in tryptophan. Immune system stimulation was induced using repeated intramuscular injections of E. coli LPS every $48 \mathrm{~h}$ for $7 \mathrm{~d}$. They hypothesized that during ISS, $\mathrm{N}$ retention would be reduced due to a reduction in the capacity for body protein deposition (PD) and an increased requirement for tryptophan to mount an immune response, resulting in a reduction in the marginal efficiency of dietary tryptophan utilization for protein deposition (i.e., the slope of the response in PD to increased tryptophan intake). The efficiency of tryptophan utilization for protein deposition indeed was reduced during ISS, the intercept of the lines, however, was similar, which means that the maintenance requirement for tryptophan was not increased during ISS in this study.

Overall, it can be concluded that the maintenance requirement for the individual amino acids may increase with 0 to $30 \%$ in pigs with an activated immune system. Based on the above described studies with chickens and pigs, the maintenance requirement of lysine, methionine + cysteine, threonine, tryptophan and arginine may increase with $15 \%, 23 \%, 5 \%, 0 \%$ and $0 \%$, respectively. It is not known if the maintenance requirements for other essential amino acids is increased by immune system activation.

\subsubsection{Efficiency of protein deposition}

Webel et al. (1998a,b) evaluated the effect of LPS-induced immune system activation on the efficiency of lysine, threonine and arginine utilization for whole-body protein accretion in young rapidly growing chickens. The efficiency of lysine utilization for protein retention was not affected (slope of the linear regression equations relating protein retention to supplemental lysine intake was similar in control and 
LPS challenged chickens; Figure 6) by LPS administration (Webel et al., 1998a). Moreover, LPS administration did not affect the efficiency of threonine (Webel et al., 1998a) and arginine utilization (Webel et al., 1998b) for protein retention. Their finding that the efficiency of utilizing digestible lysine was unaltered by immunologic stress agrees with the findings of Williams et al. (1997b). The objective of the study of Williams et al. (1997b) was to determine the effect of level of chronic IS activation via a sanitary challenge, on body nitrogen retention, efficiency of lysine utilization, and dietary lysine requirements of pigs at a body weight of $10,17.5$, and $25 \mathrm{~kg}$. Assuming a lysine content in body protein of $6.5 \%$, the efficiency of utilization of digestible lysine for body lysine deposition ranged from 0.59 to 0.72 for the low IS pigs and from 0.65 to 0.69 for the high IS pigs.

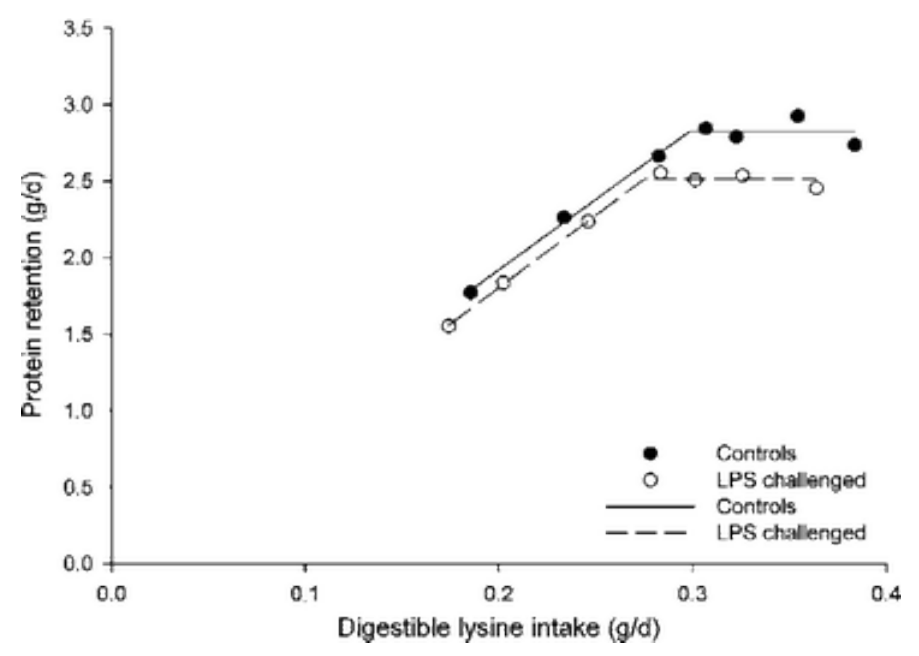

Figure 6 Best-fit broken-line plots for protein retention as a function of digestible lysine intake in chickens injected every two days with saline (control) or LPS during a 11-d period (Webel et al., 1998a).

Rakhshandeh et al. (2014) conducted two experiments in growing pigs of about $20 \mathrm{~kg}$ to determine the effect of chronic ISS by repeated intramuscular injections of increasing amounts of LPS on utilization of sulfur amino acids (SAA) intake for whole-body protein deposition. They observed that endotoxemia induced by repeated injection of increasing amounts of LPS decreased dietary SAA requirements for maximum protein deposition due to a reduced overall capacity of endotoxemic pigs for protein deposition. However, the linear relationship between SAA intake and protein deposition at levels below requirement for maximum protein deposition indicates that endotoxemia has no effect on partial efficiency of SAA utilization for protein deposition (Figure 7). In a separate study they observed that LPS-induced endotoxemia increases the optimal dietary methionine to total SAA (methionine + cysteine) ratio from 57 to $62 \%$ for protein deposition in growing pigs, suggesting that methionine is the preferred source of dietary SAA during ISS (Litvak et al., 2013). This may be due to the increased need for methionine as a methyl donor and as antioxidant in the methionine sulfoxide reductase system or due to the increased transsulfuration of methionine to cysteine for the synthesis of compounds involved in the immune response, such as glutathione and acute phase proteins (Litvak et al., 2013). 


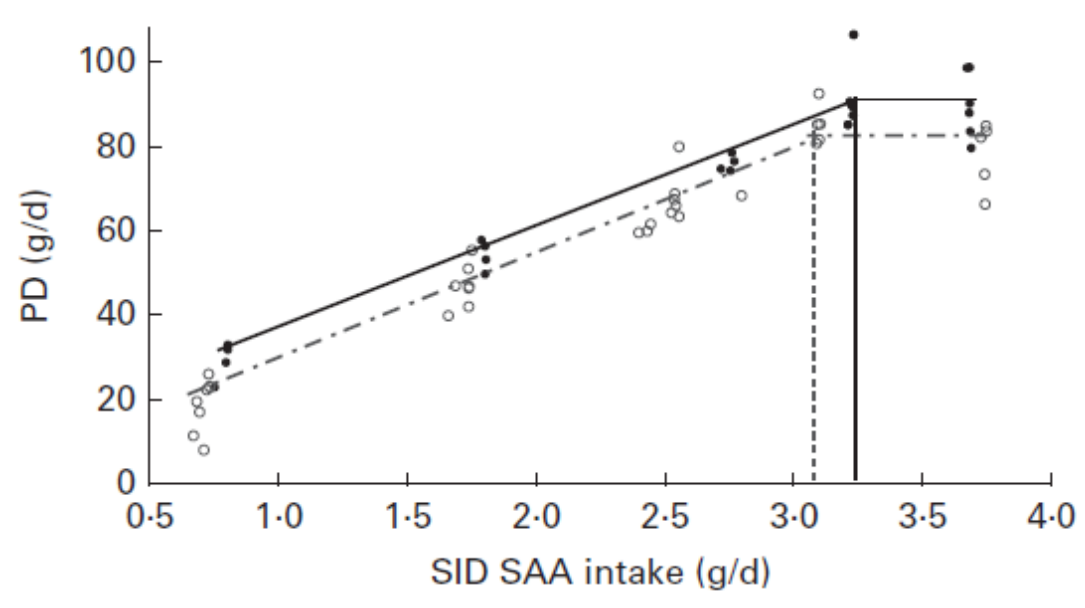

Figure 7 Best-fit linear-plateau plots for protein retention as a function of SID sulphur amino acid intake in pigs injected every two days by increasing amounts of Escherichia coli lipopolysaccharide (ISS+, - . - ) or saline (ISS-, -) during a 7-d period (Rakhshandeh et al., 2014)

De Ridder et al. (2012) examined the effect of ISS on $\mathrm{N}$ retention in growing pigs fed diets limiting in tryptophan. After a 5-d adaptation period, pigs were injected every $2 \mathrm{~d}$ with increasing amounts of E. coli LPS to induce ISS. Whole body $\mathrm{N}$ balance was measured in 3 periods: before immune stimulation (pre-ISS) and during ISS in 2 subsequent periods (ISS-1, $3 \mathrm{~d}$; ISS-2, $4 \mathrm{~d}$ ). Protein deposition increased by $88.2 \pm 5.2,82.5 \pm 5.1$, and $92.5 \pm 3.4 \mathrm{~g} / \mathrm{d}$ for each additional $\mathrm{g} / \mathrm{d}$ of SID tryptophan intake during pre-ISS, ISS-1, and ISS-2, respectively, but the intercepts were not different between periods of measurements $(-32.3 \mathrm{~g} / \mathrm{d}$ ) (Figure 8$)$. The slope of the response of protein deposition to increasing tryptophan intake (based on the common intercept) was less during ISS-1 compared with pre-ISS ( $P=0.01$ ) or ISS-2 ( $P=0.002)$ but not different between pre-ISS and ISS-2. De Ridder et al. (2012) concluded that immune system stimulation by LPS reduced the efficiency of tryptophan utilization for protein deposition, indicating that the tryptophan requirement for protein deposition is increased with about $7 \%$ during an inflammatory state.

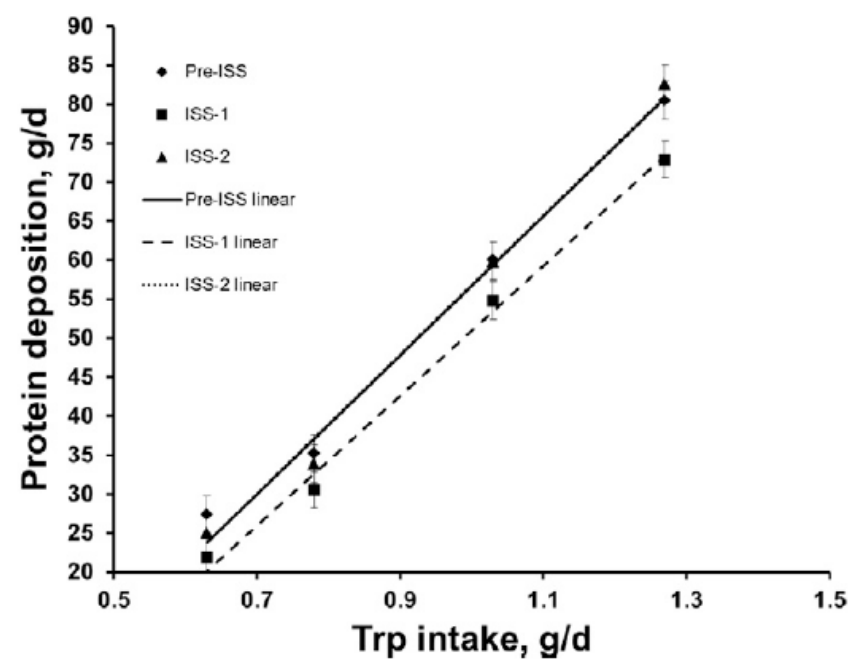

Figure 8 Linear response of protein deposition (PD) to increasing Trp intake pre-immune and post-immune system stimulation (ISS). Whole body nitrogen balance was conducted for $5 d$ before ISS (pre-ISS) and $7 d$ during ISS, which were divided into ISS-1 (3d) and ISS-2 (4d). The slopes of the response of PD to increasing Trp intake (i.e., marginal efficiency of Trp utilization for PD) were 89.0 \pm 3.0, 83.2 \pm 3.0 , and $89.2 \pm 3.0$ during the pre-ISS, ISS-1, and ISS-2 N-balance periods, respectively. The marginal efficiency of Trp was less during ISS-1 compared with pre-ISS $(P=0.01)$ or ISS-2 $(P=0.002)$ but was not different between pre-ISS and ISS-2 (De Ridder et al., 2012). 
Overall, it seems that chronic activation of the immune system by repeated challenge with E. Coli LPS has no effect on the efficiency of utilization of lysine, threonine and arginine for protein deposition in broilers and on the efficiency of utilization of methionine + cysteine for protein deposition in pigs.

However, it may reduce the efficiency of tryptophan utilization for protein deposition in pigs with about $7 \%$. It is not known if the efficiency of utilization of other essential amino acids for protein deposition is influenced by immune system activation.

\subsubsection{Maximum protein deposition}

In several studies it was shown that growing pigs with an activated immune system have a lower maximum protein deposition than healthy pigs. Williams et al. (1997c) showed that the maximum protein deposition was about 25\% lower in high IS (low sanitary status) growing pigs compared to low IS pigs (high sanitary status (90 vs $117 \mathrm{~g} / \mathrm{d}$ ). A lower feed intake of the high IS pigs only partly explains the lower protein deposition because the decrease in feed intake was lower (about 12\%) than the decrease in protein deposition (about $25 \%$ ). A higher requirement of amino acids for the production of acute phase proteins and immunoglobulins may also partly explain the lower protein deposition. The low IS pigs required about $20 \%$ greater dietary lysine concentrations and daily lysine intakes than high IS pigs to express their maximum protein deposition (Williams et al., 1997c). This greater lysine requirement of the low IS pigs is due to their greater capacity for lean tissue deposition and not to differences in the efficiency of use of lysine for body protein retention (Williams et al., 1997b). Similar results were found in growing chickens (Webel et al. 1998a,b). They evaluated the effect of LPS-induced immune system activation on the efficiency of lysine, threonine and arginine utilization for whole-body protein accretion in young rapidly growing chickens. Their studies showed that stimulation of the immune system by multiple injections of LPS reduced protein retention with about $8 \%$ (Figure 6 ) and decreased the absolute quantity of amino acids required for maximal performance of chickens. The decreased requirement for amino acids is apparently due to a reduction in the bird's capacity to accrete protein and not to a change in the efficiency of amino acid utilization (Webel et al., 1998a,b).

Rakhshandeh et al. (2014) also showed that high IS growing pigs (immune system activated by repeated intramuscular injections of increasing amounts of LPS) had a lower maximum protein deposition than low IS pigs. The maximum protein deposition was about $12 \%$ lower in pigs subjected to high IS stimulation compared to the control pigs ( $81 \mathrm{vs} 91 \mathrm{~g} / \mathrm{d}$ ). Break-point analyses of protein deposition responses yielded $8 \%$ higher estimates of SID SAA requirements for maximum protein deposition of $3.34 \mathrm{~g} / \mathrm{d}$ for low IS pigs and $3.08 \mathrm{~g} / \mathrm{d}$ for the high IS pigs (Figure 7). The reduced requirements for SAA in the high IS pigs can be attributed largely to the reduced maximum protein deposition in the high IS pigs. The observed reduction in maximum protein deposition in the high IS pigs is probably the result of a higher pro-inflammatory cytokine release and its associated endocrine changes (Rakshandeh et al., 2014; Escobar et al., 2004). Pro-inflammatory cytokines inhibit the release of anabolic hormones (e.g. somatotropin, insulin and insulin-like growth factor I), increase protein degradation in skeletal muscles and decrease the cellular uptake of amino acids in skeletal muscles by activating catabolic pathways (Johnson, 1997) resulting in a lower protein deposition. It has been suggested that protein catabolism during disease or inflammation is emphasized due to an imbalance between the supply of amino acids from endogenous proteolysis and those required for the synthesis of acute phase compounds (Reeds et al., 1994). Consequently, a greater amount of skeletal muscle protein might be degraded to provide amino acids to support the synthesis of equivalent acute phase proteins (Johnson, 2012).

Stuart et al. (2015) and Rakhshandeh (2015) performed a study to quantify the effects of a PRRSV challenge on protein deposition and amino acid metabolism in PRRSV-negative gilts (BW 9.4 \pm 0.9 $\mathrm{kg}$ ). Immune system activation was induced by intramuscular viral challenge of PRRSV-negative gilts with live PRRSV. The PRRSV challenge reduced protein deposition from 59.4 to $38.1 \mathrm{~g} / \mathrm{d}$ (about $35 \%$ reduction). In a second experiment Stuart et al. (2016) and Rakhshandeh (2015) evaluated the effects of ISS induced by two intramuscular injections of increasing amounts of LPS given $48 \mathrm{~h}$ apart on whole body protein deposition and amino acid metabolism in gilts (BW $9.4 \pm 1.1 \mathrm{~kg}$ ). ISS had no significant effect on protein deposition (59.4 vs. $55.7 \mathrm{~g} / \mathrm{d}$ ). 
Daiwen et al. (2008) conducted a study to determine the effect of LPS-induced immune challenge on performance and whole-body protein turnover in weanling pigs. They observed lower nitrogen retention in piglets challenged with LPS $(5.34 \mathrm{~g} / \mathrm{d})$ when compared with their pair-fed counterparts receiving a saline solution $(6.20 \mathrm{~g} / \mathrm{d})$. Injection of LPS markedly $(P<0.05)$ increased the protein degradation ( $16.8 \pm 1.1$ vs. $14.5 \pm 1.2 \mathrm{~g} \mathrm{~N} / \mathrm{kg} \mathrm{BW}^{0.75} / \mathrm{d}$ ). They concluded that LPS-induced immune challenge depresses growth performance, nitrogen retention and feed utilization efficiency by enhancing protein degradation rate and decreasing protein utilization for body protein retention.

Kampman-van de Hoek et al. (2015) determined the effect of immune system activation by an i.v. challenge with CFA on $\mathrm{N}$ retention and amino acid utilization in growing pigs depending on dietary amino acid supply. Pigs received an adequate or restricted amount of dietary protein. Immune system activation via CFA administration tended to reduce $\mathrm{N}$ retention with $4 \%$, the effect being independent of the dietary protein supply..

Van der Meer (2017) studied the effects of chronic, low grade immune system activation by imposing low sanitary conditions (LSC) on nutrient partitioning in growing pigs. Nitrogen retention was about $10 \%$ lower in LSC pigs than in HSC pigs ( $0.73 \mathrm{vs} 0.80 \mathrm{~g} / \mathrm{kg} \mathrm{BW} 0.60 / \mathrm{d}$ after adjusting for an equal feed intake) due to a reduction in the utilization of dietary nitrogen for nitrogen retention of LSC pigs compared to HSC pigs.

Overall, it can be concluded that immune system activation reduces the maximum deposition in pigs. The reduction may differ between type of challenges applied and will probably be affected by the impact of the challenge on immune system activation. Systemic immune system activation via a challenge with (LPS or CF) decreases the maximum protein deposition in pigs with 4 to $12 \%$. Systemic immune system activation by a pathogenic challenge (PRRSV) decreases the maximum protein deposition in pigs with $35 \%$. Immune system activation due to a sanitary challenge can decrease maximum protein deposition with 10 to $25 \%$.

\subsubsection{Amino acids costs for an activated immune system}

Activation of the immune system may increase the amino acid requirements due to the production of immune proteins such as acute phase proteins and immunoglobulins. Reeds et al. (1994) reported that acute phase proteins are relatively rich in aromatic amino acids (phenylalanine, tryptophan, and tyrosine) compared with muscle protein. According to their calculations, and assuming muscle protein is the major source for these amino acids, particularly in situations of severe decrease in feed consumption, 1.5 to $2 \mathrm{~g}$ of muscle protein should be degraded to release the amounts of amino acids necessary for the synthesis of $1 \mathrm{~g}$ of acute phase proteins (Reeds et al., 1994). However, amino acid requirements may decrease because of a reduced protein retention in the body. Because the amino acid composition of acute phase proteins and immunoglobulins differ from the amino acid composition in muscle protein (Reeds et al., 1994; Table 3), the amino acid requirements and the ratio between amino acids may change in pigs with an activated immune system. Goodband et al. (2014), however, stated that evidence is sparse or equivocal for increasing amino acid requirements during an immune challenge. While the amino acid requirements may increase with immune system activation, the decrease in muscle accretion will offset most of the changes in overall amino acid requirements (Goodband et al., 2014).

Melchior et al. (2004) performed a study to identify amino acids whose metabolism was affected by chronic lung inflammation. Six pairs of littermate piglets were selected at $28 \mathrm{~d}$ of age on the basis of their BW. One littermate received complete Freund's adjuvant (CFA) intravenously, whereas its littermate was injected with a sterile saline solution (CON). Piglets within a litter were pair-fed in order to avoid confounding effects of feed intake and inflammation on plasma amino acid concentrations. Plasma tryptophan was lower in CFA than in CON pigs, suggesting an increase in tryptophan utilization during chronic lung inflammation in pigs. Moreover, glutamine, proline, glycine, tyrosine, ornithine, total amino acid concentrations, and the ratio of tryptophan to large neutral amino acids (phenylalanine, tyrosine, valine, leucine and isoleucine) were lower in CFA than in CON pigs. In contrast, plasma histidine concentration was higher in CFA than in CON pigs. These results show that chronic lung inflammation affects individual amino acids differently and suggest that the utilization of 
some amino acids, especially tryptophan, is increased during chronic lung inflammation in pigs. Catabolism of tryptophan resulting from indoleamine 2,3 dioxygenase activation as well as tryptophan incorporation into acute phase protein may explain the increased tryptophan utilization. This supports the hypothesis that tryptophan could become a limiting essential amino acid in pigs suffering from chronic lung inflammation (Melchior et al., 2004).

Le Floc'h et al. (2006a) studied the effect of sanitary conditions on plasma amino acid concentrations of piglets after weaning. Twenty pairs of littermate piglets were selected and weaned at 28 days of age on the basis of their body weight. Within each pair, piglets were pair-fed and each one was assigned to one of the two experimental groups. The first group was housed in a clean environment and was fed an antibiotic supplemented standard diet. The second group was kept in unsanitary rooms, mixed with non-experimental piglets and was fed the same standard diet but without antibiotic supplementation. At day 41 after weaning, the ratios in plasma of leucine, threonine, tryptophan, cystein, tyrosine and proline to the sum of all amino acids were lower in pigs kept in unsanitary environment whereas the ratios for histidine and glycine were higher (Le Floc'h et al., 2006a).

Stuart et al. (2015) and Rakhshandeh (2015) performed a study to quantify the effects of a PRRSV challenge on protein deposition and amino acid metabolism in PRRSV-negative gilts (BW 9.4 \pm 0.9 $\mathrm{kg}$ ). Immune system activation was induced by intramuscular injection of PRRSV-negative gilts with live PRRSV. The PRRSV challenge increased the irreversible loss rate (ILR) for methionine (from 108 to $228 \mu \mathrm{mol} / \mathrm{kg} \mathrm{BW} / \mathrm{h}$ ) and threonine (from 83 to $129 \mu \mathrm{mol} / \mathrm{kg} \mathrm{BW} / \mathrm{h}$ ) (Figure 9). ILR is the amount of an amino acid that disappears per kg body weight per hour from the amino acid plasma pool towards organs and tissues for protein synthesis or amino acid catabolism (oxidation). The ILR for other amino acids (Lys, Trp, Ile, Leu, Val, Phe, Gln) was not affected by PRRSV. The increased ILR for methionine and threonine in PRRSV challenged pigs could be associated with enhanced utilization of methionine and threonine for synthesis of immune system metabolites and increased catabolism of these amino acids. This may increase dietary methionine and threonine requirements of health challenged pigs, relative to requirements for other essential amino acids (Stuart et al., 2015).

In a second experiment Stuart et al. (2016) and Rakhshandeh (2015) evaluated the effects of ISS induced by two intramuscular injections of increasing amounts of LPS given $48 \mathrm{~h}$ apart on whole body protein deposition and amino acid metabolism in gilts (BW $9.4 \pm 1.1 \mathrm{~kg}$ ). ISS decreased the ILR for isoleucine (from 112 to $76 \mu \mathrm{mol} / \mathrm{kg} \mathrm{BW} / \mathrm{h}$ ) and phenylalanine (from $126 \mathrm{vs} .79 \mu \mathrm{mol} / \mathrm{kg} \mathrm{BW} / \mathrm{h}$ ). The ILR of other amino acids (Lys, Met, Thr, Trp, Leu, Val, GIn) was not affected by ISS. The decrease in isoleucine and phenylalanine flux in LPS induced ISS pigs was attributed to a reduction in whole body protein synthesis or a decreased catabolism of these amino acids (Stuart et al., 2016). The finding of these experiments indicate an alteration in the use of specific amino acids levels for immune function and metabolism. The differences in the amino acid profiles also indicate disease-specific or disease severity alterations (Rakhshandeh et al., 2015). 


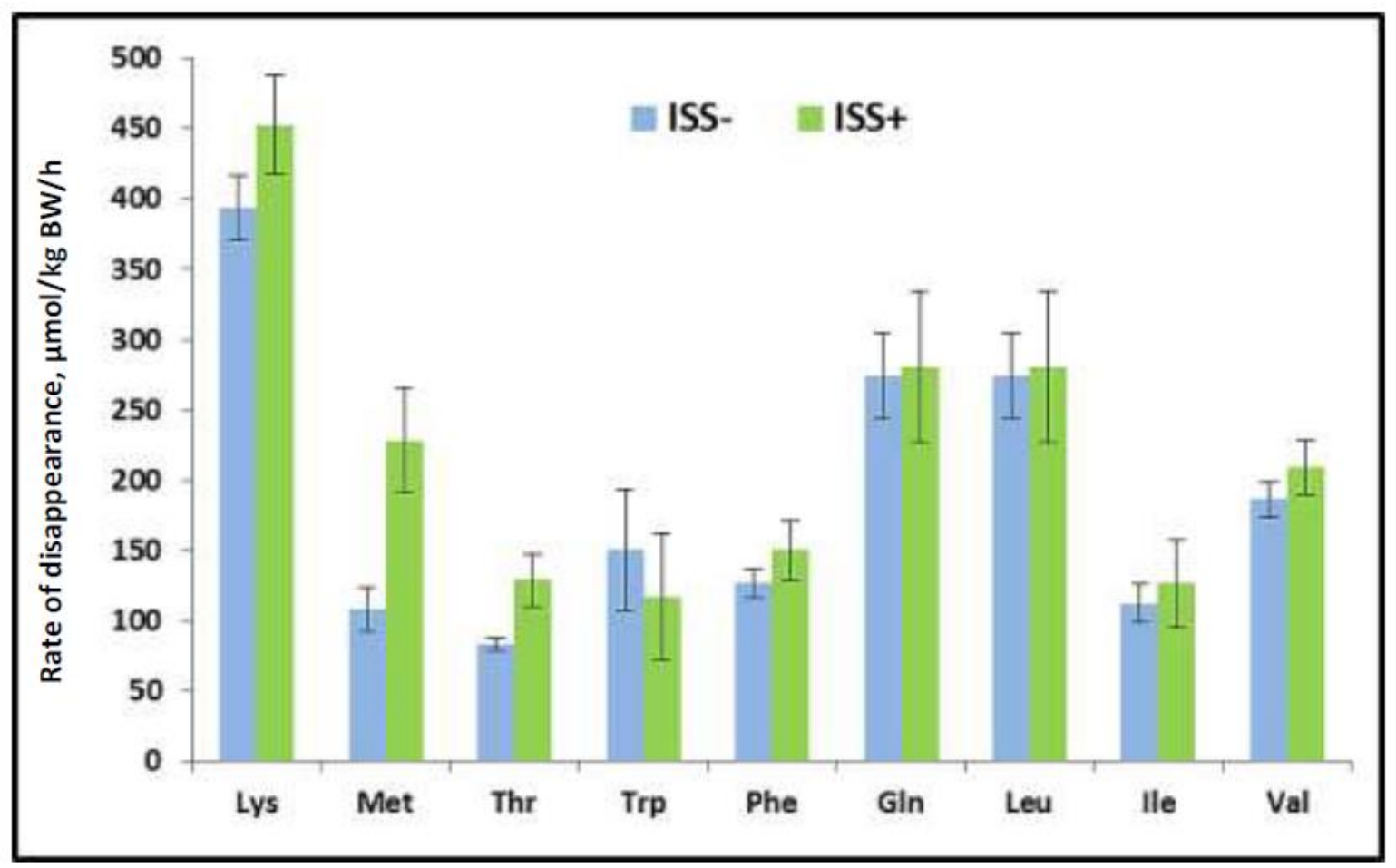

Figure 9 Impact of immune system stimulation (ISS) induced by porcine reproductive and respiratory syndrome virus (PRRSV) on rate of amino acid $(A A)$ disappearance from plasma (i.e. AA flux). Data are least square mean \pm standard error (SE) and corrected for $A A$ intake. ISS was induced by intramuscular injection of live field PRRSV. Plasma AA flux: the sum of disappearance of $A A$ from the plasma pool towards protein synthesis and catabolism (Rakhshandeh, 2015).

Kampman-Van de Hoek et al. (2016) determined the effects of health status (high (HHS) vs low (LHS) health status) and dietary amino acid supply on amino acid utilization in growing pigs. Pigs were obtained from a HSS and a LHS farm. After arrival at the research facility of Wageningen UR, pigs were fed a diet adequate in essential amino acids or deficient in methionine + cysteine, threonine and tryptophan (all at $76 \%$ of the requirement according to CVB (2008)). The LHS pigs fed the amino acid adequate diet showed compensatory body weight gain after arrival, coinciding with $7 \%$ greater nitrogen retention $(P<0.01)$ and greater efficiency of nitrogen utilization in the LHS pigs than in the HHS pigs. The LHS pigs had a greater ILR for lysine and a tendency for a greater ILR for isoleucine. This indicates a greater use for protein synthesis or greater oxidation of these amino acids. The greater urea pool size in LHS pigs compared with HHS pigs indicates that the greater ILR of these amino acids is related to greater oxidation of amino acids rather than to an increase in use for protein synthesis (Kampman-Van de Hoek et al., 2016). Especially in LHS pigs fed the deficient diet, as the increase in ILR for lysine coincided with a lower daily gain. In the LHS pigs fed the adequate diet, however, the greater ILR for lysine and leucine were more likely related to greater protein synthesis, as illustrated by a greater daily gain (Kampman-Van de Hoek et al., 2016). In HHS pigs, daily gain and protein retention were unaffected by dietary amino acid deficiency, indicating that methionine + cysteine, threonine and tryptophan were not limiting body deposition in HHS pigs (Kampman-Van de Hoek et al., 2016). This study illustrates how the competition for amino acids between protein synthesis associated with immune system activation and body protein deposition is greater when the dietary supply of methionine + cysteine, threonine and tryptophan is limited in pigs during and following a period of poor health.

Kampman-Van de Hoek et al. (2015) determined the effect of immune system activation by a challenge with CFA on $\mathrm{N}$ retention and amino acid utilization in growing pigs depending on dietary amino acid supply. Pigs received an adequate or restricted amount of dietary protein. They showed that the effect of CFA challenge on $\mathrm{N}$ retention and amino acid metabolism was largely independent of the dietary protein supply. A deficient dietary protein supply decreased blood serum concentrations of 
C-reactive protein (an acute phase protein) and to a lesser extent albumin, stressing the importance of an adequate dietary amino acid supply for the production of acute phase proteins in growing pigs (Kampman-Van de Hoek et al. (2015). Immune system activation via CFA administration reduced the ILR for valine and tyrosine, but did not lead to a significant change in plasma pool size of the measured amino acids, except for methionine. ILR of all amino acids measured, except for tryptophan, were strongly affected by dietary protein supply and were positively correlated to $\mathrm{N}$ retention. Correlations between ILR and acute phase protein indices were absent or negative, indicating that changes in amino acid utilisation for acute phase protein synthesis are quantitatively unimportant in growing pigs, or, more likely, outweighed by a decrease in muscle protein synthesis during immune system activation (Kampman-Van de Hoek et al., 2015). Melchior et al. (2004) stated that protein synthesis and AA catabolism tend to decrease free plasma AA concentrations, whereas plasma free $A A$ may be increased by protein degradation, dietary intake, and de novo synthesis of nonessential AA. It was suggested that modifications of two opposite fluxes of a particular amino acid may be without consequence for the plasma concentrations meaning that no changes in plasma amino acid levels can also be interpreted as opposite amino acid pathways (i.e. use for protein degradation and amino acid catabolism) functioning at the same rate or the absence of a change in amino acid utilisation per se (Capozzalo et al., 2017).

To quantify the amino acid use for APP synthesis during immune system activation Kampman-Van de Hoek (2015) calculated the amount of amino acids that is required for a porcine APP response, and the amount of muscle protein that needs to be mobilized to fulfil this need. The synthesis rate of haptoglobin, CRP and pigMAP were calculated for healthy pigs and for pigs with an activated immune system in three different scenarios (Table 4), i.e. induced by a porcine Circovirus infection in a commercial farm (Parra et al., 2006), a contrast in health status (Kampman-Van de Hoek et al., 2016), or induced by a CFA challenge (Kampman-Van de Hoek et al., 2015).

Table 4 Serum acute phase protein (APP) concentration and estimated synthesis rate of three $A P P$ in healthy growing pigs and in growing pigs with an activated immune system ${ }^{1,3}$ (Kampman-Van de Hoek, 2015).

\begin{tabular}{|c|c|c|c|c|c|c|}
\hline \multirow[b]{2}{*}{ Challenge } & \multirow[b]{2}{*}{ APP } & \multicolumn{2}{|c|}{$\begin{array}{l}\text { Healthy control } \\
\text { pigs }\end{array}$} & \multicolumn{2}{|c|}{$\begin{array}{l}\text { Immune system } \\
\text { activated pigs }\end{array}$} & \multirow{2}{*}{$\begin{array}{c}\text { Difference } \\
\text { in APP } \\
\text { synthesis }^{2} \\
\mathrm{mg} / \mathrm{kg} \\
\mathrm{BW}^{0.75} / \mathrm{d}\end{array}$} \\
\hline & & $\begin{array}{l}\text { Serum, } \\
\mathrm{mg} / \mathrm{mL}\end{array}$ & $\begin{array}{c}\text { APP } \\
\text { synthesis, } \\
\mathrm{mg} / \mathrm{kg} \\
\mathrm{BW}^{0.75} / \mathrm{d}\end{array}$ & $\begin{array}{l}\text { Serum, } \\
\mathrm{mg} / \mathrm{mL}\end{array}$ & $\begin{array}{c}\text { APP } \\
\text { synthesis, } \\
\mathrm{mg} / \mathrm{kg} \\
\mathrm{BW}^{0.75} / \mathrm{d}\end{array}$ & \\
\hline \multirow{4}{*}{$\begin{array}{l}\text { Porcine } \\
\text { circovirus } \\
\text { type } 2 \text { field } \\
\text { infection, } \\
\mathrm{n}=10 \\
\text { (Parra et al., } \\
2006 \text { ) }\end{array}$} & haptoglobin & 0.2 & 2.7 & 5.0 & 68.2 & 65.4 \\
\hline & CRP & 0.005 & 0.4 & 0.14 & 12.3 & 11.9 \\
\hline & pig-MAP & 0.8 & 10.7 & 3.3 & 45.2 & 34.5 \\
\hline & Sum & & 14 & & 126 & 112 \\
\hline \multirow{4}{*}{$\begin{array}{l}\text { Contrast in } \\
\text { health } \\
\text { status, } \\
\mathrm{n}=25 \\
\text { (Chapter } 4 \text { ) }\end{array}$} & haptoglobin & 1.3 & 15.9 & 2 & 24.4 & 8.5 \\
\hline & CRP & 0.363 & 28.8 & 0.442 & 35.0 & 6.2 \\
\hline & pig-MAP & 1.3 & 15.9 & 1.3 & 15.9 & 0.0 \\
\hline & Sum & & 61 & & 75 & 15 \\
\hline \multirow{4}{*}{$\begin{array}{l}\text { CFA } \\
\text { challenge, } \\
\mathrm{n}=16 \\
\text { (Chapter 5) }\end{array}$} & haptoglobin & 0.7 & 8.9 & 1.9 & 24.7 & 15.8 \\
\hline & CRP & 0.160 & 13.6 & 0.266 & 22.5 & 8.9 \\
\hline & pig-MAP & 0.2 & 2.8 & 0.9 & 11.4 & 8.6 \\
\hline & Sum & & 25 & & 59 & 33 \\
\hline
\end{tabular}

1 APP synthesis rate was estimated using equation 6.1 in the computer program SMART (Simulation and Modelling Assistant for Research and Training), to maintain serum plasma concentrations of haptoglobin, CRP and pig-MAP as observed in healthy pigs and pigs with an activated immune system. The pigs had an average bodyweight of $50 \mathrm{~kg}$ (Parra et al., 2006), 25 kg (Kampman-Van de Hoek et al., 2016) and 40 kg (Kampman-Van de Hoek et al. (2015), respectively.

2 Difference in APP synthesis rate between healthy pigs and pigs with an activated immune system.

${ }^{3}$ Chapter 4 and chapter 5 refers to the PhD thesis of Kampman-Van de Hoek (2015). 
Based on the results in Table 4 and the amino acid composition of muscle protein (Table 3),

Kampman-Van de Hoek (2015) calculated the increase in the rate of amino acid utilization required for APP synthesis and the increase in the muscle protein breakdown rate between healthy and challenged growing pigs (Table 5).

Table 5 Calculated increase in the rate of amino acid utilization required for acute phase protein (APP) synthesis and increase in the muscle protein breakdown rate between healthy and challenged growing pigs (Kampman-Van de Hoek, 2015).

\begin{tabular}{|c|c|c|c|c|c|c|}
\hline \multirow{3}{*}{$\mathrm{AA}_{\mathrm{i}}$} & \multicolumn{2}{|c|}{$\begin{array}{c}\text { Porcine circovirus type } 2 \\
\text { in } 50 \mathrm{~kg} \text { pigs } \\
\text { (Parra et al., 2006) }\end{array}$} & \multicolumn{2}{|c|}{$\begin{array}{l}\text { Contrast in health } \\
\text { status in } 25 \mathrm{~kg} \text { pigs } \\
\text { (Chapter 4) }\end{array}$} & \multicolumn{2}{|c|}{$\begin{array}{c}\text { CFA challenge in } 40 \mathrm{~kg} \\
\text { pigs } \\
\text { (Chapter 5) }\end{array}$} \\
\hline & $\begin{array}{c}\text { Increase } \\
\text { in use of } \\
\mathrm{AA}_{\mathrm{i}} \text { for } \\
\mathrm{APP}^{1}\end{array}$ & $\begin{array}{l}\text { Increase in } \\
\text { muscle } \\
\text { protein } \\
\text { breakdown } \\
\text { for APP }{ }^{2}\end{array}$ & $\begin{array}{c}\text { Increase } \\
\text { in use of } \\
\mathrm{AA}_{\mathrm{i}} \text { for } \\
\mathrm{APP}^{1}\end{array}$ & $\begin{array}{l}\text { Increase in } \\
\text { muscle } \\
\text { protein } \\
\text { breakdown } \\
\text { for APP }{ }^{2}\end{array}$ & $\begin{array}{c}\text { Increase } \\
\text { in use of } \\
\mathrm{AA}_{\mathrm{i}} \text { for } \\
\mathrm{APP}^{1}\end{array}$ & $\begin{array}{l}\text { Increase in } \\
\text { muscle } \\
\text { protein } \\
\text { breakdown } \\
\text { for APP }{ }^{2}\end{array}$ \\
\hline & & & \multicolumn{2}{|c|}{$\mathrm{mg} / \mathrm{kg} B W^{0.75} /$ day } & & \\
\hline Phe & 9.6 & 239 & 1.9 & 45 & 3.8 & 94 \\
\hline Tyr & 12.1 & 310 & 1.9 & 47 & 3.8 & 94 \\
\hline Trp & 5.9 & $\underline{526^{3}}$ & 1.0 & $\underline{96^{3}}$ & 1.9 & $\underline{181^{3}}$ \\
\hline Leu & 19.8 & 250 & 2.9 & $\overline{31}$ & 6.3 & 78 \\
\hline Ile & 10.7 & 228 & 1.9 & 31 & 3.1 & 72 \\
\hline Val & 18.4 & 362 & 1.9 & 47 & 5.7 & 111 \\
\hline Lys & 17.0 & 201 & 2.9 & 29 & 5.0 & 61 \\
\hline His & 7.2 & 238 & 1.0 & 28 & 1.9 & 67 \\
\hline Met & 3.7 & 139 & 0.0 & 17 & 1.3 & 43 \\
\hline Cys & 3.7 & 368 & 1.0 & 57 & 1.3 & 109 \\
\hline Thr & 12.5 & 297 & 1.9 & 39 & 3.8 & 93 \\
\hline Arg & 8.0 & 140 & 1.0 & 15 & 2.5 & 43 \\
\hline Pro & 10.5 & 257 & 1.0 & 31 & 3.1 & 79 \\
\hline Gly & 11.4 & 248 & 1.0 & 29 & 3.8 & 76 \\
\hline Ser & 13.1 & 374 & 1.9 & 50 & 4.4 & 125 \\
\hline Ala & 13.0 & 228 & 1.0 & 23 & 3.8 & 65 \\
\hline
\end{tabular}

${ }^{1}$ The increase in the utilization rate of AAi required for each APP was calculated by multiplying the estimated difference in APP synthesis (Table 4) by the amino acid composition of each APP. To estimate the total costs of amino acids for APP synthesis, it was assumed that haptoglobin, CRP, and pig-MAP represent half of the total amount of APP synthesized after immune system activation. The sum of the difference in AAi quantity required for the synthesis of these three APP between healthy pigs and pigs with an activated immune system was therefore multiplied by 2 .

${ }^{2}$ The rate of muscle protein breakdown $\left(\mathrm{mg} / \mathrm{kg} \mathrm{BW}^{0.75} / \mathrm{d}\right)$, needed to provide AAi for APP synthesis was calculated by dividing the amount of AAi required for APP ( $\left.\mathrm{g} / \mathrm{kg} \mathrm{BW}^{0.75} / \mathrm{day}\right)$ by the muscle content of $\mathrm{AAi}(\mathrm{g} / \mathrm{g})$.

${ }^{3}$ The amount of muscle protein that is broken down for APP synthesis, with Trp being first limiting for APP synthesis is underlined.

As shown in Table 5, tryptophan is the first limiting amino acid for APP synthesis when muscle protein is mobilized, followed by cysteine, valine and serine. Based on these calculations, Kampman-Van de Hoek (2015) concluded that of the reduction in whole body protein deposition observed in growing pigs challenged with CFA (Kampman-Van de Hoek et al., 2016), approximately $30 \%$ could be attributed to the loss of muscle protein for incorporation of amino acids into APP.

Sakkas et al. (2016) studied the effect of health status of growing-finishing farms on amino acid metabolism of growing pigs on six commercial pig farms with a different health status. The ILR for tryptophan, methionine and phenylalanine differed between pigs of different farms. The ILR for isoleucine, leucine, valine, lysine and tyrosine did not differ between farms. No clear relationships were found between concentrations of blood acute phase proteins and ILR (disappearance of plasma amino acids for protein synthesis or for oxidation in organs and tissues) or the plasma pool size of essential amino acids. Thus, there were no indications that $\mathrm{N}$-metabolism and $\mathrm{N}$-requirements were changed or increased in pigs on farms with clinically healthy animals but with pigs showing increased concentrations of acute phase proteins in blood. It was concluded that the costs for the production of acute phase proteins are relatively low in pigs with an activated immune system not showing clinical signs of infections and disease. 


\subsubsection{Nutrient metabolism during and after LPS challenge using the amino acid}

and glucose clamp technique

Dekker et al. (2004) determined the effects of immune system activation by an intravenous challenge with E. coli derived lipopolysaccharides (LPS) on whole body amino acid (AA) and glucose metabolism. LPS and control (placebo) growing pigs were pair-fed to maintain equal nutritional status among pigs in both experimental groups throughout the study. They showed that the effects of systemic LPS challenge on systemic AA and glucose metabolism resulted in significant changes in net metabolic transport (flux) of AA and glucose from the circulating blood to organs and tissues in the body compared to control pigs. The transport (flux) of AA and glucose from blood to body tissues is designated in the present report as whole body net metabolic utilisation (in grams of AA or glucose per kg BW per day) abbreviated as NMU. LPS challenge in growing pigs caused an increase in NMU for all AA combined and a decrease in NMU for glucose. LPS challenge in growing pigs caused an increase in NMU for isoleucine, leucine, valine and tryptophan. A more detailed outcome of the results of this study and an explanation of the AA and glucose clamp technique to calculate NMU of 20 individual AA and glucose at the whole body level is given in the textbox below and in Appendix 1.

\section{The clamp technique}

Koopmans et al $(2003,2006,2009,2011)$ used a biomedical technique (AA and glucose clamp technique) in pigs to quantify the net metabolic utilization (NMU) of 20 individual $A A$ and glucose at the whole body level in growing pigs. In the clamp technique, $20 \mathrm{AA}$ and glucose are infused in the portal vein in fasting pigs. This reflects the situation during and after a meal, when hydrolysed protein and carbohydrates are transferred via the gut wall and appear as AA and glucose in the portal vein. The infusion of the $A A$ and glucose during the clamp can therefore be considered as a highly digestible protein-carbohydrate meal directly administered to the portal blood circulation of the pig. During the clamp, a constant amount of insulin ( $1 \mathrm{mU}$ insulin. kg-1 BW.min-1) is co-infused in the portal vein to stimulate organs and tissues in the body of the pig to metabolise the 20 AA and glucose at a NMU which reflects a condition after ingestion of a medium-sized meal. Based on a feeding strategy with two meals per day, the metabolizable energy (ME) of the medium-sized meal would be $575 \mathrm{~kJ} \mathrm{ME} / \mathrm{kg}$ $\mathrm{BW}^{0.75}$, which is equivalent to a feeding level of 2.5 times the maintenance requirements for $\mathrm{ME}$ (Koopmans et al., 2006). Quantification of the NMU of AA and glucose during the clamp is standardized at an insulin infusion rate of $1 \mathrm{mU}$ insulin $/ \mathrm{kg} \mathrm{BW} / \mathrm{min}$. Changes in anabolic capacity of pigs are measured at this constant insulin-infusion rate, because insulin sensitivity (represents anabolic capacity of the pig) may be different between pigs within and among experimental treatments. The results of the clamp studies both reflect changes in the absolute values of NMA for AA and glucose but also reflect qualitative changes in NMU between individual AA. Results derived from the clamp studies in the present report are therefore both presented from a quantitative perspective (changes in absolute NMU of individual AA; see Figures 10,13,16, and 19) and from a qualitative perspective (changes in the ratio between individual AA for NMU; see Figures 11, 14, 17, and 20). The latter perspective gives insight in the relative contribution of individual AA to total NMU for all AA combined. Extrapolated to metabolic AA requirements of pigs, the latter indicates which individual AA seem deficient (in shortage) and which individual $A A$ is available in excess to the pig. The rationale behind the methodology of the clamp technique is further explained in Appendix 1.

To induce activation of the immune system in pigs, E. coli lipopolysaccharide (LPS) was infused intravenously ( $2 \mu \mathrm{g} \cdot \mathrm{kg}^{-1} \mathrm{BW} \cdot \mathrm{h}^{-1}$ for $9 \mathrm{~h}$ ) and control (healthy) pigs received placebo infusion. All pigs were subject to the AA and glucose clamp technique twice: a first time during the final 3 hours of LPS (or placebo) infusion (i.e. the acute phase of LPS challenge) and the second time one-day post LPS (or placebo) infusion (i.e. one-day after LPS challenge). To maintain equal nutritional status among pigs throughout the study, all pigs were fed at the restricted level of $1150 \mathrm{~kJ} \mathrm{ME} / \mathrm{kg} \mathrm{BW}{ }^{0.75}$ which is equal to 2.5 times maintenance requirements for ME (Koopmans et al., 2006). 
Results during the acute phase of LPS challenge

During the acute phase during LPS challenge, the whole body NMU for all 20 amino acids combined (the sum of $20 \mathrm{AA}$ ) and for glucose was statistically not different between LPS vs. C pigs ( $2.1 \pm 1.1$ vs $2.5 \pm 0.6$ g. kg-1 BW.day ${ }^{-1}$ and $29 \pm 12$ vs $34 \pm 5{\mathrm{~g} . \mathrm{kg}^{-1} \text { BW.day }}^{-1}$, respectively).

For individual $A A$, whole body NMU (in $\mathrm{mg} \mathrm{AA} / \mathrm{kg} B W /$ day) was increased significantly in acute phase for LPS vs C pigs for the essential AA Trp (49 vs $26 \mathrm{mg} / \mathrm{kg} \mathrm{BW/day,} \mathrm{+89 \% )} \mathrm{and} \mathrm{decreased}$ significantly for the essential AA His (28 vs $76 \mathrm{mg} \mathrm{AA} / \mathrm{kg} B W /$ day, $-63 \%$ ). The NMU for the nonessential AA Ala and Pro were decreased in LPS challenged pigs (Figure 10).

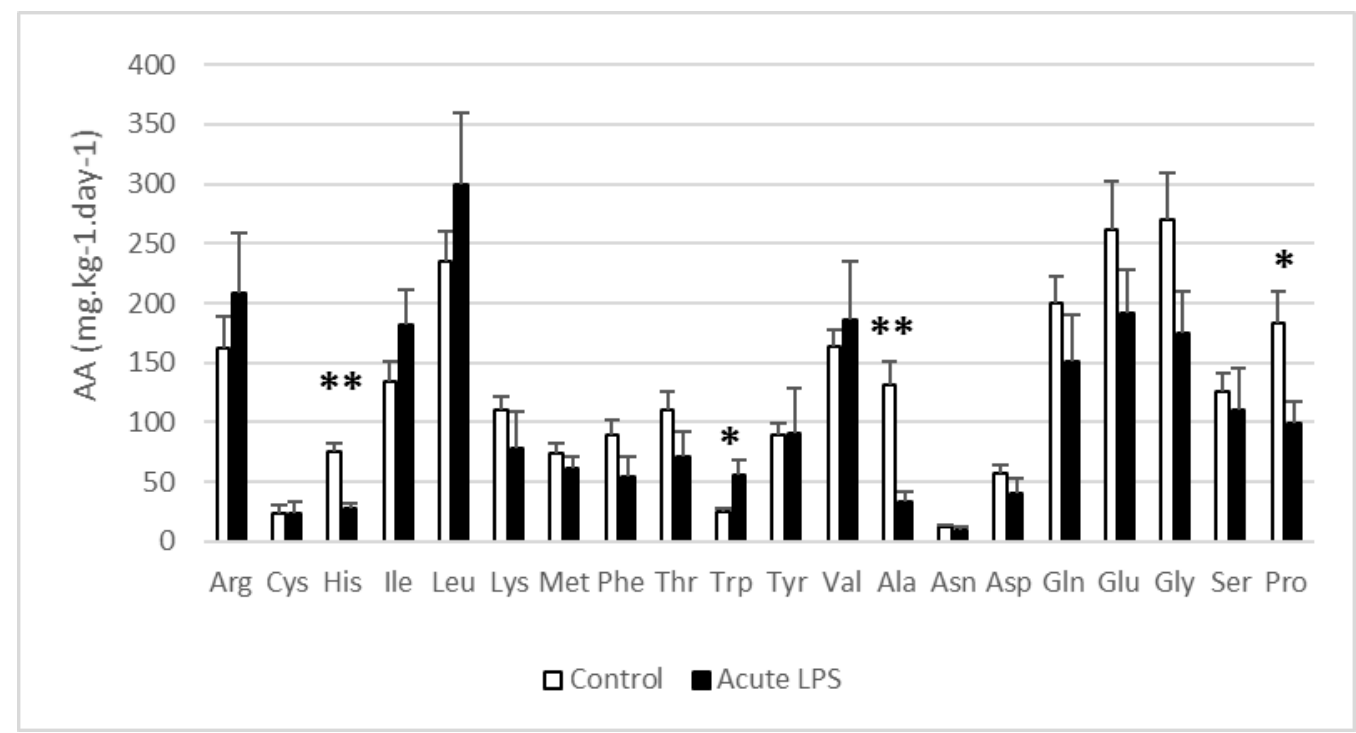

Figure 10 Whole body net metabolic AA utilisation (NMU in mg AA per $\mathrm{kg} B W$ per day) in acute phase $L P S$ treated pigs and control pigs. The $A A$ infusion rate reflects the acute phase of LPS challenge and is designated as Acute LPS. Data are means +/- SEM. ${ }^{*} p<0.05$, $* * p<0.01$.

Expressed as percentage individual AA of total AA, the whole body NMU of acute phase LPS vs $C$ pigs was increased significantly (\% of total AA) for the (semi-)essential AA Arg (10 vs 6\%), Ile (9 vs $5 \%$ ), Leu (14 vs 9\%), Trp (3 vs 1\%), Val ( 8 vs 7\%) and decreased significantly for His ( 1 vs $3 \%$ ), Phe (2 vs $3 \%$ ) and Thr (3 vs 4\%). The NMU for the non-essential AA Ala, Asp and Pro were decreased in LPS challenged pigs (Figure 11). 


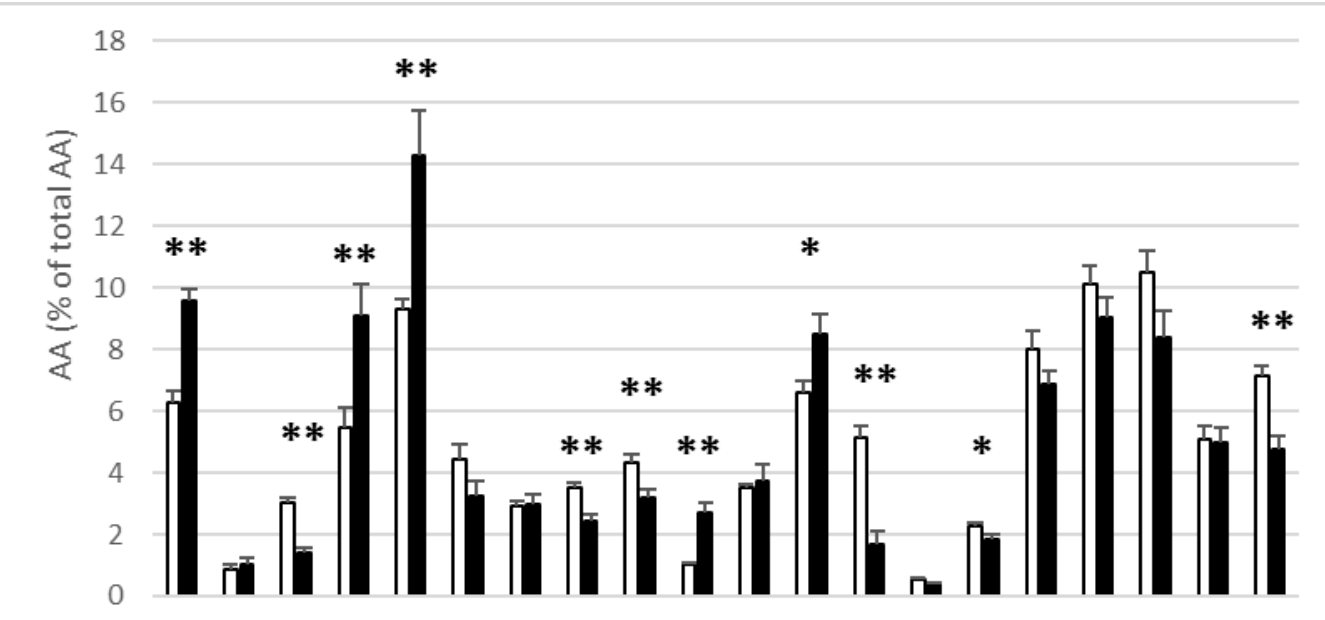

Arg Cys His lle Leu Lys Met Phe Thr Trp Tyr Val Ala Asn Asp Gln Glu Gly Ser Pro

$\square$ Control

Acute LPS

Figure 11 Whole body net metabolic AA utilisation (NMU as \% of total AA) in acute phase LPS treated pigs and control pigs. The $A A$ infusion rate reflects the acute phase of LPS challenge and is designated as Acute LPS. Data are means +/- SEM. ${ }^{*} p<0.05$, $* * p<0.01$.

When expressed as percentage individual AA compared to Lys, the whole body NMU of acute phase LPS vs C pigs was significantly increased (\% of Lys) for the essential AA Ile (321 vs 125\%), Leu (496 vs $218 \%$ ), Trp (93 vs $24 \%$ ), Tyr (117 vs $83 \%)$ and Val (288 vs $154 \%$ ) and decreased significantly for His (48 vs $70 \%$ ). The NMU for the non-essential AA Ala was decreased in LPS challenged pigs (Figure 12).

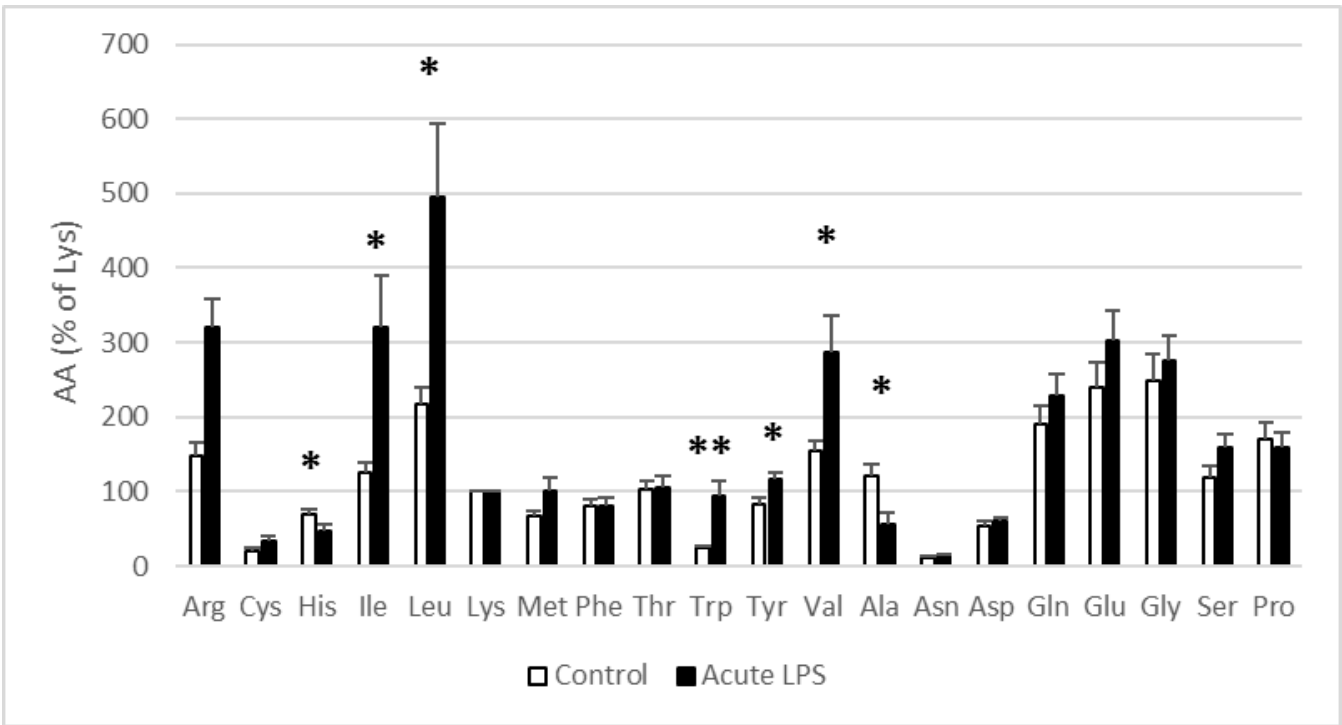

Figure 12 Whole body net metabolic AA utilisation (NMU as \% AA compared to Lys) in acute phase $L P S$ treated pigs and control pigs. The $A A$ infusion rate reflects the acute phase of $L P S$ challenge and is designated as Acute LPS. Data are means $+/-$ SEM. ${ }^{*} p<0.05,{ }^{*} p<0.01$.

In summary, the acute phase of LPS challenge induced a general increase in the systemic utilization of the essential AA Ile, Leu, Val, Trp in the body and a decrease in the utilization of His.

\section{One-day post LPS challenge}

The whole body NMU for all 20 AA combined was increased in one-day post LPS challenge vs C pigs

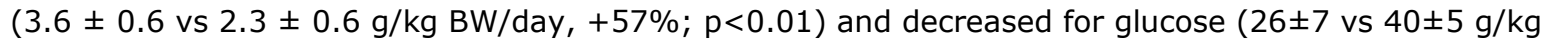


$\mathrm{BW} /$ day, $-35 \% ; \mathrm{p}<0.01)$, resulting in a $133 \%$ increase $(\mathrm{p}<0.01)$ in the NMU of total AA compared to glucose (NMU of AA divided by the NMU of glucose) in one-day post LPS challenge vs $C$ pigs $(0.14 \pm 0.01$ vs $0.06 \pm 0.01$, respectively). In other words, this means that in one-day post LPS challenge pigs, metabolism in organs and tissues of pigs becomes more dependent on AA compared to glucose.

Per individual AA, whole body NMU (in mg AA. $\mathrm{kg}^{-1} \mathrm{BW}$.day ${ }^{-1}$ ) was increased in one-day post LPS challenge vs C pigs for the essential AA Arg (200 vs 139, +44\%), Cys (30 vs 15, +100\%), His (93 vs $54,+72 \%)$, Ile $(171$ vs $107,+60 \%)$, Leu (331 vs $180,+84 \%)$, Lys $(238$ vs $178,+34 \%)$, Phe (151 vs $84,+80 \%)$, $\operatorname{Thr}(157$ vs $102,+54 \%), \operatorname{Trp}(42$ vs $26,+62 \%), \operatorname{Tyr}(130$ vs $88,+48 \%)$ and Val (213 vs $121,+76 \%)$. The NMU for the non-essential AA Asn, Asp, Gln, Glu, Gly and Ser were increased (Figure 13).

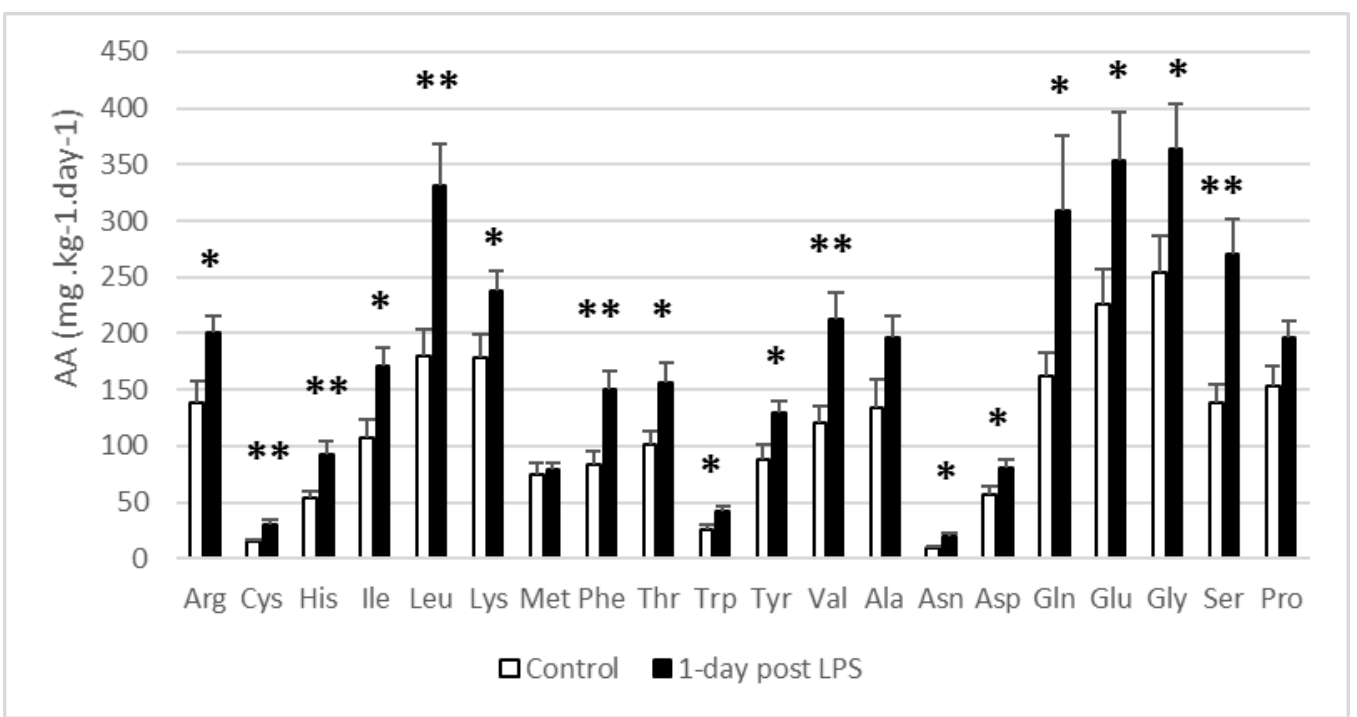

Figure 13 Whole body net metabolic AA utilisation (NMU in $\mathrm{mg} A A$ per $\mathrm{kg}$ body weight per day) in one-day post LPS treated pigs and control pigs. The AA infusion rate reflects one-day after LPS challenge and is designated as 1-day post LPS. Data are means +/- SEM. $* p<0.05, * * p<0.01$.

Expressed as percentage individual $A A$ of total $A A$, the whole body NMU of one-day post LPS challenge vs $C$ pigs was decreased (\% of total $A A$ ) for the essential AA Lys ( 7 vs 8 ) and Met (2 vs 3 ). The NMU for the non-essential AA Ser was increased and for Pro was decreased (Figure 14). 


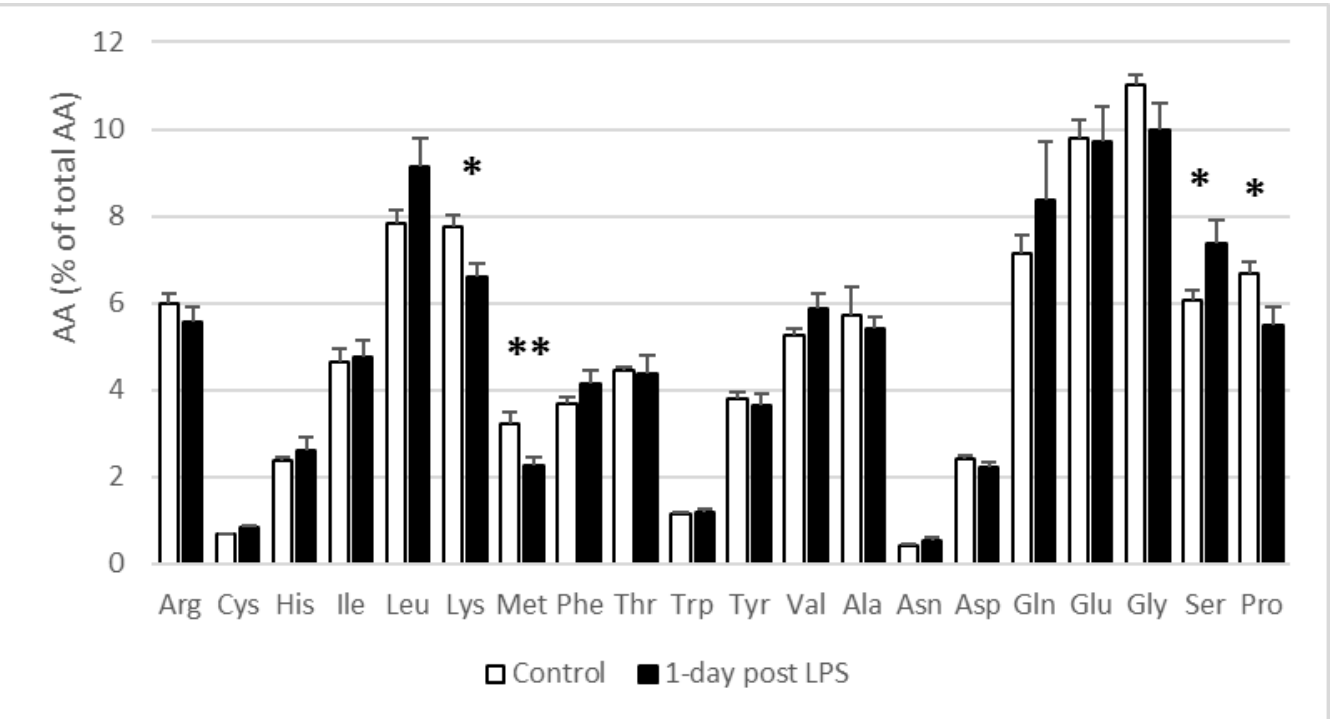

Figure 14 Whole body net metabolic AA utilisation (NMU as \% of total AA) in one-day post LPS treated pigs and control pigs. The $A A$ infusion rate reflects one-day after LPS challenge and is designated as 1-day post LPS. Data are means +/- SEM. ${ }^{*} p<0.05,{ }^{*} p<<0.01$.

When expressed as percentage individual AA compared to Lys, the whole body NMU of one-day post LPS challenge vs C pigs was increased (\% of Lys) for Cys (13 vs 9), Leu (138 vs 102), Phe (63 vs 48 ) and Val (89 vs 68). The NMU for the non-essential AA Asn and Ser were increased (Figure 15).

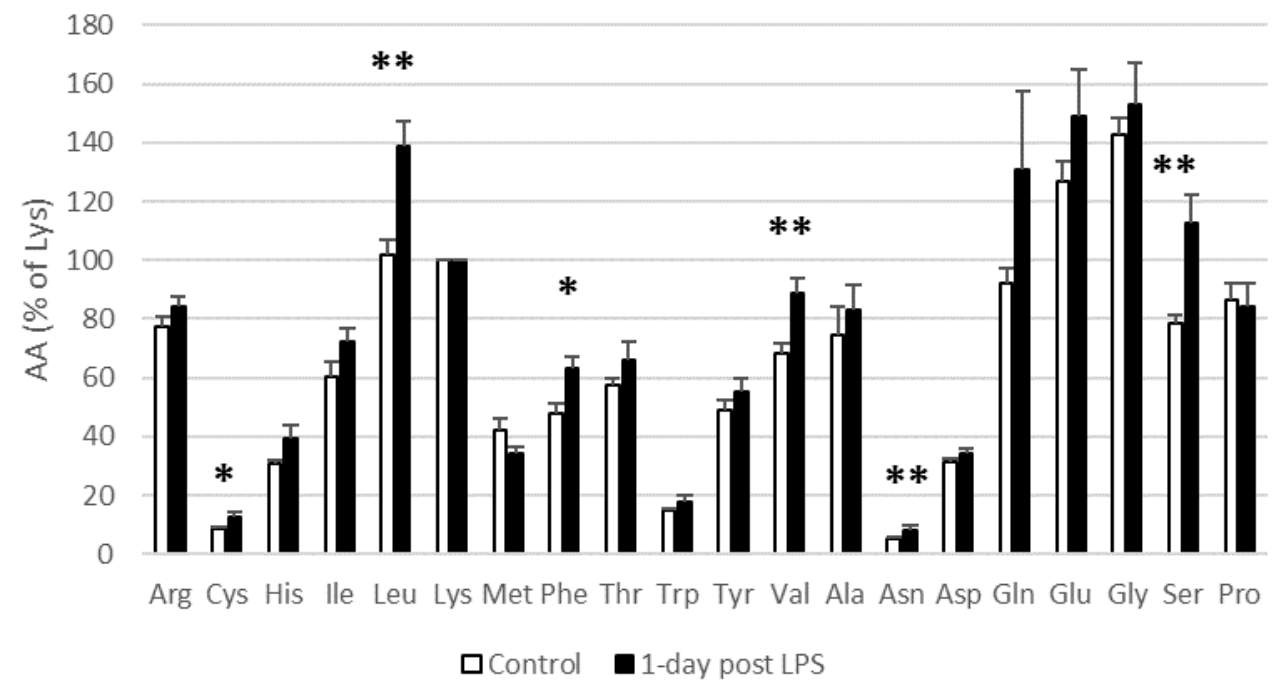

Figure 15 Whole body net metabolic AA utilisation (as \% AA compared to Lys) in one-day post LPS treated pigs and control pigs. The AA infusion rate reflects one-day after $L P S$ challenge and is designated as 1-day post LPS. Data are means +/- SEM. $* p<0.05, * * p<0.01$.

In summary, one-day post LPS challenge induced a general increase in the NMU of the essential AA Cys, Leu, Phe, and Val.

The overall (integral) effect of LPS-induced immune system activation on NMU for 20 individual AA and glucose can be reflected by averaging the NMU of the acute phase of LPS challenge and the NMU oneday after LPS challenge. Therefore we calculated the mean values for both time points. The whole body NMU for all 20 AA combined was increased in overall LPS vs C pigs $(2.9 \pm 0.3$ vs $2.4 \pm 0.2 \mathrm{~g}$.

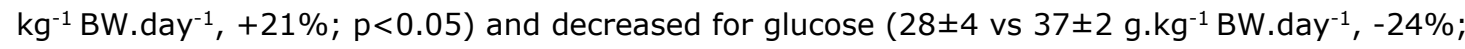
$p<0.01$ ), resulting in a $57 \%$ increase $(p<0.01)$ in the NMU of total AA compared to glucose (AA 
divided by glucose) in overall LPS vs C pigs ( $0.11 \pm 0.01$ vs $0.07 \pm 0.01$, respectively). This means that in overall LPS challenged pigs, metabolism becomes more dependent on AA compared to glucose.

Per individual AA, whole body NMU (in mg AA. $\mathrm{kg}^{-1} \mathrm{BW}$.day ${ }^{-1}$ ) was increased in overall LPS vs C pigs for the essential AA Ile (177 vs $121,+46 \%$ ), Leu (315 vs $207,+52 \%)$, Trp (49 vs 26, $+89 \%$ ), Val (199 vs $142,+40 \%) ; \mathrm{p}<0.09$ ) (Figure 16$)$.

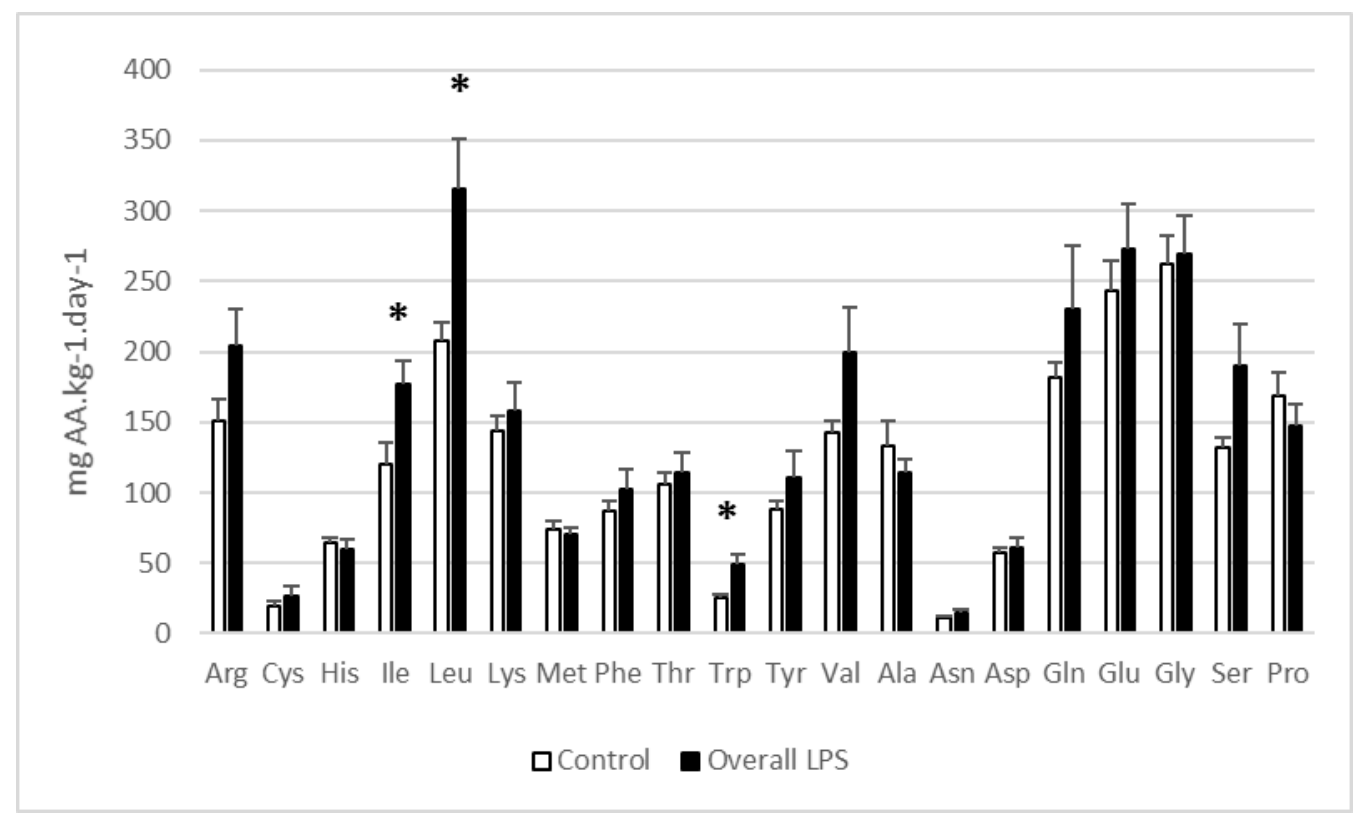

Figure 16 Whole body net metabolic AA utilisation (NMU in $\mathrm{mg} A$ A per $\mathrm{kg}$ body weight per day) in LPS treated pigs and control pigs. The AA infusion rate reflects the mean of the acute phase of LPS challenge and one-day after LPS challenge and is designated as Overall LPS. Data are means $+/-$ SEM. $* p<0.05, * * p<0.01$.

Expressed as percentage individual AA of total AA, the whole body NMU of overall LPS vs $C$ pigs was increased (\% of total AA) for Arg (8 vs 6), Ile (7 vs 5), Leu (12 vs 9), Trp (2 vs 1), Val (7 vs 6) and decreased for His ( 2 vs 3 ) and Lys (5 vs 6 ). The NMU for the non-essential AA Ala, Asp, Gly and Pro were decreased (Figure 17). 


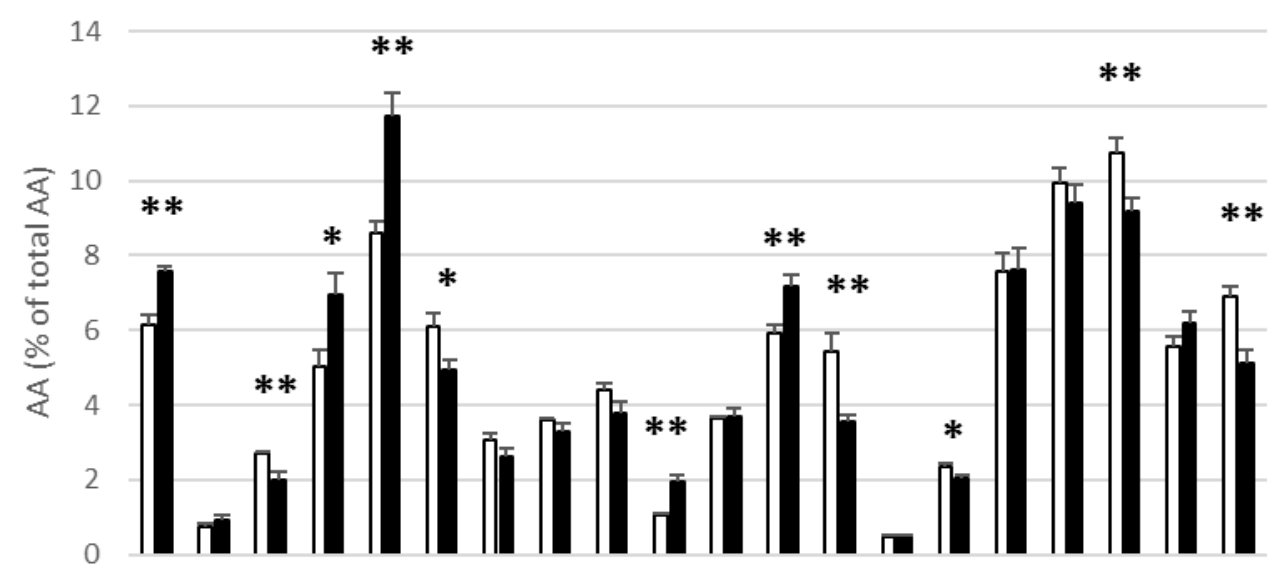

Arg Cys His Ile Leu Lys Met Phe Thr Trp Tyr Val Ala Asn Asp Gln Glu Gly Ser Pro

$\square$ Control

Overall LPS

Figure 17 Whole body net metabolic AA utilisation (NMU as \% of total AA) in LPS treated pigs and control pigs. The $A A$ infusion rate reflects the mean of the acute phase of LPS challenge and one-day after LPS challenge and is designated as Overall LPS. Data are means +/SEM. $* p<0.05, * * p<0.01$.

When expressed as percentage individual AA compared to Lys, the whole body NMU of overall LPS vS C pigs was increased (\% of Lys) for Arg (130 vs 105), Ile (114 vs 84), Leu (202 vs 147), Trp (31 vs 18) and Val (125 vs 101). The NMU for the non-essential AA Ser was increased (Figure 18).

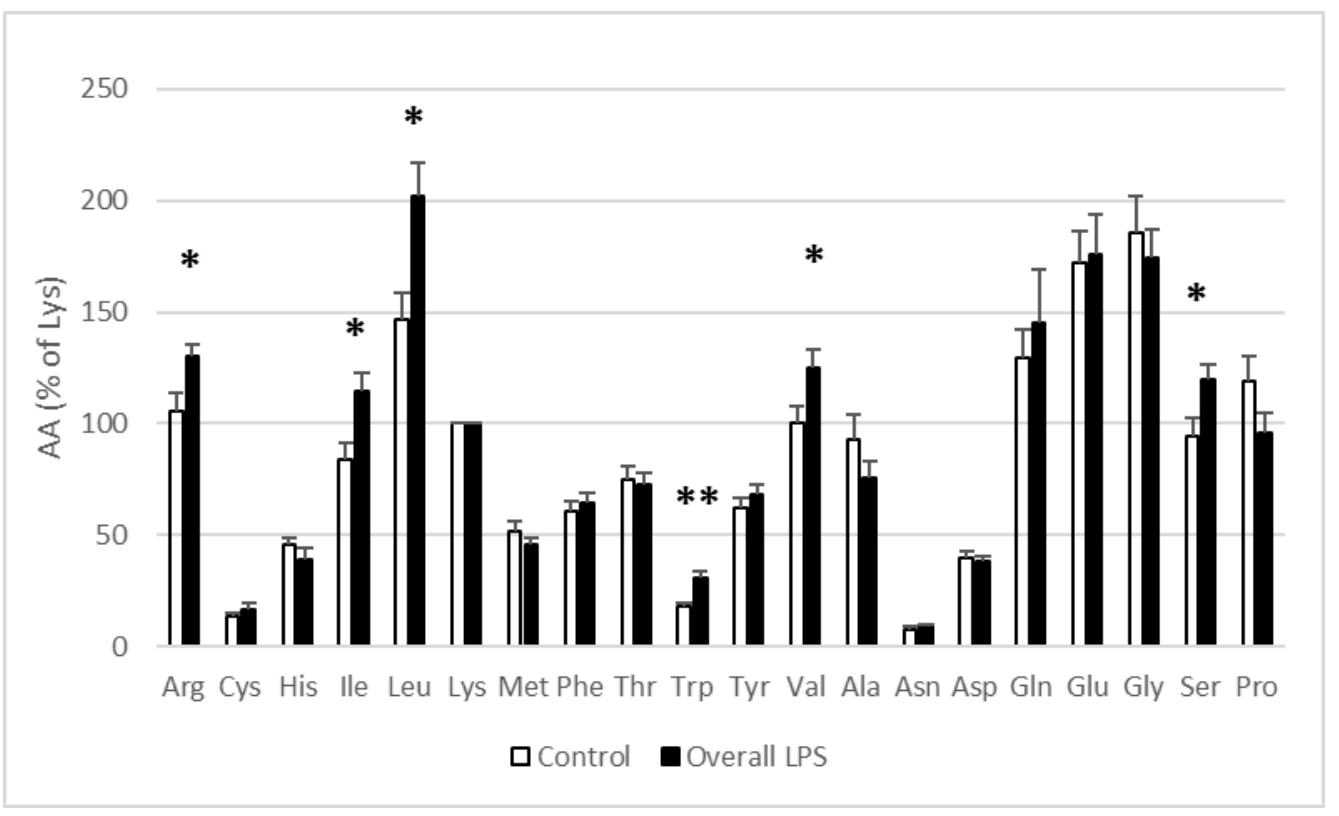

Figure 18 Whole body net metabolic AA utilisation (NMU as \% AA compared to Lys) in LPS treated pigs and control pigs. The AA infusion rate reflects the mean of the acute phase of LPS challenge and one-day after LPS challenge and is designated as LPS overall. Data are means + /- SEM. ${ }^{*} p<0.05, * * p<0.01$.

In summary, the overall phase of LPS challenge induced a general increase in the NMU of the essential AA Arg, Ile, Leu, Val, Trp.

Case study of natural infection

In the studies with the clamp technique described above, in two pigs accidently a natural infection and immune system activation occurred. Both pigs suffered from fever $\left(41^{\circ} \mathrm{C}\right)$ and showed thin faeces. 
One pig was diagnosed as being infected by Salmonella whereas the other pig was not infected by Salmonella but suspected to be infected by pathogenic E. coli (no further laboratory analysis on faeces was carried out). In these two, naturally infected pigs the whole body NMU of Ile, Leu, Val and Trp (Figures 19, 20 and 21) were numerically increased (statistical evaluation was not carried out due to the small group size) compared to the control, non-infected group, similar to the effects of systemic LPS challenge in pigs as quantified above (Figures 10-18).

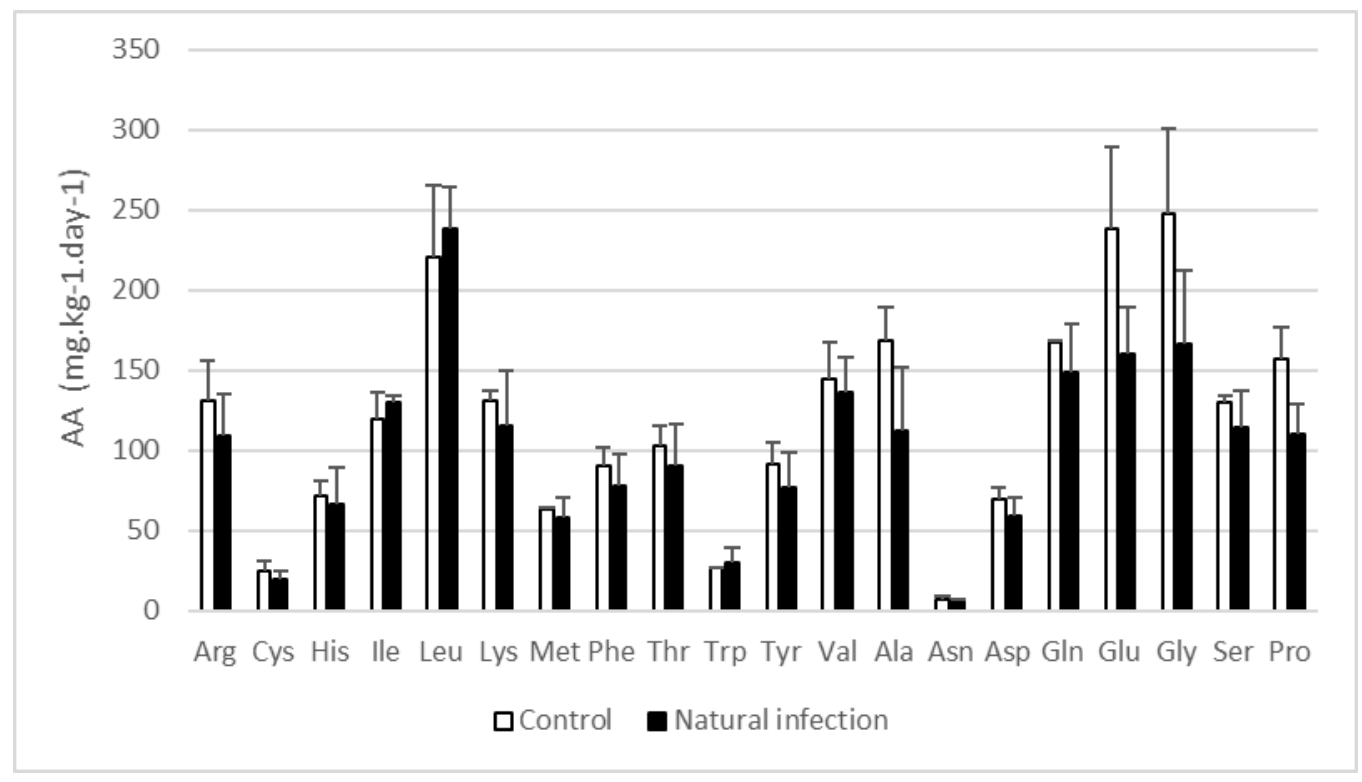

Figure 19 Whole body net metabolic AA utilisation (NMU in mg AA per kg body weight per day) in two naturally infected pigs and two control pigs. The $A A$ infusion rate reflects the situation during natural infection. Data are means $+/-S D$.

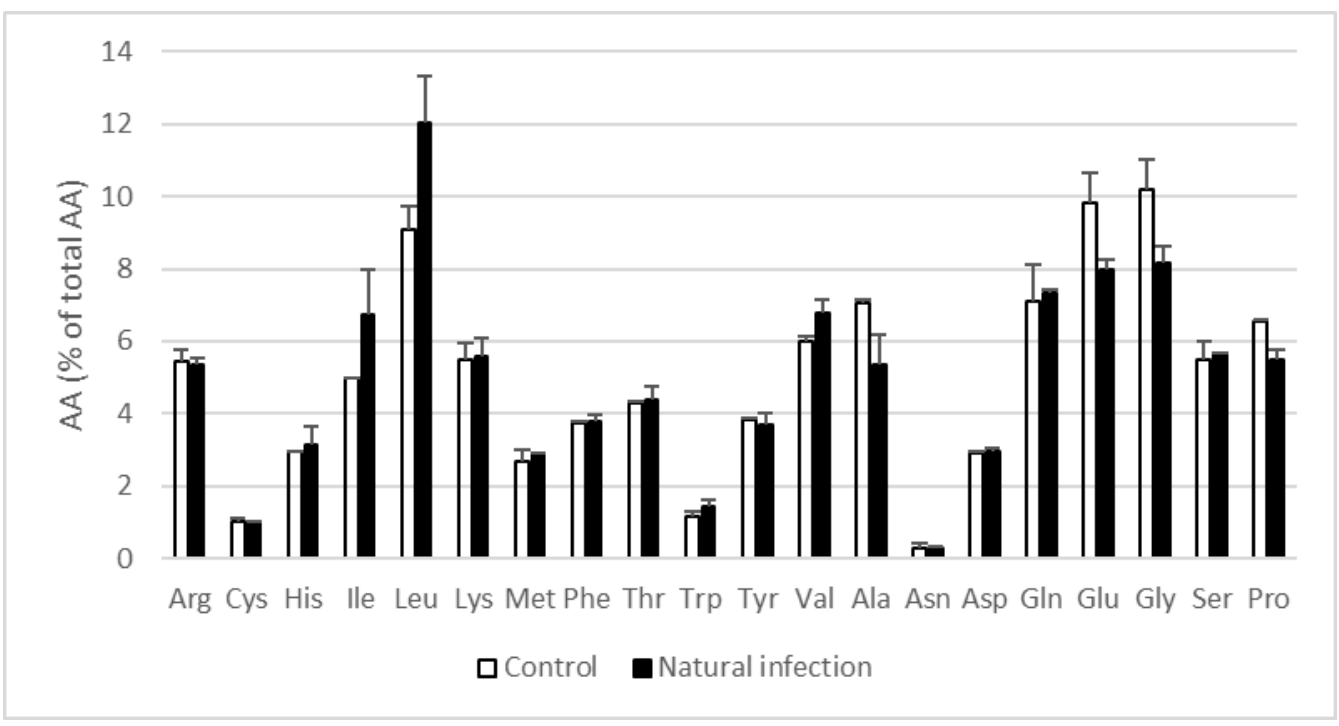

Figure 20 Whole body net metabolic AA utilisation (NMU as \% of total $A A$ ) in two naturally infected pigs and two control pigs. The $A A$ infusion rate reflects the situation during natural infection. Data are means $+/-S D$. 


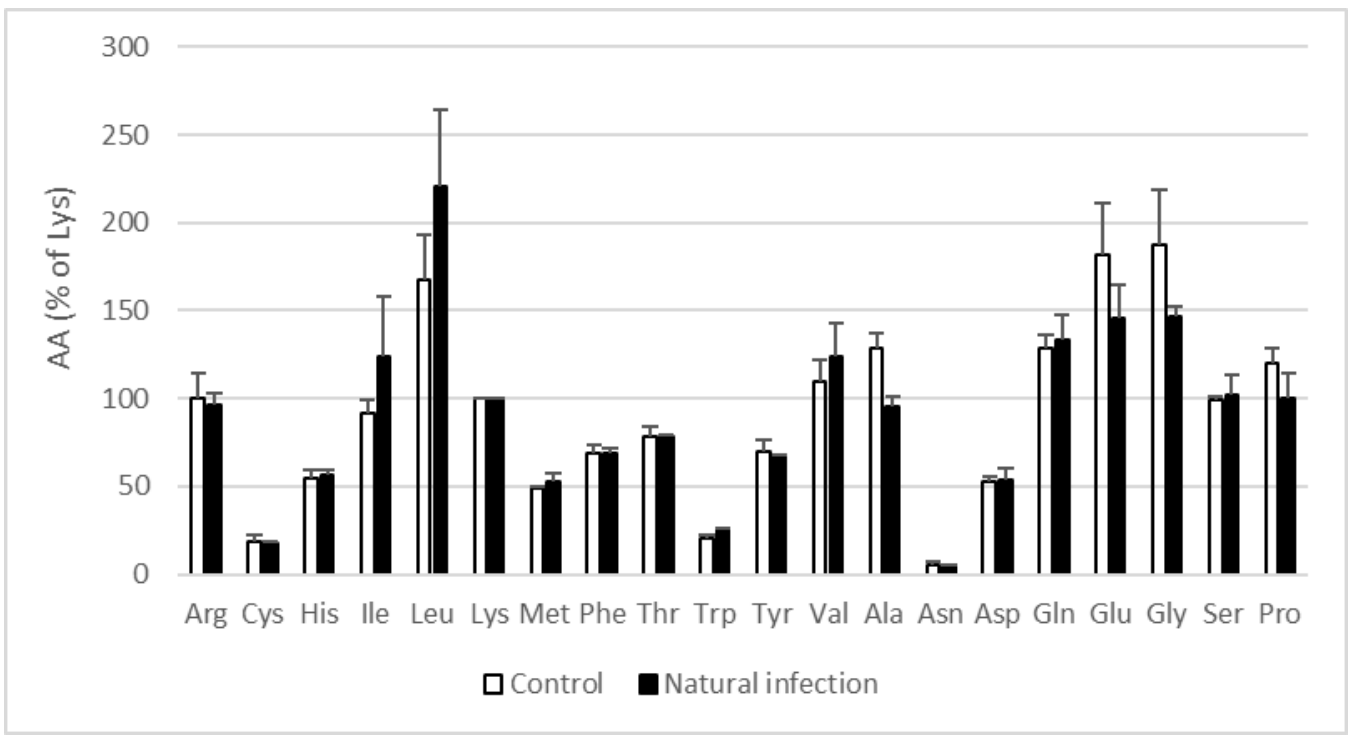

Figure 21 Whole body net metabolic AA utilisation (NMU as \% AA compared to Lys) in two naturally infected pigs and two control pigs. The $A A$ infusion rate reflects the situation during natural infection. Data are means $+/-S D$.

In summary, a natural infection of pigs induced a numerical increase in the NMU of the essential AA similar to the effects measured for the overall phase of LPS challenge of pigs for Ile, Leu, Val, Trp.

Overall it can be concluded that sub(clinical) infection and immune system activation alters the whole body NMU of pigs for particular AA and glucose. Considering the "overall LPS immune system activation", the NMU (based on data in Figures 16 and 17) of the essential AA is consistently increased for the BCAA Ile $(+40-46 \%)$, Leu $(+33-52 \%)$, Val $(+17-40 \%)$ and for Trp $(+89-100 \%)$. The NMU of overall LPS-challenged pigs for glucose decreased by $24 \%$.

\subsubsection{Whole body protein turnover in pigs during LPS challenge}

In the study of Koopmans et al. (2003), the clamp technique was combined with a constant intraportal infusion of the stable isotope ${ }^{13} \mathrm{C}$-leucine, which allowed for the calculation of whole body leucine turnover, also indicated as irreversible loss rate (ILR) of leucine, as discussed by Kampman-van de Hoek et al. (2015 thesis, 2015, 2016)). Whole body leucine turnover, or ILR, is calculated by means of the isotope dilution principle as discussed previously (Koopmans et al., 2003; Kampman-Van de Hoek et al. $(2015$ thesis, 2015,2016$)$. The most commonly used tracer or marker in whole body protein

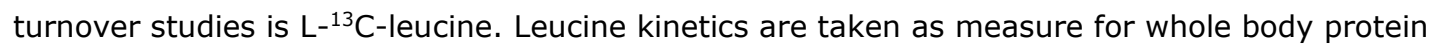
turnover, from which the major part is reflected by turnover of skeletal muscle (Newsholme et al, 2008). The method using $\mathrm{L}^{13} \mathrm{C}$-leucine is considered the method of reference (Wagenmakers, 1999).

In such studies whole body leucine turnover is considered equal to the leucine appearance in blood from whole body protein degradation plus the leucine appearance in blood from the infused amino acid mixture during the clamp study and equal to the leucine disappearance from blood to contribute to whole body protein synthesis and to leucine oxidation.

It was shown using the clamp study in healthy pigs (Koopmans et al., 2003) that leucine appearance in blood from body protein degradation accounted for $87 \%$ (1.57 g leucine. $\mathrm{kg}^{-1} \mathrm{BW}$.day ${ }^{-1}$ ) of whole body leucine turnover ( $1.8 \mathrm{~g}$ leucine. $\left.\mathrm{kg}^{-1} \mathrm{BW} . \mathrm{day}^{-1}\right)$ and that leucine appearance in blood from the infused AA mixture accounted for $13 \%\left(0.23 \mathrm{~g}\right.$ leucine. $\mathrm{kg}^{-1}$ BW.day $\left.{ }^{-1}\right)$ of whole body leucine turnover (Table 6). From a quantitative point of view, this indicates that recycling (protein degradation) of endogenous body AA is much more important as source of AA for protein synthesis than the appearance of AA derived from exogenous sources, such as the infused mixture of AA during the clamp, which can be considered as parenteral nutrition. 
Extrapolated, this suggests that the contribution of AA derived from feed only accounts for $13 \%$ of total AA turnover, i.e. the total amount of AA available to the pig for metabolic purposes. Indeed, Kampman-Van de Hoek et al. (2015 thesis, 2015, 2016) showed that $19 \%$ (0.37 g leucine. $\mathrm{kg}^{-1}$ BW. day ${ }^{-1}$ ) of AA were available for metabolism derived from the diet and $81 \%$ (1.94 g leucine. $\mathrm{kg}^{-1}$ BW. day ${ }^{-1} \mathrm{~g}$ ) of AA were available for metabolism coming from protein degradation in organs and tissues in the body (Table 6), very comparable to the results obtained by Koopmans et al., (2003). Both studies suggest that during the prandial state, there is a continuous breakdown of body protein which leads to an ample availability of AA for protein synthetic purposes in any organ or tissue in the body. The contribution of the diet to AA availability in the body seems therefore 5 to 6 times smaller than the AA availability resulting from protein degradation in the body.

Clamp studies have also been conducted in healthy pigs and in pigs with an experimentally induced activation of the immune system by intravenous LPS infusion (Dekker et al., 2004) as described before. These clamp studies (Dekker et al., 2004) were conducted with a simultaneous infusion of ${ }^{13} \mathrm{C}$ leucine allowing for the calculation of whole body leucine turnover. The results obtained from ${ }^{13} \mathrm{C}$ leucine showed in normal (healthy) pigs that leucine release in blood from body protein degradation accounted for $72 \%\left(0.53 \mathrm{~g}\right.$ leucine. $\mathrm{kg}^{-1} \mathrm{BW}$. day $\left.{ }^{-1} \mathrm{~g}\right)$ of total AA turnover and that leucine appearance in blood from the infused AA mixture accounted for $28 \%\left(0.21 \mathrm{~g}\right.$ leucine. $\mathrm{kg}^{-1} \mathrm{BW}$.day $\left.{ }^{-1} \mathrm{~g}\right)$ of total $\mathrm{AA}$ turnover (Table 6). In pigs with LPS-induced immune system activation, leucine release in blood from body protein degradation accounted for $78 \%\left(0.66 \mathrm{~g}\right.$ leucine. $\mathrm{kg}^{-1} \mathrm{BW}$.day $\left.{ }^{-1}\right)$ of total AA turnover and leucine appearance in blood from the infused AA mixture accounted for $22 \%\left(0.19 \mathrm{~g}\right.$ leucine. $\mathrm{kg}^{-1}$ BW.day ${ }^{-1} \mathrm{~g}$ ) of total AA turnover (Table 6). This is comparable to the results obtained by Kampmanvan de Hoek et al. (2015 thesis, 2015, 2016) in pigs with terpentine-induced immune system activation where it was shown that leucine release in blood from body protein degradation ( $1.81 \mathrm{~g}$ leucine. $\mathrm{kg}^{-1}$ BW.day ${ }^{-1} \mathrm{~g}$ ) contributed for more than $80 \%$ to metabolic availability of leucine whereas, leucine appearance in blood from the diet ( $0.36 \mathrm{~g}$ leucine. $\mathrm{kg}^{-1}$ BW.day ${ }^{-1}$ ) contributed for less than $20 \%$ to availability of leucine in metabolism (Table 6 ). Taken together, under conditions of both normal health and immune system activation, the contribution of endogenous body protein degradation to metabolic AA availability in the body is 5-fold larger than the contribution of AA from the diet and/or from parenteral nutrition in clamp studies.

Table 6 Whole body leucine turnover ${ }^{1}$, exogenous leucine appearance in blood (from infusion, Koopmans et al. or from the diet, Kampman et al.) and leucine appearance in blood from whole body protein degradation (endogenous leucine) during intravenous clamp studies (Koopmans et al.) or oral feeding (Kampman et al.) in healthy or immune challenged pigs.

\begin{tabular}{|c|c|c|c|}
\hline & Leucine turnover & Exogenous leucine & Endogenous leucine \\
\hline $\begin{array}{l}\text { Koopmans et al. (2003), } \\
\text { healthy pigs }\end{array}$ & $1.80(100 \%)$ & $0.23(13 \%)$ & $1.57(87 \%)$ \\
\hline $\begin{array}{l}\text { Kampman-Van de Hoek et al. } \\
\text { (2015), healthy pigs }\end{array}$ & $2.31(100 \%)$ & $0.37(19 \%)$ & $1.94(81 \%)$ \\
\hline $\begin{array}{l}\text { Dekker et al. (2004), } \\
\text { Healthy pigs }\end{array}$ & $0.74(100 \%)$ & $0.21(28 \%)$ & $0.53(72 \%)$ \\
\hline $\begin{array}{l}\text { Dekker et al. (2004), LPS } \\
\text { challenged pigs }\end{array}$ & $0.85(100 \%)$ & $0.19(22 \%)$ & $0.66(78 \%)$ \\
\hline $\begin{array}{l}\text { Kampman-Van de Hoek et al. } \\
\text { (2015), terpentine challenged } \\
\text { pigs }\end{array}$ & $2.17(100 \%)$ & $0.36(20 \%)$ & $1.81(80 \%)$ \\
\hline
\end{tabular}

A more detailed discussion on the literature related to trauma, immune system activation and whole body protein turnover is presented in Appendix 2. 


\subsubsection{Immune system activation and changes in glucose and amino acid metabolism in humans with an activated immune system}

Studies in man and model animal species show that immune system activation is accompanied by hypoglycemia and insulin resistance of tissues. The hormonal and cytokine milieu during immune system activation is insulin-antagonistic, and thus causes insulin resistance, to warrant increased whole body protein degradation in order to provide the body with ample AA to repair any tissue damage related to immune system activation. In addition, insulin resistance of tissues reduces glucose uptake by cells in tissues and reduces glucose oxidation in skeletal muscle, fat and liver to provide the central nervous system with sufficient glucose. Glucose is the sole energy source for the brain. During immune system activation, whole body protein degradation is increased and the surplus AA, not used for protein synthesis, will be oxidized. The increase in (surplus) AA oxidation is further accelerated by the reduction in glucose oxidation (substrate competition, the so called Randle cycle) during immune system activation. The Randle cycle (Randle et al, 1963; Ferrannini et al, 1988; Koopmans et al, 2011) predicts that high intracellular glucose availability increases glucose oxidation and reduces $A A$ and/or NEFA (non-esterified fatty acids) oxidation, and vice versa. Glucose or AA or NEFA oxidation is not only regulated by insulin but also driven by mass-action (diffusion from blood into cells). High blood glucose or AA or NEFA concentrations increase their respective oxidation. Immune system activation is characterized by insulin resistance for whole body glucose metabolic utilization and oxidation. The result is that the body (in this case the insulin sensitive tissues skeletal muscle, liver and adipocytes) is less able to generate energy from glucose. As a consequence, the body will generate energy from alternative energy sources like AA. During immune system activation, there is ample supply of surplus AA in blood, and due to the low glucose oxidation, AA oxidation will be facilitated and amplified to meet the energy demand of the body. Therefore, the presence of sufficient starch and glucose in the diet seems essential for pigs with a strongly activated immune system. Additional highly digestible starch and glucose in the diet may counteract the hypoglycemia in such condition, and thus provide the central nervous system with sufficient energy, and potentially also reduces $A A$ oxidation due to substrate competition. When the extra dietary glucose is provided to pigs with an activated immune system in concert with extra dietary Val, Ile, Leu, and Trp, the endogenous drive of pigs with an activated immune system to increase whole body protein degradation and concomitant increase in AA oxidation may be further reduced. In addition, from literature in the biomedical domain it is known that providing mixtures of specific carbohydrates, (hydrolysed) proteins and free AA can be effective in muscle recovery after muscle catabolism (Saris and van Loon, 2004).

\subsubsection{Beneficial effects of supplementing dietary BCAA on performance of pigs with an activated immune system.}

Little information is available on the effects of branched chain amino acids (BCAA; Val, Ile, Leu) supplementation to the diet on performance of pigs under immune challenged conditions. Most information comes from the biomedical (human-related) literature describing the beneficial effects of BCAA on skeletal muscle anabolism.

Dietary BCAA supplementation have also been studied in relation to trauma, endurance exercise and catabolic diseases. The branched chain amino acids (BCAA), and in particular leucine have been suggested to have unique specificity in stimulating protein synthesis and reducing protein degradation in muscle (Kimball et al, 2002; DeFronzo RA and Ferrannini, 1992; Busquets et al. 2000). In normal healthy subjects, the effects of leucine on protein anabolism are observed at supra-physiological levels and less or not at physiological levels (Waterlow, 2006). However, under conditions of trauma, catabolic conditions, muscle breakdown and/or inflammation (Dardevet et al, 2002; Durham et al. 2009, Kimball et al. 2002), leucine maybe effective in stimulating muscle protein synthesis and inhibiting muscle protein degradation at physiological concentrations (Nicastro et al. 2012). In case of endurance exercise, leucine may support an increase in lean body mass and strength, and a decrease in body fat (Saris and Van Loon, 2004, Wilson et al., 2013). Also, the inflammatory response which occurs after exercise maybe modified by oral BCAA and thereby enhancing recovery of muscle damage and degradation after exercise. Negro et al. (2008) have shown that BCAA are able to modify the cytokine response after exercise, for instance by decreasing plasma IL-4 concentrations. Yoon (2016) reported in his review that supplemental BCAA improve metabolic health under catabolic disease 
conditions and that normalized BCAA concentrations in plasma are associated with improved insulin sensitivity. The BCAA-associated improvement in insulin sensitivity may be a key-factor in the preservation of whole body protein accretion during catabolic diseases. In their reviews, Laviano et al, (2005) and Manders et al. (2012) concluded that BCAA appear to exert significant antianorectic and anticachectic effects, and their supplementation may represent a viable intervention to counteract the "anabolic resistance" to feeding, not only for patients suffering from chronic diseases, but also for those individuals at risk of sarcopenia due to age, immobility or prolonged bed rest, including trauma, orthopedic or neurologic patients. Indeed, in a recent study by Tsien et al. (2015), the authors concluded that impaired mTOR1 signaling and increased autophagy in skeletal muscle of patients with alcoholic cirrhosis was acutely reversed by BCAA. Tamanna and Mahmood (2014), concluded in their review that the BCAA, unlike other amino acids, are primarily metabolized in the extrahepatic tissues and play a role in regulation of protein synthesis and turnover in peripheral tissues as well as maintenance of the body glutamate-glutamine level. In strenuous and traumatic conditions, the BCAA are oxidized which limits their availability in tissues. Such condition affects the body glutamateglutamine pool and protein synthesis mechanisms. Thus BCCA supplementation is emerging as a nutritional strategy for treating many diseases. In 2018, two more reviews on BCAA were published by Nie et al. and Zhou et al. in which the authors concluded that BCAA play critical roles in glucose and lipid metabolism, protein synthesis, as well as intestinal health and immune system functionality. Catabolism and balance of BCAA are closely associated with health and disease. Hence, optimizing dietary BCAA levels should have a positive effect on the parameters associated with health and disease. For instance, it has been reported that dietary supplementation with BCAA promoted intestinal development, enhanced enterocyte proliferation, increased intestinal absorption of amino acids (AA) and glucose, and improved the immune defenses of post-weaning piglets.

\subsection{Effects of amino acid supplementation on performance of pigs}

Several dose-response and amino acid supplementation studies were conducted to investigate the optimal dietary amino acid level in pigs with an activated immune system compared to healthy pigs as a classical way to derive amino acid requirements for optimal performance in populations of pigs. In these studies, the effects of immune system activation on maintenance requirement, efficiency of protein deposition or maximum protein deposition were not studied.

Le Floc'h et al. (2006b) studied the performance and plasma concentrations of tryptophan in weaned piglets $(8-30 \mathrm{~kg})$ fed diets containing graded levels of SID tryptophan (15\%, 18\%, $21 \%$ and $24 \%$ relative to SID lysine) and either or not suffering from a moderate inflammation induced by poor sanitary conditions and control pigs housed in good sanitary conditions. They hypothesised that a tryptophan supply above the current recommendation may be required to prevent the decrease in plasma tryptophan concentration and to maximise growth of pigs suffering from a moderate inflammation (Figure 22). 

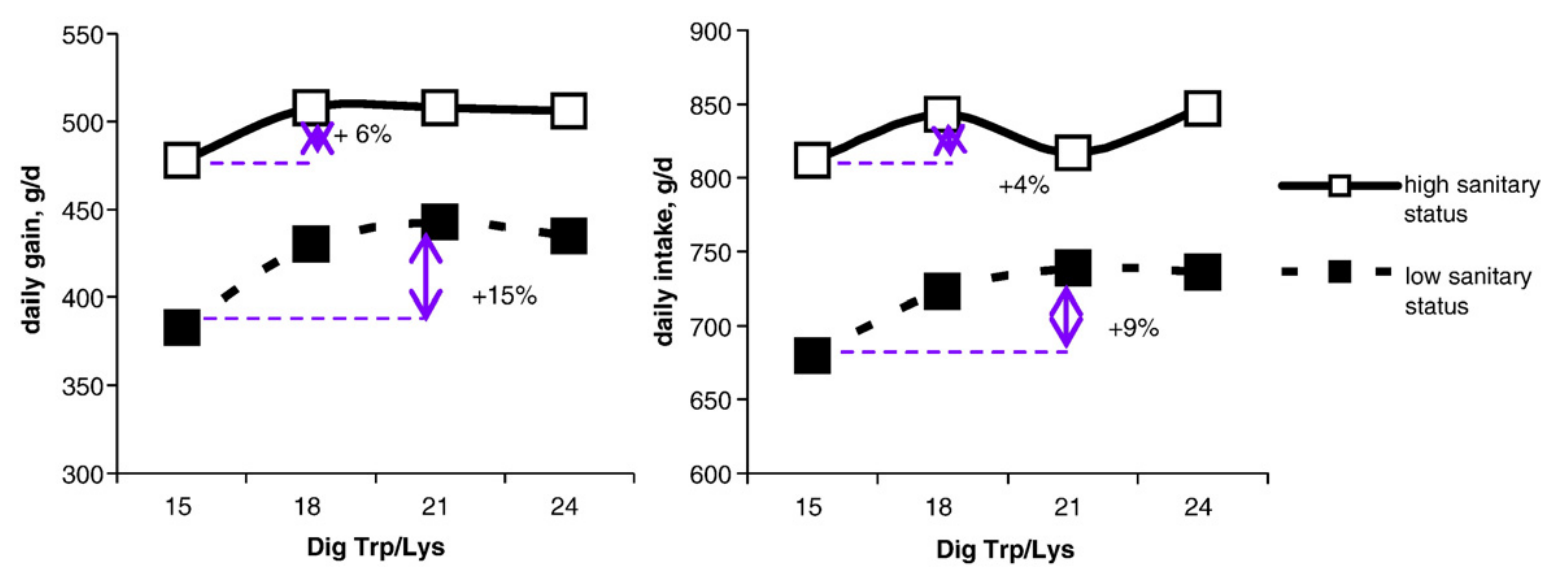

Figure 22 Effect of increasing SID tryptophan to lysine ratio on daily gain and feed intake of 8-30 $\mathrm{kg}$ pigs housed in good sanitary conditions (high sanitary status) and poor sanitary conditions (low sanitary status) (Le Floc'h et al., 2006b).

Pigs with a low sanitary status (LSS) consumed less feed and grew less than pigs with a high sanitary status (HSS) irrespective of the tryptophan content in the diet (Le Floc'h et al., 2006b). Increasing the SID tryptophan to lysine ratio from 15 to $21 \%$ increased daily gain with about $6 \%$ in the HSS pigs and with about $15 \%$ in the LSS pigs. At a SID tryptophan to lysine ratio from $15 \%$, LSS pigs grew $20 \%$ less than HSS pigs. At a SID tryptophan to lysine ratio from $21 \%$, LSS pigs grew $13 \%$ less than HSS pigs. So, a higher SID tryptophan to lysine ratio in the diet can reduce the difference in daily gain between HSS and LSS pigs but it cannot totally prevent a reduction in daily gain in LSS pigs.

Trevisi et al. (2009) tested the effect of tryptophan addition to a standard weaning diet and oral challenge with enterotoxigenic Escherichia coli K88 (ETEC) on growth and health of weanling piglets susceptible or non-susceptible to the intestinal adhesion of ETEC. On day 5 after weaning, pigs were orally challenged with $1.5 \mathrm{~mL}$ suspension containing $10^{10} \mathrm{cfu} E T E C / \mathrm{mL}$ or placebo. The tryptophan diet was produced by the addition of $1 \mathrm{~g}$ of I-Trp/kg to the basal diet (3.4 vs $2.5 \mathrm{~g} / \mathrm{kg}$ total tryptophan). Additional tryptophan allowed susceptible pigs to partially compensate for the effects of an Escherichia coli infection by increasing feed intake and maintaining growth.

Koopmans et al. (2012) studied the possible beneficial effects of a high level of surplus dietary Trp ( $+5 \mathrm{~g}$ of $\mathrm{Trp} / \mathrm{kg}$ of diet) on factors related to stress, immunology, behaviour, and $\mathrm{N}$ retention were investigated in postweaning piglets (approximately $15 \mathrm{~kg}$ of BW) challenged for $10 \mathrm{~d}$ with intravenous bacterial lipopolysaccharide (from Escherichia coli). Two diets fed restrictively (732 kJ of NE/kg of $\mathrm{BW}^{0.75} / \mathrm{d}$ ) were compared, 1) a basal diet (apparent ileal digestible $\operatorname{Trp}=1.9 \mathrm{~g} / \mathrm{kg}$; the recommended amount of Trp to warrant near-optimal growth in non-endotoxemic piglets), and 2) a Trp-enriched basal diet ( $+5 \mathrm{~g}$ of free L-Trp/kg), with 8 individually housed piglets per diet. The ADFI, ADG (346 vs. $302 \mathrm{~g} / \mathrm{d}$; pooled SE $=14 \mathrm{~g} / \mathrm{d} ; P=0.11)$, body $\mathrm{N}$ retention $(11.6 \mathrm{vs} .11 .0 \mathrm{~g} / \mathrm{d}$; pooled SE $=0.2 \mathrm{~g} / \mathrm{d} ; P$ $=0.18)$, and $\mathrm{G}: \mathrm{F}(0.55$ vs. 0.49 ; pooled $\mathrm{SE}=0.03 ; P=0.17)$ were not different between the groups fed Trp and the basal diet. The authors concluded that surplus compared to recommended dietary Trp supply had limited effects on performance and $\mathrm{N}$ retention in a pig model of systemic immune system activation.

Jayaraman et al. (2015) studied the optimum SID threonine to lysine ratio in weaned piglets reared under clean or unclean sanitary conditions. The dietary treatments were 5 graded levels of SID threonine to lysine $(55,59,63,67$ and $71 \%)$. Under clean sanitary conditions, the optimal SID threonine to lysine ratio based on G:F was $65 \%$. Under unclean sanitary conditions, the estimated optimal SID threonine to lysine ratio for overall G:F using was $66.5 \%$. They concluded that an average optimal SID threonine of lysine ratio of 65 and $66.5 \%$ could be used to optimize feed efficiency for weaned pigs under clean and unclean sanitary conditions, respectively.

Kahindi et al. (2017) conducted an experiment to determine the optimum sulphur containing amino acid (SAA) to lysine ratio in weaned piglets reared under clean or unclean sanitary conditions. The 
dietary treatments were 5 graded levels of SID SAA to lysine (52\%, 56\%, 60\%, 64\% and 68\%). Under clean sanitary conditions, the optimal SAA to lysine ratio based on plasma urea nitrogen and villus height were 60 and $60 \%$, respectively. Under unclean sanitary conditions, the optimal SAA to lysine ratio based on plasma urea nitrogen and villus height were respectively 63 and $66 \%$. The higher SAA to lysine ratio for villus height in piglets raised under unclean sanitary condition indicate that, SAA requirement for gut tissue development could be higher in piglets when sanitary condition is poor (Kahindi et al., 2017). They concluded, that in poor sanitary conditions, it is prudent to increase the dietary SAA content above the requirement for growth.

Van der Meer et al. (2016) studied the performance of growing pigs (17 to $110 \mathrm{~kg}$ ) with a low (LSC) or high sanitary condition (HSC) that had ad libitum access to either a normal crude protein (CP) concentration diet $(17,15$, and $15 \% \mathrm{CP}$ for the starter, grower, and finisher phase, respectively) or a low CP concentration diet (20\% CP reduced relative to normal protein for each phase), each of which containing a basal AA profile or a supplemented AA profile. The basal level was supposed to cover the $A A$ requirements for maintenance purposes, excluding the requirements for the immune system, and for body weight gain (growth). The supplemented diet contained 20\% more methionine (Met), threonine (Thr), and tryptophan (Trp) relative to lysine on an apparent ileal digestible basis compared with the basal diet. Poor sanitary conditions decreased average daily gain and G:F compared to high sanitary conditions. Dietary supplementation of Met, Thr, and Trp improved the G:F in LSC pigs but not in HSC pigs, illustrating that dietary requirements for these AA are affected by sanitary conditions (van der Meer et al., 2016). Their study suggests that dietary supplementation of Met, Thr, and/or Trp, in addition to provision of AA for covering basal requirements for protein deposition, is beneficial for animal performance under poor sanitary conditions.

Capozzalo et al. (2017) tested the hypothesis that pigs challenged with an enterotoxigenic strain of E. coli (ETEC) will improve performance by dietary supplementation of sulphur amino acids (SAA) and tryptophan (Trp) above the current recommended levels in the immediate post-weaning period. Four diets were formulated according to a $2 \times 2$ factorial arrangement of treatments with two levels of SID SAA : lysine ratio ( 0.52 vs 0.60$)$ and two levels of SID tryptophan : lysine ratio ( 0.16 vs 0.24$)$. Pigs were individually housed and were fed the diets for 14 days after weaning. Pigs were infected with ETEC on days 5, 6, and 7 after weaning. Increasing Trp $(P=0.036)$ and SAA $(P=0.028)$ improved feed conversion ratio, and combined supplementation of SAA and Trp further improved FCR than individual supplementation of either SAA or Trp $(P=0.092)$.

Li et al. (1999) conducted a study to determine the effects of increasing dietary threonine levels on performance, plasma levels of free amino acids, plasma urea nitrogen and immune function in growing pigs. The basal diet contained $9.2 \mathrm{~g} / \mathrm{kg}$ lysine and $5.9 \mathrm{~g} / \mathrm{g}$ threonine. L-threonine was added to the basal diet to provide $6.8,7.7$ and $8.9 \mathrm{~g} / \mathrm{kg}$ threonine in the remaining three diets. On day 7 , all pigs were injected with either Bovine Serum Albumin (BSA) or Swine Fever Attenuated Vaccine (SFAV) to determine humoral antibody response. The highest weight gain occurred at $6.8 \mathrm{~g} / \mathrm{kg}$. The concentration of plasma urea nitrogen decreased $(p<0.01)$ and reached a plateau when dietary threonine increased from 5.9 to $6.8 \mathrm{~g} / \mathrm{kg}$. Serum threonine increased $(p<0.01)$ and serum lysine decreased $(p<0.01)$ as dietary threonine increased, with both amino acids showing sharp inflection points at $6.8 \mathrm{~g} / \mathrm{kg}$ dietary threonine. Increasing dietary threonine levels increased serum IgG concentration $(p<0.01)$ and anti-BSA antibody $(p<0.01)$ level. In conclusion, although maximum growth rate of pigs occurred at a dietary Thr level of $6.8 \mathrm{~g} \mathrm{~kg}$, higher Thr levels were needed to maximize humoral antibody production and IgG levels.

Overall, it can be concluded that dietary supplementation of methionine + cysteine, threonine and tryptophan, in addition to provision of AA for covering basal requirements for protein deposition, might be beneficial for pigs with an activated immune system due to an immune challenge or due to poor sanitary conditions. Hardly attention has been given to the potential beneficial role of (supplementing) other AA, such as BCAA (Val, Ile, Leu) in immune challenged pigs in relation to growth performance and responses of the immune system. 


\section{Consequences of health status for amino acid and energy requirements at the level of the diet}

In the previous part of the report, available information on the effects of health status of pigs on energy, protein and amino acid metabolism has been reviewed and quantified as far as possible. Effects of health challenges were described in relation to feed intake, nutrient digestibility, postabsorptive nutrient utilization, and induction of synthesis of immune proteins. A variety of methodologies and challenge models to create differences in health status are used to study effects of health status on nutrient metabolism and utilization. To apply this information in feed formulation, it is required to translate the consequences of immune system activation and related compromised health status on nutrient requirements. Quantitative information on amino acid requirements of pigs under different health conditions can be translated into optimal dietary amino acid concentrations based on the quantitative information of the present literature review and making qualified assumptions about effects of health status on e.g. feed intake and maximum protein deposition under a particular condition of health challenge.

In this chapter model calculations are presented to calculate quantitative changes in amino acid metabolism and requirements (Lys, Met + Cys, Thr, Trp, Val, Ile, Leu, His and Phe +Tyr) and in energy requirements when the health status is compromised. Required changes in dietary amino acid levels as a result of changes in amino acid requirements are estimated, assuming that changing dietary amino acid levels can compensate to a predefined extent for the reduced feed intake, protein retention and growth performance under conditions of health challenge. The model used for the calculations is based on a factorial approach to calculate protein deposition (PD) in growing pigs, using a pig of $50 \mathrm{~kg}$ body weight as reference. Calculations have been performed for different scenarios of compromised health status representing both acute and chronic conditions of immune system activation and conditions in which gut or systemic health is compromised. Changes in voluntary feed intake, amino acid digestibility, maintenance requirements for amino acids, synthesis of immune proteins, efficiency in post absorptive amino acid utilization and effects on the maximum protein deposition $\left(P D_{\max }\right.$ ) were considered. In addition, effects of health challenges on energy requirements were calculated. 


\subsection{Model to calculate effects of health status on amino acid and energy requirements and consequences for dietary levels of amino acids and energy}

The principles of the model developed in Excel and assumptions in the model are shortly described below:

- A pig of $50 \mathrm{~kg}$ body weight with a feed intake of $1700 \mathrm{~g} / \mathrm{d}$ is taken as a reference.

- Reference scenario (with no health challenge): Protein deposition (PD) in the body is determined by the post-absorptive availability of essential amino acids provided via a reference diet. PD under this condition is equal to $P D_{\max }$, the maximum (genetic) PD of the pig weighing $50 \mathrm{~kg}$ and assuming the dietary supply of energy is not limiting PD in this condition.

- $\quad$ Reference diet: a barley, maize, soybean meal based starter diet which was evaluated by Pluk and van Krimpen (2018). The reference diet contained $165 \mathrm{~g} / \mathrm{kg} \mathrm{CP}$ and $9.3 \mathrm{~g} / \mathrm{kg}$ SID Lys and was supplemented with free Lys, Met, Thr, Trp and Val to balance its AA profile relative to Lys (Appendix 3).

- The amino acid requirements for maintenance purposes (basal protein turnover, integument losses, basal endogenous amino acid losses at ileal level) are taken from INRAPORC (van Milgen et al., 2008) (Appendix 5). In the present calculations basal endogenous AA losses at ileal level were calculated based on feed intake as fed instead of on dry matter intake, while using data on basal AA losses on the basis of dry matter intake. It was calculated in retrospect that this inconsistency has had only small effects on the calculated PD of maximum 1-2 $\mathrm{g} / \mathrm{d}$ depending on the amino acid considered.

- Amino acid composition of body protein in pigs is taken from van Milgen et al. (2008) and Le Bellego and Noblet (2002) (Appendix 5).

- Values for the maximum efficiency of using standardized amino ileal digestible (SID) amino acids for protein synthesis and deposition in the body are taken from Noblet et al. (2002), and similar to the values used in InraPorc, with slight modifications. The maximum efficiency of Ile was increased from 0.60 to 0.68 as initial calculations suggested an unrealistic deficiency for Ile in the reference diet. The value for Met + Cys was increased from 0.51 to 0.54 as initial calculations suggested that the reference diet used for the calculations would be slightly deficient in Met+Cys, while the ratio between Met+Cys relative to Lys on a SID basis in the reference diet was in agreement with the current recommendations for growing/finishing pigs with a value of $60 \%$ (van der Peet-Schwering and Bikker, 2018).

- The potential PD of the pig for each individual amino acid is calculated based on their quantitative post-absorptive availability taking into account their values for post-absorptive utilization. An example of the calculation of the (potential) body protein deposition based on Lys is given in Appendix 4. The calculated potential PD can be higher than the defined PDmax for an amino acid indicating that the amino acid is available in excess of the assumed requirement.

- It is assumed that the actual PD of a pig is equal to the lowest potential PD value calculated for each of the nine essential amino acids, adopting the concept of ideal amino acid profiles and limiting amino acids in pigs (Fuller te al., 1989). The actual PD is always below or maximum equal to the defined PD max.

- $\quad$ Five scenarios were defined related to conditions in which the health status is compromised and the immune system is activated. An overview of the scenarios is given in Table 7 . They relate to conditions of acute and chronic disease states and relate to gut (gut disease, diarrhoea e.g. related to E. coli infection and PIA) and systemic diseases (e.g. lung diseases such as Porcine Reproductive and Respiratory Syndrome (PRRS) and Actinobacillus pleuropneumoniae (APP)). In addition, a scenario of low sanitary conditions to which pigs in practice can be imposed is included. The latter reflects a scenario of suboptimal health and chronic activation of the immune system. 
Table 7 Description of five health scenario for which the effects were calculated on amino acid metabolism and requirements for amino acids and energy.

\begin{tabular}{lcccc} 
& Acute & Chronic & Gut \\
& $1-7 \mathrm{~d}$ & $>7 \mathrm{~d}$ & $\mathrm{x}$ & - \\
\hline 1 & $\mathrm{x}$ & - & $\mathrm{x}$ & - \\
\hline 2 & - & $\mathrm{x}$ & - & $\mathrm{x}$ \\
\hline 3 & $\mathrm{x}$ & - & - & $\mathrm{x}$ \\
\hline 5 & - & $\mathrm{x}$ & $\mathrm{x}$ & $\mathrm{x}$ \\
\hline
\end{tabular}

- Based on the results of the literature review in the present report (Chapters 1-3), a quantitative estimate was made for each of the health scenarios with regard to their effects on 1 . voluntary feed intake, 2. standardized ileal amino acid digestibility, 3. induction of proteins related to activation of the immune system (e.g. acute phase proteins, cytokines, proteins in immune cells), 4. efficiency of amino acid utilization in post absorptive metabolism 5. PD max and 6 . the maintenance requirement for energy (Table 8 ). The effects under 4 . relate to changes in protein turnover (ratio between protein synthesis and degradation) and increased amino acid imbalances at organ and tissue level resulting in increased amino acid losses via oxidation under conditions of immune challenge.

Table 8 Defined factors considered in the model for calculating AA and energy requirements in pigs (50 kg body weight) under different scenario of health challenge.

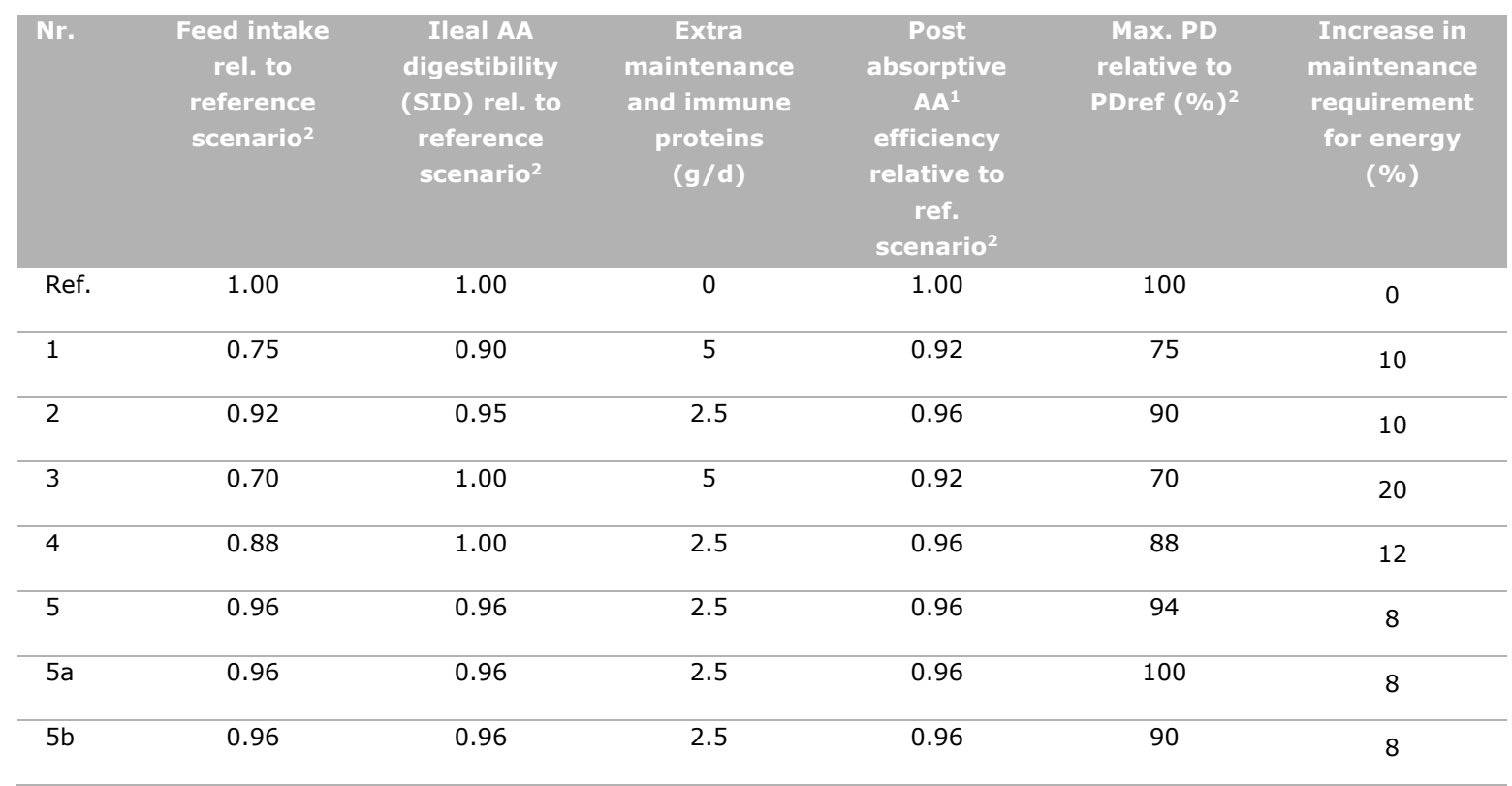

${ }^{1}$ Trp, Val, Leu and Ile, other essential AA unaffected.

${ }^{2}$ Values ranging from 0 to 1 (value for reference scenario) or between 0 and $100 \%$ (value for reference scenario).

- The effects of the health challenge scenario on reduction of feed intake, ileal protein and amino acid digestibility and increase in maintenance requirements for energy were qualified estimates based on the results of the present literature review (Chapters 1-3). Settings can be changed in the calculation model by the user.

- In the literature only limited data are available on the quantitative synthesis of immune system proteins under conditions of health challenge. Kampman-van de Hoek (2015) estimated the quantitative production of acute phase proteins in pigs (Table 4). She came to a mean estimate of $1 \mathrm{~g}$ of acute phase proteins (APP) synthesized per day for a pig of $50 \mathrm{~kg}$ in the acute phase of an infection. Given the fact that APP represent only a portion of the total immune proteins synthesized (considering in addition e.g. cytokines and proteins in immune cells), we assumed in 
our calculations that chronic challenges require $2.5 \mathrm{~g}$ of immune proteins per day and acute challenges $5 \mathrm{~g} / \mathrm{d}$ for a pig of $50 \mathrm{~kg}$. Amino acid composition of immune proteins were based on data in Table 3 of the present report. The mean values for APP on the one hand and immune globulins on the other hand were averaged.

- The present literature review shows that the effects of health challenge on efficiency of amino acid utilization for protein synthesis are only studied to a limited extent. Available studies showed that immune system activation seems to have no effects on the post-absorptive utilization of Lys, Met+Cys, Thr and Arg for PD. However, one study showed a reduction in the efficiency of Trp utilization for PD in pigs of about $7 \%$ after immune challenge. In addition, results reported in the present report (paragraph 3.4.5) on the net metabolic utilization of amino acids in pigs after LPS challenge with the amino acid and glucose clamp technique showed that the overall net metabolic flux of Trp and the branched chain amino acids (Val, Ile and Leu) was increased, suggesting higher requirements and/or inevitable losses for these amino acids. For these reasons in the acute and chronic health scenario the efficiency of utilization of Trp, Val, Ile and Leu were reduced with 8 and $4 \%$, respectively (Table 8 ).

- The model calculates the effects of the compromised health scenarios on amino acid metabolism and PD and availability of energy compared to the reference pig. The calculated PD expressed relative to the PD in the reference condition with no health challenge $(149 \mathrm{~g} / \mathrm{d})$ is also calculated as a percentage and indicated as the scenario performance level.

- In a next step, the dietary concentrations of SID amino acids were increased to enhance amino acid availability for protein metabolism and body PD. In this way it is assumed that the negative effects of health/immune challenge on protein metabolism and PD can be counteracted. In practical conditions this can be achieved by increasing the level of supplementation of free amino acids to the diet or by increasing the dietary protein content to increase the supply of SID amino acids to the pigs, under the condition that availability of energy is not limiting PD. It is assumed that the increase in supply of SID amino acids increases PD till the maximum PD defined for that condition is reached. The calculated value for PD is maximum equal to the PDmax assumed for the reference scenario considering a pig of $50 \mathrm{~kg}$ as reference $(149 \mathrm{~g} / \mathrm{d})$ or to the maximum PD defined for that scenario (Table 9), as it is known that conditions of compromised health can result in a lower maximum PD capacity in pigs (Paragraph 3.4.3. of the present report).

- $\quad$ The required dietary levels of SID essential amino acids in the reference and challenge scenario are calculated as well as their ratio relative to Lys.

- The protein efficiency (protein retention relative to protein intake expressed as a \%) for each of the scenarios is also calculated.

- $\quad$ The PD can also be influenced by the availability of metabolisable energy (ME) or net energy (NE). Energy provided via the diet is used to cover the maintenance requirements for energy (M) (290 $\mathrm{kJ} \mathrm{NE} / \mathrm{kg}^{0.75}$ ) and for deposition of protein and fat in the body. Based on the principles adopted in TMV (van der Peet-Schwering et al., 1994), it is assumed that pigs fed up to $1.3 \times$ M only deposit protein, and at higher levels of energy intake (above $1.3 \times \mathrm{M}$ ) fat and protein are deposited in a fixed ratio (the so called marginal ratio) till $\mathrm{PD}_{\max }$ is reached. The marginal ratio for the reference pig of $50 \mathrm{~kg} \mathrm{BW}$ was set at 1.28 . Using this value, the reference pig consuming $1700 \mathrm{~g}$ of diet per day (EW 1.10) would consume just sufficient energy to show a PD of $149 \mathrm{~g} / \mathrm{d}$. Reduction of feed intake in different scenario of health status, limits energy intake and health challenges increase maintenance requirements for energy, thereby limiting availability of energy for PD. In the calculations it is assumed that energy availability for protein deposition can be increased by increasing the energy density of the diet. The required increase in energy density is calculated to ensure that sufficient energy is available for realizing the maximum defined PD for the health scenario of consideration. It was assumed that the ME requirement for protein and fat deposition in the body are $52.9 \mathrm{~kJ}$ ME per $\mathrm{g}\left(23.8 \mathrm{~kJ} / \mathrm{g}\right.$ and $\mathrm{k}_{\mathrm{p}}$ 0.45) for protein and $48.5 \mathrm{~kJ}$ ME per $\mathrm{g}$ (38.8 $\mathrm{kJ} / \mathrm{g}$ and $\mathrm{k}_{\mathrm{f}} 0.80$ ) for fat (van der Peet-Schwering et al., 1994), the $\mathrm{k}_{\mathrm{f}}$ value being adjusted from 0.75 to 0.80 . An example of the calculation for the effects of health status on the energy requirements for maintenance and protein and for energy deposition in the body is given in Appendix 6. 


\subsection{Results}

With the factorial model the PD of pigs in the reference condition on the reference diet was calculated. The results are presented in the left part of Figure 23. The dietary supply of Lys, Met+Cys, Thr and Trp matched the requirements for these amino acids in this condition and resulted in a calculated PD of $149 \mathrm{~g} / \mathrm{d}$. The dietary supply of Val, Ile, Leu, His and Phe+Tyr was in excess of the requirement for a pig of $50 \mathrm{~kg}$ in the reference scenario. When adjusting the model settings according to a low sanitary status condition (scenario 5; Table 8) PD was reduced to $123 \mathrm{~g} / \mathrm{d}$ and Trp appeared to be the first limiting amino acid under this condition (Figure 23; right panel), followed by Thr, Val, Lys, Met+Cys and Ile. The protein efficiency (the ratio of body protein deposition to protein intake) was calculated to be reduced from 53 to $46 \%$. When assuming that the maximum PD would not have been affected in this condition (max. PD $100 \%$ of PDmax in reference condition) and availability of energy is not limiting PD, increasing the supply of SID Trp, Thr, Val, Lys, Met+Cys and Ile via the diet would restore PD to the same level as in the reference condition. It is important to mention that feed intake was supposed to be reduced by $4 \%$ in the low sanitary condition relative to the reference condition, while the PD was supposed to reach the PD of the reference condition. This means that nutrient density (including SID essential amino acids) needed to be increased in this scenario, which increased also values for protein efficiency (e.g. to $55 \%$ in scenario 5 a adjusted compared to $53 \%$ in the reference scenario).

Figure 24 (upper panel) shows the required increase in dietary amino acid level (SID basis) due to an acute gut challenge (scenario 2) to maintain performance of the reference scenario and the lower panel shows the related dietary amino acid profile relative to Lys. The dietary level of Lys, Met+Cys, Thr, Trp, Val and Ile had to be increased with $0.9,0.5,0.7,0.3,0.6$, and $0.3 \mathrm{~g} / \mathrm{kg}$ SID amino acid, respectively. The ratio to Lys on a SID basis was slightly increased for Thr and Trp in this condition.

If it is assumed that the maximum PD is only $90 \%$ from that of the reference scenario (PD $134 \mathrm{~g} / \mathrm{d}$ ) only the level of SID Trp, Thr and Met+Cys in the diet had to be increased. Protein efficiency in this case was calculated to be increased only from 46 to $50 \%$.
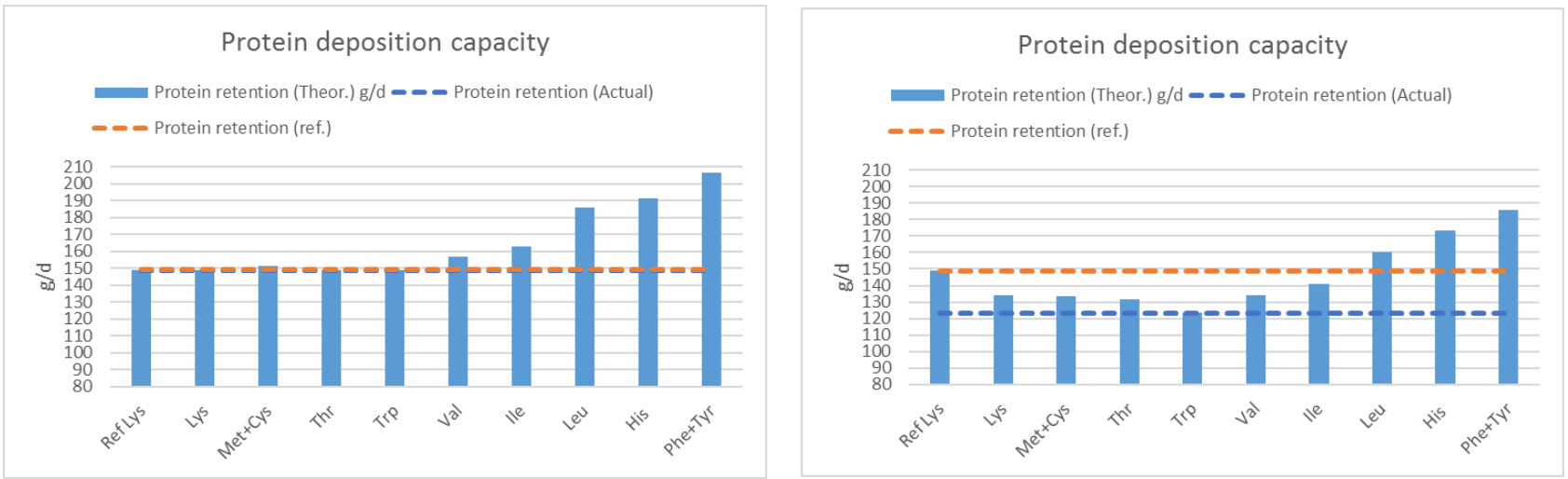

Figure 23 Calculated potential protein deposition ( $P D 149 \mathrm{~g} / \mathrm{d}$ ) based on the dietary supply of essential amino acids of the reference diet in the control, unchallenged reference condition (left) and after challenge via low sanitary conditions (PD $123 \mathrm{~g} / \mathrm{d}$; scenario 5a) (right).

In the same way model calculations were performed for health scenario 1 to 4 . Results are presented in Table 9. Acute and chronic gut related health problems were calculated to reduce PD from 149 to 75 and $116 \mathrm{~g} / \mathrm{d}$, respectively, reducing protein efficiency from 53 to 36 and 45\%, respectively. PD could be increased to the defined maximum value for the respective conditions (Table 8 ) by increasing the dietary level of SID Trp, Thr, Val, Met+Cys, Lys and Ile (in order of limitation) and SID Trp, Thr, Met+Cys, Val, Lys and Ile, respectively.

Acute and chronic systemic health problems were calculated to reduce PD from 149 to 80 and 118 $\mathrm{g} / \mathrm{d}$, respectively, reducing protein efficiency from 53 to 41 and $48 \%$, respectively. PD could be 
increased to the maximum value under the respective conditions by increasing the dietary level of SID Trp, Val, Thr, Met+Cys, Lys and Ile (in order of limitation) and SID Trp, Thr, Val, Lys, Met+Cys, and Ile, respectively.

Graphical presentations of the results for the different health scenario are given in Figures 24-28.

The results in Table 9 for the effects on the availability of energy in the different health scenarios indicate that this is an important factor in relation to the capacity to deposit protein in the body. In all scenarios, energy availability became a limiting factor for protein deposition (Table 9; column max. PD based on energy availability), although slightly less than the supply of essential amino acids. It was calculated that the energy density of the diet needed to be increased with 2 (scenario $5 b$ ) to $22 \%$ (scenario 1) in order to reach the maximum PD for that scenario, if the dietary content of SID amino acids, and thus the amino acid supply to the pig, is adequately increased.

The model allows calculations with different settings (to be defined by the user) for the assumed effects of health status/condition on 1 . voluntary feed intake, 2. standardized ileal amino acid digestibility, 3. production of proteins related to activation of the immune system 4. efficiency of amino acid utilization in post absorptive metabolism and 5. $P D_{\max }$ and 6 . maintenance requirements for energy. 
Table 9 Model calculations of the effects of different scenario of health status of pigs on body protein deposition and protein efficiency and effects of increase in the required dietary level of SID amino acids and dietary energy density on counteracting the reduction in protein deposition in the different health scenario.

\begin{tabular}{|c|c|c|c|c|c|c|c|c|c|}
\hline Nr. & $\begin{array}{l}\text { Sce- } \\
\text { nario }^{1}\end{array}$ & $\begin{array}{c}\mathrm{PD}_{\max } \\
\text { relative to } \\
\mathrm{PD}_{\text {ref }}(\%)\end{array}$ & $\begin{array}{l}\text { PD }(\mathrm{g} / \mathrm{d}) \text {, } \\
\text { Perfor- } \\
\text { mance } \\
\text { level } \\
(\%)^{2}\end{array}$ & $\begin{array}{l}\text { Protein } \\
\text { efficienc } \\
\text { y }(\%)\end{array}$ & $\begin{array}{l}\text { PD }(\mathrm{g} / \mathrm{d}) \text {, } \\
\text { Perfor- } \\
\text { mance } \\
\text { level }(\%) \\
\text { AA adj. }\end{array}$ & $\begin{array}{c}\text { Protein } \\
\text { efficiency } \\
(\%), \\
\text { AA adj. }\end{array}$ & $\begin{array}{c}\text { Increase of } \\
\text { dietary AA } \\
(\text { SID })^{3}\end{array}$ & $\begin{array}{l}\text { Max. PD based } \\
\text { on energy } \\
\text { availability } \\
\text { (g/d) and rel. } \\
\text { to ref. } \\
\text { scenario } \\
(=100)\end{array}$ & $\begin{array}{l}\text { Required } \\
\text { increase in } \\
\text { energy density } \\
\text { of the diet to } \\
\text { reach max. PD } \\
\text { in scenario }{ }^{4}\end{array}$ \\
\hline Ref. & Ref. & 100 & $\begin{array}{c}149 \\
(100)\end{array}$ & 53 & - & - & - & $\begin{array}{c}149 \\
(100)\end{array}$ & $\begin{array}{c}1.000 \\
(E W 1.10)\end{array}$ \\
\hline 1 & $A-G$ & 75 & $\begin{array}{c}75 \\
(50)\end{array}$ & 36 & $\begin{array}{l}112 \\
(75)\end{array}$ & 53 & $\begin{array}{c}\text { Trp, Thr, Val, } \\
\text { Met+Cys, } \\
\text { Lys, Ile, Leu }\end{array}$ & $\begin{array}{c}84 \\
(56)\end{array}$ & $\begin{array}{c}1.220 \\
(E W 1.34)\end{array}$ \\
\hline 2 & $C-G$ & 90 & $\begin{array}{l}116 \\
(78)\end{array}$ & 45 & $\begin{array}{l}134 \\
(90)\end{array}$ & 52 & $\begin{array}{c}\text { Trp, Thr, } \\
\text { Met+Cys, } \\
\text { Val, Lys, Ile }\end{array}$ & $\begin{array}{l}121 \\
(81)\end{array}$ & $\begin{array}{c}1.080 \\
(E W 1.19)\end{array}$ \\
\hline 3 & A-S & 70 & $\begin{array}{c}80 \\
(54)\end{array}$ & 41 & $\begin{array}{l}104 \\
(70)\end{array}$ & 53 & $\begin{array}{c}\text { Trp, Val, Thr, } \\
\text { Met+Cys, } \\
\text { Lys, Ile }\end{array}$ & $\begin{array}{c}85 \\
(57)\end{array}$ & $\begin{array}{c}1.145 \\
(\text { EW 1.26) }\end{array}$ \\
\hline 4 & C-S & 88 & $\begin{array}{l}118 \\
(79)\end{array}$ & 48 & $\begin{array}{l}131 \\
(88)\end{array}$ & 53 & $\begin{array}{l}\text { Trp, Thr, } \\
\text { Met+Cys, } \\
\text { Val, Lys }\end{array}$ & $\begin{array}{l}122 \\
(82)\end{array}$ & $\begin{array}{c}1.055 \\
(\text { EW 1.16) }\end{array}$ \\
\hline $5 a$ & LSC & 100 & $\begin{array}{l}123 \\
(83)\end{array}$ & 46 & $\begin{array}{c}149 \\
(100)\end{array}$ & 55 & $\begin{array}{l}\text { Trp, Thr, Val, } \\
\text { Lys, } \\
\text { Met+Cys, Ile }\end{array}$ & $\begin{array}{l}131 \\
(88)\end{array}$ & $\begin{array}{c}1.105 \\
(\text { EW 1.22) }\end{array}$ \\
\hline $5 b$ & LSC & 90 & $\begin{array}{l}123 \\
(83)\end{array}$ & 46 & $\begin{array}{l}134 \\
(90)\end{array}$ & 50 & $\begin{array}{l}\text { Trp, Thr, } \\
\text { Met+Cys }\end{array}$ & $\begin{array}{l}131 \\
(88)\end{array}$ & $\begin{array}{c}1.020 \\
(E W 1.12)\end{array}$ \\
\hline
\end{tabular}

${ }^{1} \mathrm{~A}$ : acute, C: chronic, G: gut, S: systemic, LSC: low sanitary conditions

2relative to PDref (PD in reference scenario)

3required increase in AA level (SID) in the order of limitation

${ }^{4}$ relative increase in energy density of the diet relative to the energy value of the reference diet $(\mathrm{EW} 1.10=1.000)$ 

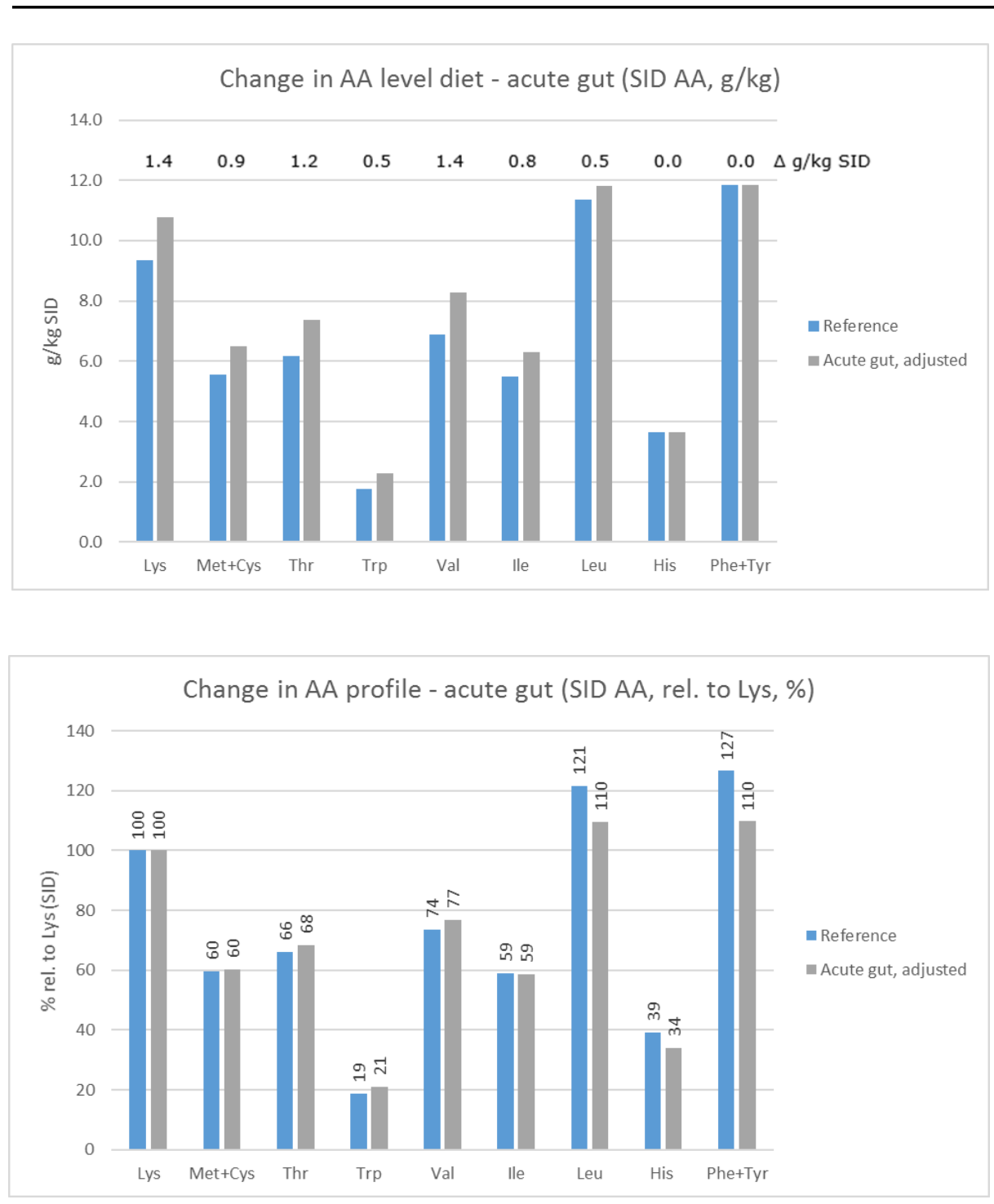

Figure 24 Change in dietary amino acid levels and profile (rel. to Lys) in a condition of acute challenge of the gut (scenario 1) to improve PD from 50 to $75 \%$ (assumed $P D_{\max }$ under that condition) compared to the reference, non-challenged scenario. 

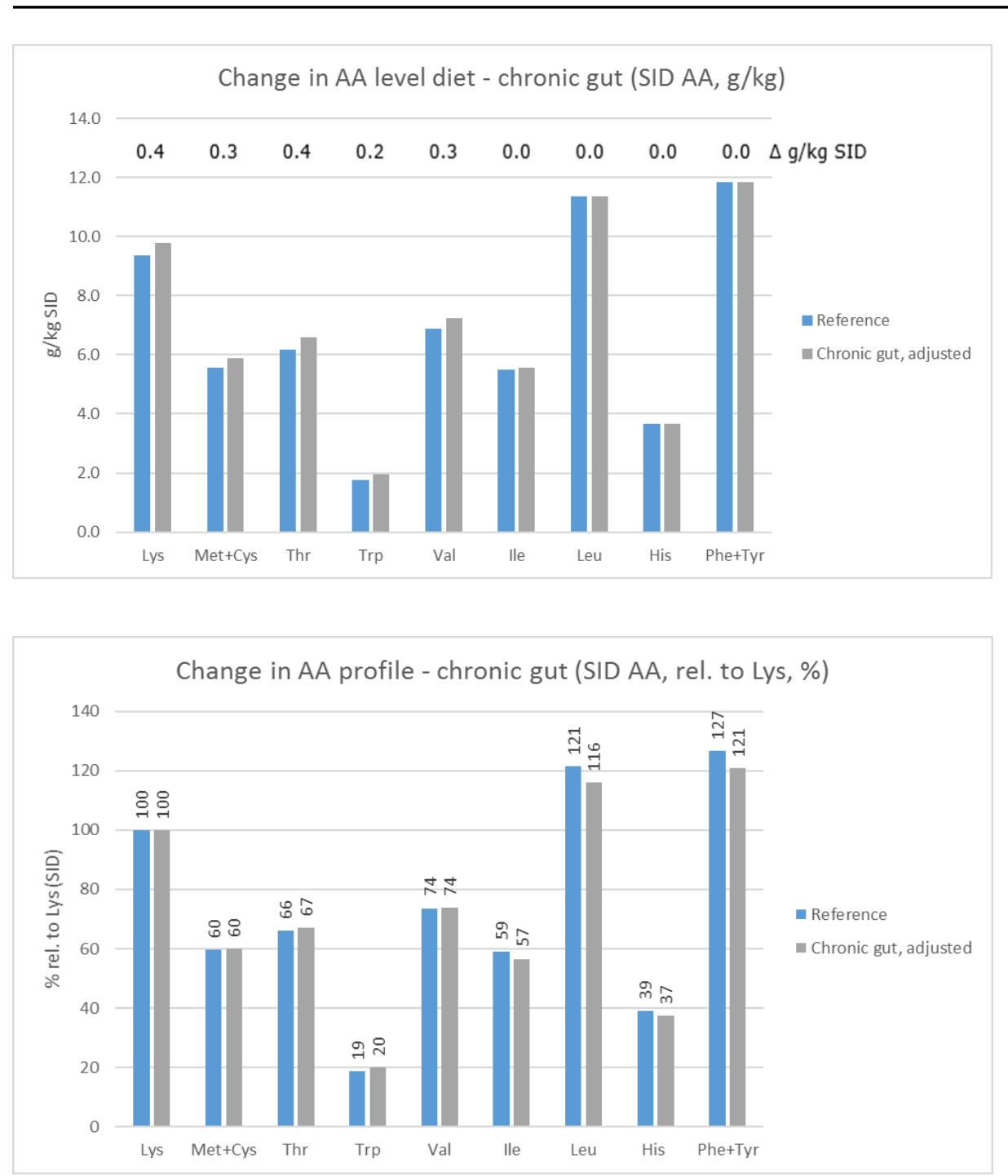

Figure 25 Change in dietary amino acid levels and profile (rel. to Lys) in a condition of chronic challenge of the gut (scenario 2) to improve PD from 78 to $90 \%$ (assumed $P D_{\max }$ under that condition) compared to the reference, non-challenged scenario. 

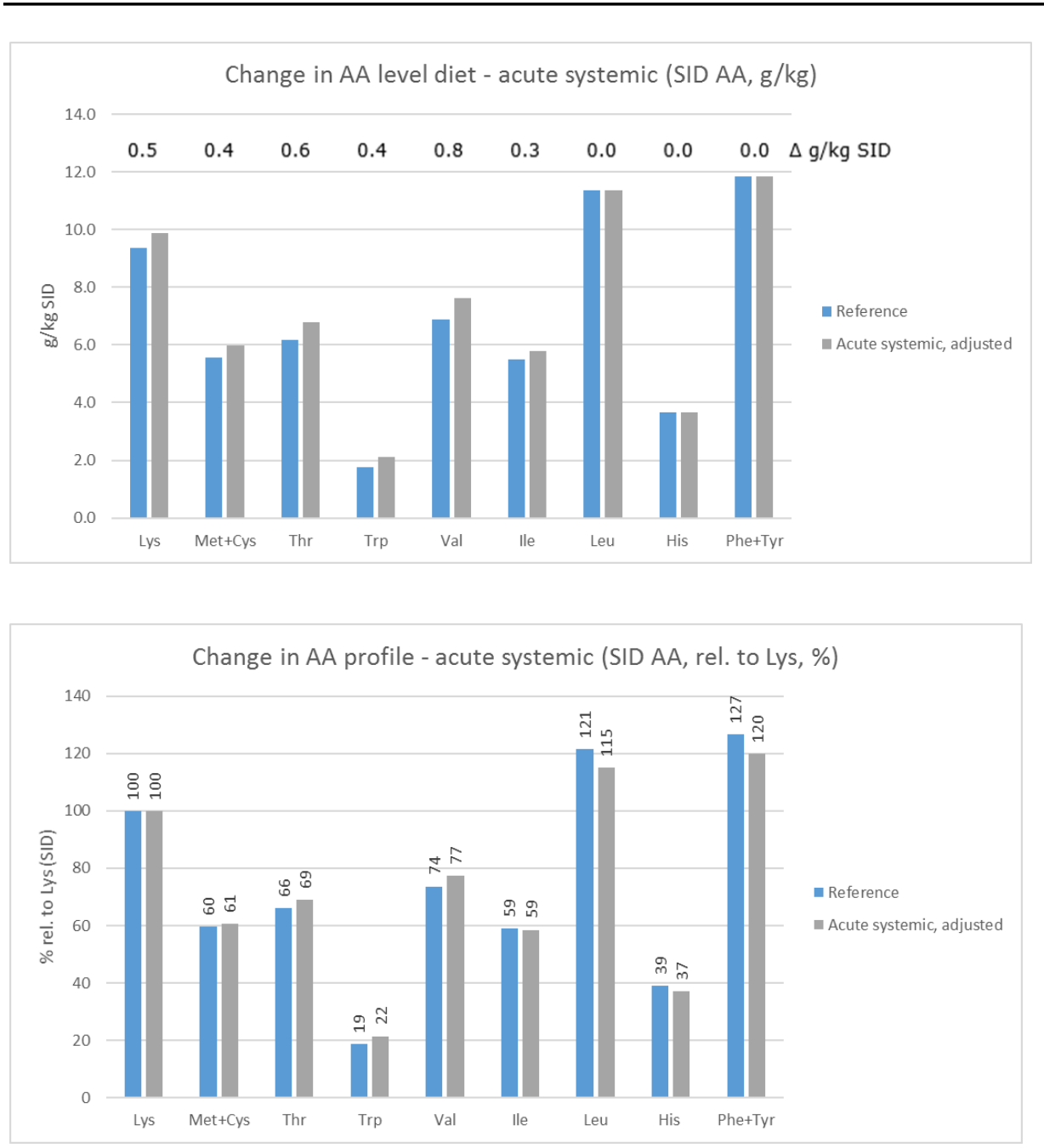

Figure 26 Change in dietary amino acid levels and profile (rel. to Lys) in a condition of acute systemic challenge (scenario 3) to improve PD from 54 to $70 \%$ (assumed PDmax under that condition) compared to the reference, non-challenged scenario. 

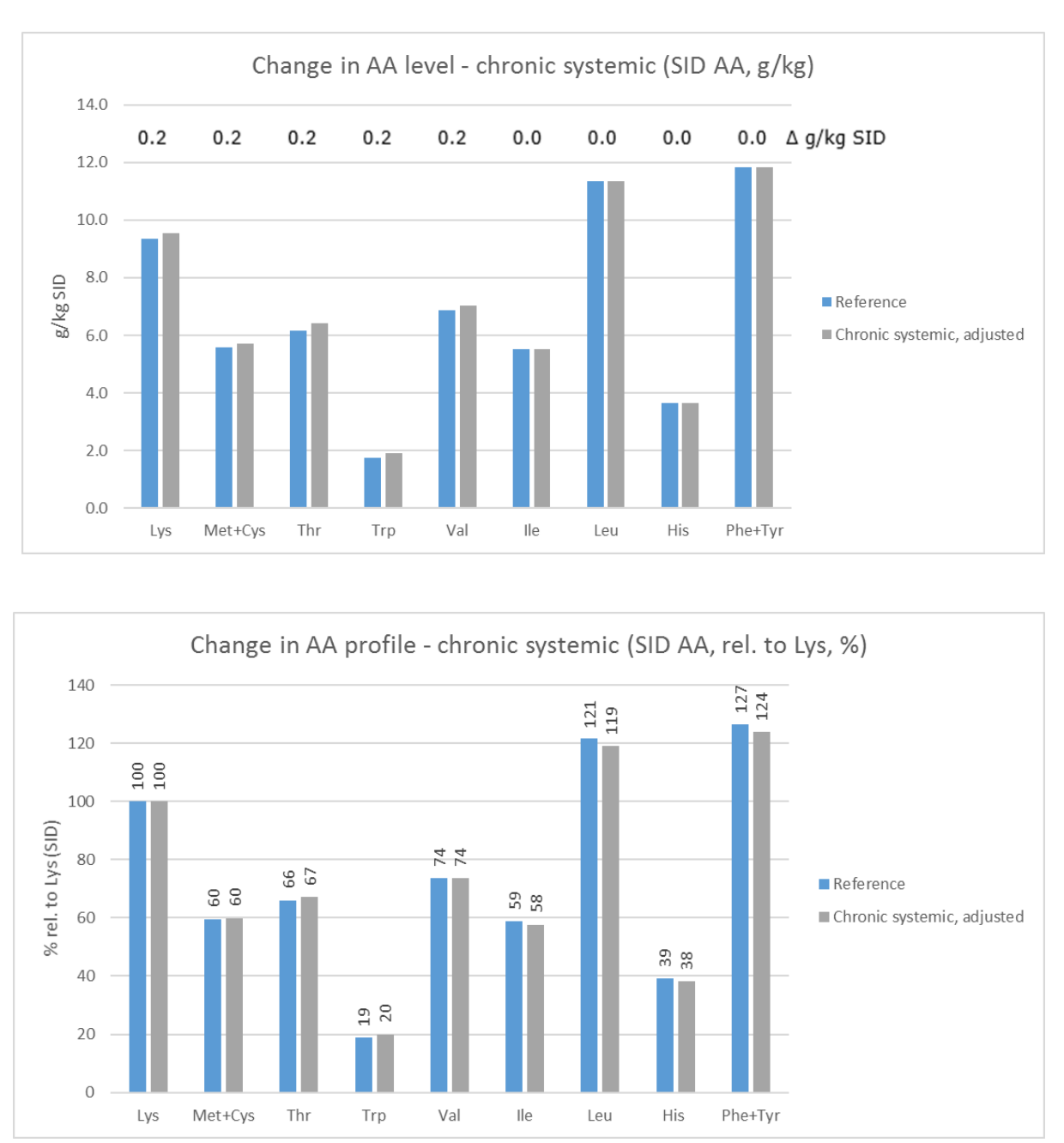

Figure 27 Change in dietary amino acid levels and profile (rel. to Lys) in a condition of chronic systemic challenge (scenario 4) to improve PD from 79 to 88\% (assumed PDmax under that condition) compared to the reference, non-challenged scenario. 

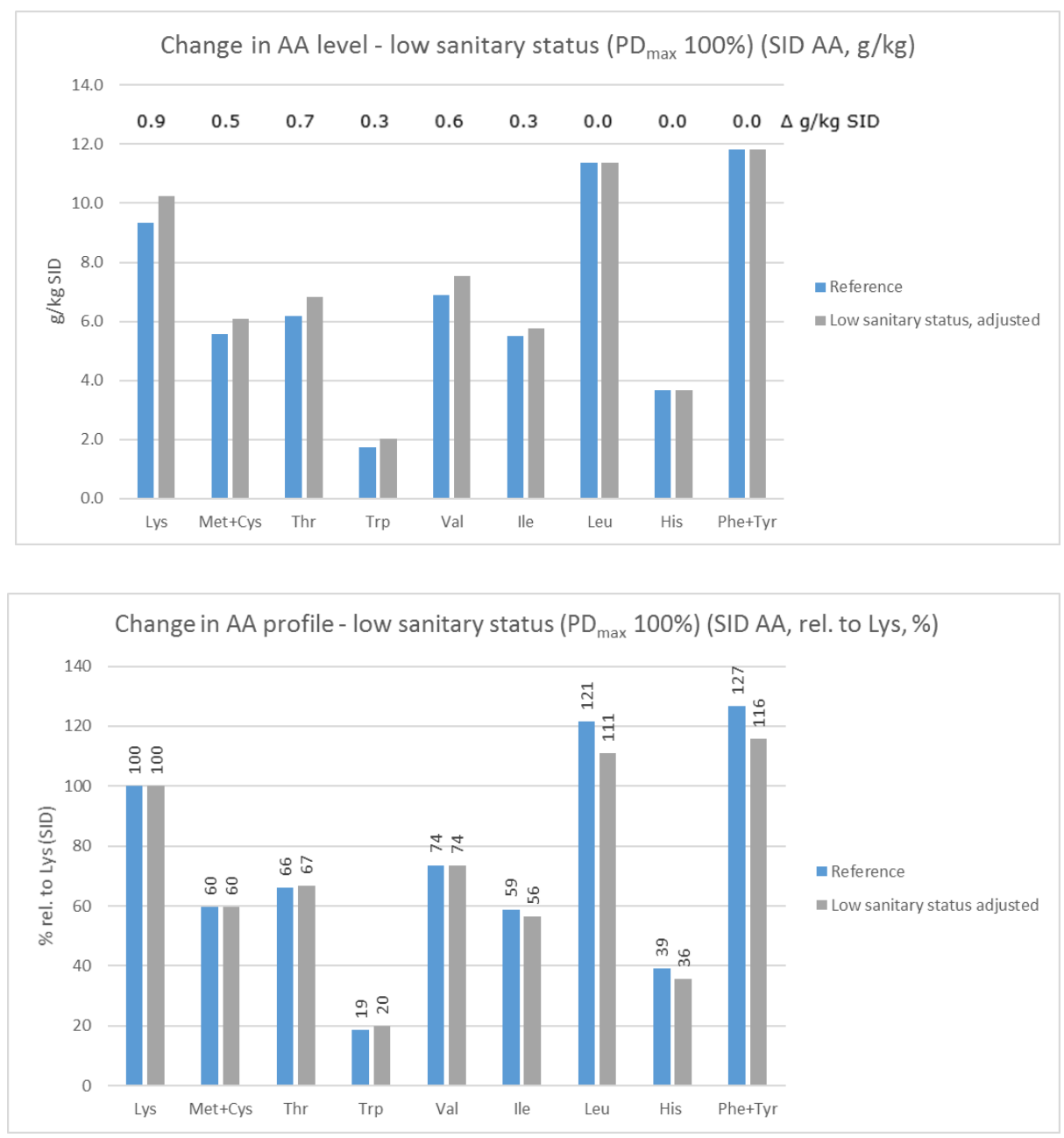

Figure 28 Change in dietary amino acid levels and profile (rel. to Lys) in a condition of low sanitary status to improve PD from 83 to 100\% (assumed PDmax under that condition) compared to the reference, non-challenged scenario. 


\subsection{Discussion}

A factorial model was used to estimate the effects of health status condition on protein deposition and requirements for essential amino acids and energy in a reference pig with $50 \mathrm{~kg}$ body weight and an assumed maximum protein deposition capacity of $149 \mathrm{~g} / \mathrm{d}$ of a pig having that body weight. Most existing growth model for pigs e.g. Halas (2004), INRAPorc (2008), and NRC (2012) consider a number of animal factors such as sex and genetic capacity to deposit protein, but do not take into account effects of health status. The current model considering a pig of $50 \mathrm{~kg}$ body weight fed a diet based on barley, maize and soybean meal, is based on a number of calculations and assumptions, assuming the principle that protein deposition is driven by availability of essential amino acids and energy below the PDmax of pigs and that the supply of amino acids can be changed by modifying the concentration of SID essential amino acids in diet and the supply of energy by the increasing energy density of the diet. The first can be achieved by increasing the level of essential amino acids in free form either or not in combination with changing the ingredient composition leading to an increased supply of ileal digestible amino acids.

The model allows to take into account effects of health status on voluntary feed intake, standardized ileal digestibility of essential amino acids, synthesis of immune proteins, efficiency of using essential amino acids for protein synthesis in post absorptive metabolism, effects on maximum PD and maintenance requirement for energy.

Five scenario were selected for which model calculations were made, representing different conditions of health challenge considering gut and systemic challenges, both in acute and chronic form and a scenario called "low sanitary conditions". For these scenarios, settings had to be defined based on expertise judgement for the major parameters in the model, in part based on the results of a review of the literature as presented in this report. For some of the relevant factors, the experimental basis for estimating the quantitative effects is rather small and require further attention in future research. The model, however, is flexible and parameters can be changed to values for these factors which are in line with particular conditions of interest. In addition, values can be changed in future based on relevant new information from research and literature.

Among the factors, effects on voluntary feed intake and maximum PD for a scenario are of particular importance in relation to the outcome of the calculations. While in literature effects of health condition or challenge on feed intake are frequently reported, effects on PD are mostly not provided. The latter is related to the difficulty to determine (maximum) PD under suboptimal conditions, as it is difficult to maintain pigs in steady state conditions with regard to health status for a prolonged period of time.

The model calculations for the different scenario show that compromising gut or systemic health reduce protein deposition with 17 to $50 \%$ relative to the reference scenario in which the pig of $50 \mathrm{~kg}$ deposits $149 \mathrm{~g}$ of protein per day and reduces protein efficiency from 53 to $36 \%$. By increasing the dietary supply of SID essential amino acids, PD can be increased to the PD of the reference scenario or to the $\mathrm{PD}_{\max }$ defined for that condition of health status, values for $\mathrm{PD}_{\max }$ ranging from 70 (acute systemic challenge) to $100 \%$ (low sanitary status) of the $\mathrm{PD}_{\max }$ in the reference scenario. The protein efficiency increased by the increase in supply of SID amino acids to values in the range of 50 to $55 \%$, depending on the scenario. The former applies to conditions in which the supply of dietary energy is not limiting PD. However, our calculations showed that the supply of dietary energy can also limit PD in most conditions related to the lower feed (and energy) intake, a lower digestibility of dietary energy and increased maintenance requirements for energy under suboptimal health conditions. This indicates that increasing only dietary levels of SID amino acids without considering energy density of the diet will not result in maximum improvement of PD under conditions of compromised health. The calculations showed that the energy density needs to be increased rather substantially (up to more than $20 \%$ ) in conditions of a severe compromised health status. It should be further evaluated in performance studies with pigs in different health conditions whether feeding diets with a (very) high energy density is feasible under low health conditions in which feed intake is reduced. The calculations show, however, the importance of considering energy requirements and energy intake in optimizing diets for pigs with a compromised health status. 
To increase protein deposition under conditions of health challenge, it was calculated that the supply of dietary of essential amino acids needs to be increased. Depending of the scenario, increased supply of Trp, Thr, Met+Cys, Lys, Ile and/or Leu is required to increase PD in the respective conditions. In most cases first Trp, followed by Thr became the first limiting amino acids to counteract the negative effects of health status on PD. The importance of considering these amino acids, and in particular Trp, in conditions of suboptimal health in pigs has also been suggested in other studies (Le Floc'h et al., 2009; de Ridder et al., 2012; Kampman-van de Hoek, 2015; Le Floc'h et al., 2018).

In most scenario, assuming that dietary energy supply is not limiting, it was calculated that the reference diet was adequate in the supply of His and Phe+Tyr, and in most cases Leu (except for the "acute gut" scenario). The dietary supply of SID Lys needed to be increased with $1.4,0.4,0.5,0.2$, $0.9 \mathrm{~g} / \mathrm{kg}$ in scenario 1 to 5 , respectively, (Figure 23-28) relative to the reference diet containing 9.3 $\mathrm{g} / \mathrm{kg}$ SID Lys, a relative increase of $15,4,5,2$, and $10 \%$, respectively. The dietary supply of SID Trp needed to be increased with $0.5,0.2,0.4,0.2$ and $0.3 \mathrm{~g} / \mathrm{kg}$ in scenario 1 to 5 , relative to the reference diet containing $1.7 \mathrm{~g} / \mathrm{kg}$ SID Lys, a relative increase of 29, 12, 24, 12 and 18\%, respectively. The former indicates that for the different scenario, the optimal ratio of SID Trp to Lys increased from 19 to 21,20,22, 20 and 20\%, respectively. In the same way, also required levels of dietary SID Met+Cys, Thr, Val, Ile and Leu (the latter only in scenario 1) as well as their ratio to Lys changed in most cases. Generally, the required changes in absolute levels of dietary essential amino acids were higher than the changes in the ratio relative to Lys.

It should be noticed that results of the model calculations are also somewhat dependent on the diet ingredient and nutrient (amino acid) composition of the diet as the latter determine dietary SID amino acid levels and profile, and their potential relative limitation under health challenge conditions.

It is concluded that the present model calculations based on the use of a factorial model to estimate effects on amino acid and energy requirements are useful to quantify the effects of a variety of health challenge/condition scenario on optimal levels of dietary amino acids and energy to support performance and protein efficiency. Results are dependent of the parameter settings for the calculated scenario, the settings being based on data from literature. Settings can be modified by the users. For some parameters the settings cannot be completely substantiated related to a limitation in available data. This could be improved by targeted experiments providing new data on the effects of specific conditions of health status on critical responses of pigs in relation to their zootechnical performance. One of the critical factors in the model calculations is the assumption on the extent PD can be maintained under particular conditions of health challenge. Relative to other essential amino acids, Trp and Thr seem to become first limiting under conditions of low health of pigs when their diet would not be changed. In addition, results obtained with the calculations give directions on how diet composition for growing pigs should be changed in terms of levels of essential amino acids, their ratio and energy density under conditions of health challenge. The results show that calculated absolute dietary amino acid levels are more affected than their profile relative to Lys, when modified diets targeted for low health conditions are not limiting in energy.

Before results of the model calculations can be applied validation studies are recommended with pigs kept under defined health conditions to confirm the effects of increasing dietary amino acid and energy levels on maintaining growth performance and protein efficiency. 


\section{$5 \quad$ Conclusions}

Feed intake and digestibility:

- $\quad$ Stimulation of the immune system using different challenge models with live pathogens (different pathogens and challenge levels) that lead to subclinical diseases in a naïve host can reduce feed intake in the range of 3 to $25 \%$.

- Systemic immune system activation may decrease the digestibility of protein and amino acids in pigs with 1 to $2 \%$. The digestibility of energy seems hardly affected by systemic immune system activation.

- Immune system activation due to a sanitary challenge may reduce the ileal or faecal digestibility of protein and amino acids with 1 to $7 \%$ and the faecal digestibility of energy with about 3\%.

- Especially, when the health status of the gastrointestinal tract is compromised by a challenge, digestibility of protein, amino acids and energy will be reduced.

Energy requirements:

- Systemic immune system activation by a non-pathogenic challenge may increase the maintenance requirement for energy with 10 to $30 \%$. Immune system activation due to a sanitary challenge may increase the maintenance requirement for energy with 7 to $12 \%$.

- As far as studied, no effect of immune system activation on the efficiency of the use of dietary ME for total energy retention or for retention of energy in body protein and fat was observed.

Amino acid requirements:

- $\quad$ The maintenance requirement for the individual amino acids may increase with 0 to $30 \%$ in pigs with an activated immune system. The maintenance requirement of lysine, methionine + cysteine, threonine, tryptophan and arginine may increase with 15\%, 23\%, 5\%, 0\% and 0\%, respectively. It is not known if the maintenance requirements of other essential amino acids are increased by immune system activation.

- Immune system activation has no effect on the post-absorptive utilization of lysine, methionine + cysteine, threonine and arginine for protein deposition. However, it may reduce the efficiency of tryptophan utilization for protein deposition in pigs with about $7 \%$. It is not known if the efficiency of utilization of other essential amino acids for protein deposition is influenced by immune system activation.

- $\quad$ Systemic immune system activation via a challenge with e.g. LPS or Complete Freund adjuvans decreases the maximum protein deposition in pigs with 4 to $12 \%$. Systemic immune system activation by a pathogenic challenge (PRRSV) decreases the maximum protein deposition in pigs with up to $35 \%$. Immune system activation due to a sanitary challenge can decrease maximum protein deposition with 10 to $25 \%$.

- Activation of the immune system may increase the amino acid requirements due to the production of immune proteins such as acute phase proteins and immunoglobulins. However, amino acid requirements may decrease because of a reduced protein retention in the body, related to enhanced body protein degradation. Because the amino acid composition of acute phase proteins and immunoglobulins differ from the amino acid composition in muscle protein, the amino acid requirements and the ratio between amino acids may change in pigs with an activated immune system.

- Immune system stimulation increases the metabolism and requirements of at least methionine + cysteine, tryptophan and threonine. Dietary supplementation of methionine + cysteine, threonine and tryptophan, in addition to provision of AA for covering basal requirements for protein deposition, might be beneficial for pigs with an activated immune system.

- Moreover, branched chain amino acids (valine, leucine and isoleucine) have been shown to play an important role in immune function and in the protection against skeletal muscle degradation during conditions of (strong) immune system activation. Immune system stimulation via a systemic challenge with LPS increased the net metabolic utilisation (NMU) for 
the branched chain amino acids with on average 30\%, suggesting an enhanced requirement for these amino acids under these conditions.

- Changes in amino acid requirements for specific amino acids are dependent on the type of (subclinical) disease and type and degree of immune system activation, and therefore difficult to quantify accurately. Changes in requirements for BCAA are related to the recovery after skeletal muscle degradation during immune system activation, independent on the type of disease or type of immune system activation. BCAA may therefore serve a more general purpose during immune system activation to support or maintain the growth performance of pigs.

Based on the results of the literature review, model calculations were made, representing different conditions of health challenge considering gut and systemic challenges, both in acute and chronic form and a scenario called "low sanitary conditions". For all scenario evaluated, the required increase in absolute levels of dietary essential amino acids was higher than the changes in the ratio relative to Lys. Relative to other essential amino acids, Trp and Thr seem to become first limiting under conditions of low health of pigs when their diet would not be changed. The calculations showed that the supply of dietary energy can also limit protein deposition related to a lower feed (and energy) intake, a lower digestibility of dietary energy and increased maintenance requirements for energy under suboptimal health conditions. This indicates that increasing only dietary levels of (SID) amino acids without considering energy density of the diet will not result in maximum support of protein deposition under conditions of compromised health. 


\section{References}

Adewole, D.I., I.H. Kim, and C.M. Nyachoti. 2016. Gut Health of Pigs: Challenge Models and Response Criteria with a Critical Analysis of the Effectiveness of Selected Feed Additives - A Review. Asian Australasian Journal of Animal Science, 29, 909-924.

AgroVision. 2017. Kengetallenspiegel 2016. Bedrijfsvergelijking AgroVision B.V.

Balaji, R., K.J. Wright, J.L. Turner, C.M. Hill, S.S. Dritz, B. Fenwick, J.A. Carroll, M.E. Zannelli, L.A. Beausang and J.E. Minton. 2002. Circulating cortisol, tumour necrosis factor-a, interleukin-1B, and interferon- $y$ in pigs infected with Actinobacillus pleuropneumoniae. Journal of Animal Science, 80, 202-207.

Bannink, A., Z. Mroz, S.J. Koopmans, A.J.M. Jansman en J. Dijkstra. 2005. Nutriëntenverbruik door weefsels in het maagdarmkanaal. Rapport 05/I00725, Animal Sciences Group, Lelystad, The Netherlands.

Baracos, V.E., W.T. Whittemore and R. Gale. 1987. The metabolic costs of fever. Canadian Journal of Physiology and Pharmacology, 65, 1248-1254.

Black J.L., H.J. Bray and L.R. Giles. 1999. The thermal and infectious environment. In A quantitative biology of the pig (ed. I. Kyriazakis), pp. 71-97. CAB International, Wallingford.

Busquets, S., B. Alvarez, M. Llovera, N. Agell, F.J. López-Soriano, J.M. Argilés. 2000. Branched-chain amino acids inhibit proteolysis in rat skeletal muscle: mechanisms involved. Journal of Cellular Physiology, 184, 380-384.

Calder, P.C. and P. Yaqoob. 2012. Nutrient regulation of the immune response. In Present knowledge in nutrition, $10^{\text {th }}$ ed., pp 688-708. Editors: J.W. Erdman, I.A. Macdonald and S.H. Zeisel, Chichester, UK, Wiley-Blackwell.

Campos, P.H., E. Merlot, M. Damon, J. Noblet, and N. Le Floc'h. 2014. High ambient temperature alleviates the inflammatory response and growth depression in pigs challenged with Escherichia coli lipopolysaccharide. Veterinary Journal, 200, 404-409.

Capozzalo, M.M., J.C. Kim, J.K. Htoo, C.F.M. de Lange, B.P. Mullan, C.F. Hansen, J.W. Resink and J.R. Pluske. 2017. Pigs experimentally infected with an enterotoxigenic strain of Escherichia coli have improved feed efficiency and indicators of inflammation with dietary supplementation of tryptophan and methionine in the immediate post-weaning period. Animal Production Science, 57, 935-947.

Centraal Veevoederbureau. 2008. Tabellenboek veevoeding. CVB-reeks nr. 46.

Colditz I.G. 2002. Effects of the immune system on metabolism: implications for production and disease resistance in livestock. Livestock Production Science, 75, 257-268.

Conde-Aguilera J.A., R. Barea, N. Le Floc'h, L. Lefaucheur, J. van Milgen. 2010. A sulfur amino acid deficiency changes the amino acid composition of body protein in piglets. Animal 4, 1349-1358.

Coop, R.L., A.R. Sykes, and K.W. Angus. 1982. The effect of three levels of intake of Ostertagia circumcincta larvae on growth rate, feed intake and body composition of growing lambs. Journal of Agriculture Science Cambridge, 98, 247-255.

Daiwen, C. Z. Keying, and W. Chunyan. 2008. Influences of lipopolysaccharide-induced immune challenge on performance and whole-body protein turnover in weanling pigs. Livestock Science, 113, 291-295.

Dardevet, D., C. Sornet, G. Bayle, J. Prugnaud, C. Pouyet, J. Grizard. 2002. Postprandial stimulation of muscle protein synthesis in old rats can be restored by a leucine-supplemented meal. Journal of Nutrition, 132, 95-100.

De Greeff, Astrid, Janneke Allaart, Carlijn de Bruijn, Dirkjan Schokker, Petra Roubos, Hélène Winkelman-Goedhart, Stéphanie Vastenhouw, Lisette Ruuls, Johanna Rebel, Mari Smits. 2016. LPS Challenge in Jonge Biggen. Report 1009, Wageningen Livestock Research, Wageningen.

De Ridder, K., C.L. Levesque, J.K. Htoo, and C.F.M. de Lange. 2012. Immune system stimulation reduces the efficiency of tryptophan utilization for body protein deposition in growing pigs. Journal of Animal Science, 90, 3485-3491.

DeFronzo, R.A., E. Ferrannini. 1992. Insulin actions in vivo: protein metabolism. In: International Textbook of Diabetes Mellitus. Edited by K.G.G.M. Alberti, R.A. DeFronzo, H. Keen, P. Zimmet. John Wiley \& Sons Ltd. 467-511.

Dekker, R.A., J.T.M. van Diepen, Z. Mroz en S.J. Koopmans. 2004. kwantificering van de glucose- en aminozuurstofwisseling bij gezonde en (subklinisch) geïnfecteerde vleesvarkens. Rapport 04/0000587, Animal Sciences Group, Lelystad, The Netherlands. 
Demas, G.E., V. Chefer, M.I. Talan and R.J. Nelson. 1997. Metabolic costs of mounting an antigenstimulated immune response in adult and aged C57BL/6J mice. American Journal of Physiology, 273, R1631-R1637.

Eraud, C., O. Duriez, O. Chastel and B. Faivre. 2005. The energetic costs of humoral immunity in the collared dove, Streptopelia decaocto: is the magnitude sufficient to force energy-based trade-offs. Functional Ecology, 19, 110-118.

Escobar, J., W.G. van Alstine, D.H. Baker and R.W. Johnson. 2004. Decreased protein accretion in pigs with viral and bacterial pneumonia is associated with increased myostatin expression in muscle. Journal of Nutrition, 134, 3047-3053.

Ferrannini, E., S. Bevilacqua, L. Lanzone, R. Bonadonna, L. Brandi, M. Oleggini, C. Boni, G. Buzzigoli, D. Ciociaro, L. Luzi, and R.A. DeFronzo. 1988. Metabolic interactions of amino acids and glucose in healthy humans. Diabetes Nutr. Metab. 3: 175-186.

Goodband. B., M. Tokach, S. Dritz, J. DeRouchey and J. Woodworth. 2014. Practical starter pig amino acid requirements in relation to immunity, gut health and growth performance. Journal of Animal Science and Biotechnology, 5:12, 1-11

Greiner, L.L., T.S. Stahly and T.J. Stabel. 2000. Quantitative relationship of systemic virus concentration on growth and immune response in pigs. Journal of Animal Science, 78, 2690-2695.

Grimble, R.F., A.A. Jackson, C. Persaud, M.J. Wride, F. Delers and R. Engler. 1992. Cysteine and glycine supplementation modulate the metabolic response to tumor necresis factor a in rats fed a low protein diet. Journal of Nutrition, 122, 2066-2073.

Halas, V., J. Dijkstra, L. Babinsky, M.W.A. Verstegen and W. Gerrits. 2004. Modelling of nutrient partitioning in growing pigs to predict their anatomical body composition. 1 . Model description. Br. J. Nutr. 92, 707-723.

Heegaard, P.M.H., A. Stockmarr, M. Piñeiro, R. Carpintero, F. Lampreave, F.M. Campbell, D.P. Eckersall, M.J.M. Toussaint, E. Gruys, and S.N. Sorensen. 2011. Optimal combinations of acute phase proteins for detecting infectious disease in pigs. Veterinary Research, 42, 1-13.

Houdijk, J.G.M. and S.L. Athanasiadou. 2003. Direct and indirect effects of host nutrition on ruminant gastrointestinal nematodes. In Proceedings of the VI international symposium on the nutrition of herbivores: matching herbivore nutrition to ecosystems biodiversity (eds t'Mannetje, L., L. Ramirez-Aviles, C.A. Sandoval-Castro and J.C. Ku-vera, JC), pp. 213-236. Universidad Autónoma de Yucatán, Merida, Mexico.

Houdijk, J.G.M., D.H. Anderson, and I. Kyriazakis. 2005. Induction of experimental sub-clinical postweaning colibacillosis in pigs. Proceedings British Animal Science. 47, 84.

Jahoor, F. L. Wykes, M. Del Rosario, M. Frazer and P.J. Reeds. 1999. Chronic protein undernutrition and an acute inflammatory stimulus elicit different protein kinetic responses in plasma but not in muscle of piglets. Journal of Nutrition, 129, 693-699.

Jayaraman, B., J. Htoo, and C.M. Nyachoti. 2015. Effects of dietary threonine:lysine ratioes and sanitary conditions on performance, plasma urea nitrogen, plasma-free threonine and lysine of weaned pigs. Animal Nutrition, 1, 283-288.

Johnson, R.W. 1997. Inhibition of growth by pro-inflammatory cytokines: an integrated view. Journal of Animal Science, 75, 1244-1255.

Kahindi, R.K., A. Regassa, J.K. Htoo, and C.M Nyachoti. 2017. Optimal sulfur amino acid to lysine ratio for post weaning piglets reared under clean or unclean sanitary conditions. Animal Nutrition, 3, 380-385.

Kahindi, R.K., A. Regassa, J.K. Htoo, and C.M Nyachoti. 2018. Growth performance and expression of genes encoding enzymes involved in methionine and cysteine metabolism in piglets fed increasing sulphur amino acid to lysine ratio during enterotoxigenic Escherichia coli challenge. Canadian Journal of Animal Science, 98, 333-340.

Kampman-van de Hoek E. 2015. Impact of health status on amino acid requirements of growing pigs: Towards feeding strategies for farms differing in health status. PhD Dissertation, Wageningen University, Wageningen, the Netherlands.

Kampman-van de Hoek, E. W.J.J. Gerrits, J.J.G.C. van den Borne, C.M.C. van der Peet-Schwering, H. van Beers-Scheurs, and A.J.M. Jansman. 2011. Selectie van een onderzoeksmodel voor het bestuderen van de invloed van immuunsysteem activatie op de aminozuurbehoefte van varkens, WUR Livestock Research, Wageningen, The netherlands.

Kampman-van de Hoek, E., A.J.M. Jansman, J.J.G.C. van den Borne, C.M.C. van der Peet-Schwering, H. van Beers-Schreurs, and W.J.J. Gerrits. 2016. Dietary amino acid deficiency reduces the utilization of amino acids for growth in growing pigs after a period of poor health. Journal of Nutrition, 146, 51-58. 
Kampman-van de Hoek, E., P. Sakkas, W.J.J. Gerrits, J.J.G.C. van den Borne, C.M.C. van der PeetSchwering, and A.J.M. Jansman. 2015. Induced lung inflammation and dietary protein supply affect nitrogen retention and amino acid metabolism in growing pigs. Britsh Journal of Nutrition, 113, 414-425.

Kim, J.C., B.P. Mullan, B. Frey, H.G. Payne, and J.R. Pluske. 2012. Whole body protein deposition and plasma amino acid profiles in growing and/or finishing pigs fed increasing levels of sulfur amino acids with and without Escherichia coli lipopolysaccharide challenge. Journal of Animal Science, 90, 362-365.

Kimball, S.R., P.A. Farrell, L.S. Jefferson. 2002. Invited review: role of insulin in translational control of protein synthesis in skeletal muscle by amino acids or exercise. Journal of Applied Physiology 93, 168-180.

Klasing, K.C. and B.J. Johnstone. 1991. Monokines in growth and development. Poultry Science, 70, 1781-1789.

Klasing, K.C. and C.C. Calvert. 1999. The care and feeding of an immune system: an analysis of lysine needs. Pages 253-263 in G.E. Lobley et al., eds. Protein metabolism and nutrition. Wageningen Press, The Netherlands.

Klis, J.D. van der and A.J.M. Jansman. 2002. Optimising nutrient digestion, absorption and gut barrier function in monogastrics: reality or illusion? Pages 15-36 in M.C. Blok et al., eds. Nutrition and health of the gastrointestinal tract. Wageningen Academic Publishers, Wageningen, The Netherlands.

Koopmans, S.J., A.C. Guzik, J. vd Meulen, R. Dekker, J. Kogut, B.J. Kerr and L. Southern. 2006. Effects of supplemental L-tryptophan on serotonin, cortisol, intestinal integrity, and behavior in weanling piglets. Journal of Animal Science, 84, 963-971.

Koopmans, S.J., F.J. van der Staay, N. Le Floc'h, R. Dekker, J.Th.M. van Diepen, and A.J.M. Jansman. 2012. Effects of surplus dietary L-tryptophan on stress, immunology, behavior and nitrogen retention in endotoxemic pigs. Journal of Animal Science, 90, 241-251.

Koopmans, S.J., J. v.d. Meulen, R. Dekker, H. Corbijn and Z. Mroz. 2006. Diurnal variation in insulinstimulated systemic glucose and amino acid utilization in pigs fed with identical meals at 12-hour intervals. Hormone and Metabolic Research, 38, 607-613.

Koopmans, S.J., J. van der Meulen, J. Wijdenes, H. Corbijn and R. Dekker. 2011. The existence of an insulin-stimulated glucose and non-essential but not essential amino acid substrate interaction in diabetic pigs. BMC Biochemistry 12, 25.

Koopmans, S.J., M. Ruis, R. Dekker and M. Korte. 2009. Surplus dietary tryptophan inhibits stress hormone kinetics and induces insulin resistance in pigs. Physiology and Behaviour, 98, 402-410.

Koopmans, S.J., M. Ruis, R. Dekker, H. v Diepen, M. Korte and Z. Mroz. 2005. Surplus dietary tryptophan reduces plasma cortisol and noradrenaline concentrations and enhances recovery after social stress in pigs. Physiology and Behaviour, 85, 469-478.

Koopmans, S.J., Z. Mroz, R. Dekker, J. Wijdenes, S. v.d. Crabben, A. Ackermans and H.P. Sauerwein. 2003. Insulin stimulated net utilisation of plasma glucose and amino acids in growing pigs. Proc. 1st International Symp. on Energy and Protein Metabolism. pp. 197-200.

Kyriazakis, I. and A. Doeschl-Wilson. 2009. Anorexia during infection in mammals: variation and its sources. In Voluntary food intake in pigs, $1^{\text {st }}$ ed., pp 307-322. Wageningen, the Netherlands, Wageningen Academic Publishers.

Kyriazakis, I., D.H. Anderson, J.D. Oldham, R.L. Coop and F. Jackson. 1996. Long-term subclinical infection with Trichostrongylus colubriformis: Effects on feed intake, diet selection and performance of growing lambs. Veterinary Parasitology, 61, 297-313.

Kyriazakis, I., G.C. Emmans and R. McDaniel. 1993. Whole body amino-acid composition of the grazing pig. Journal of the Science of Food and Agriculture, 62, 29-33.

Kyriazakis, I.and J.G.M. Houdijk. 2007. Food intake and performance of pigs duirng health, disease and recovery. 62 ${ }^{\text {nd }}$ Easter School in the Agricultural and Food Sciences (ed. J. Wiseman, M.A. Varley, S. McOrist and B. Kemp), 493-513.

Labussière, E., J. van Milgen, C.F.M. de Lange, and J. Noblet. 2011. Maintenance energy requirements of growing pigs and calves are influenced by feeding level. Journal of Nutrition, 141, 1855-1861.

Labussière, E., S. Dubois, H. Gilbert, J. N. Thibault, N. Le Floc'h, J. Noblet and J. van Milgen. 2015. Effect of inflammation stimulation on energy and nutrient utilization in piglets selected for low and high residual feed intake. Animal, 9:10, 1653-1661.

Laviano, A., M. Muscaritoli, A. Cascino, I. Preziosa, A. Inui, G. Mantovani, F. Rossi-Fanelli. 2005. Branched-chain amino acids: the best compromise to achieve anabolism? Current Opinion in Clinical Nutrition and Metabolic Care. 8, 408-414.

Le Bellego, L., J. Noblet. 2002. Performance and utilization of dietary energy and amino acids in piglets fed low protein diets. Livest. Prod. Sci. 76, 45-58. 
Le Floc'h, N. C. Jondreville, J.J. Matte and B. Sève. 2006a. Importance of sanitary environment for growth performance and plasma nutrient homeostatis during the post-weaning period in piglets. Archives of Animal Nutrition, 60, 23-34.

Le Floc'h, N. et al., 2006b. Gepubliceerd in Orffa "Invloed van de gezondheidsstatus en het verbod op AMGB op de aminozuurbehoefte van varkens".

Le Floc'h, N., D. Melchior and C. Obled. 2004. Modifications of protein and amino acid metabolism during inflammation and immune system activation. Livestock Production Science, 87, 37-45.

Le Floc'h, N., D. Melchior, and B. Sève. 2008. Dietary tryptophan helps to preserve tryptophan homeostasis in pigs suffering from lung inflammation. J Anim Sci 86: 3473-3479.

Le Floc'h, N., L. LeBellego, J. J. Matte, D. Melchior, and B. Sève. 2009. The effect of sanitary status degradation and dietary tryptophan content on growth rate and tryptophan metabolism in weaning pigs. J Anim Sci 87: 1686-1694.

Le Floc'h, N., A. Wessels, E. Corrent, G. Wu and P. Bosi. 2018. The relevance of functional amino acids to support the health of growing pigs. Anim. Feed Sci. Techn., 245, 104-116.

Le Floc'h1, N., C. Knudsen, T. Gidenne, L. Montagne, E. Merlot and O. Zemb. 2014. Impact of feed restriction on health, digestion and faecal microbiota of growing pigs housed in good or poor hygiene conditions. Animal, 8, 1632-1642.

Li, P., Y.-L. Yin, D. Li, S. Woo Kim, and G. Wu. 2007. Amino acids and immune function. British Journal of Nutrition, 98, 237-252.

Li. D., X. Changtinga, Q. Shiyana and Z. Jinhuia. 1999. Effects of dietary threonine on performance, plasma parameters and immune function of growing pigs. Animal Feed Science and Technology, 78, 179-188.

Litvak, N., A. Rakhshandeh, J. K. Htoo, and C. F. M. de Lange. 2013. Immune system stimulation increases the optimal dietary methionine to methionine plus cysteine ratio in growing pigs. Journal of Animal Science, 91, 4188-4196.

Lochmiller, R.L. and C. Deerenberg. 2000. Trade-0ffs in evolutionary immunology: just what is the cost of immunity? OIKOS, 88, 87-98.

Manders, R.J., J.P. Little, S.C. Forbes and D.G. Candow. 2012. Insulinotropic and muscle protein synthetic effects of branched-chain amino acids: potential therapy for type 2 diabetes and sarcopenia. Nutrients, 4, 1664-1678.

McLamb, B.L., A.J. Gibson, E.L. Overman, C. Stahl, and A.J. Moeser. 2013. Early weaning stress in pigs impairs innate mucosal immune responses to enterotoxigenic $\mathrm{E}$. coli challenge and exacerbates intestinal injury and clinical disease. PLOS ONE 8: e59838.

Melchior, D., B. Sève and N. Le Floc'h. 2004. Chronic lung inflammation affects plasma amino acid concentration in pigs. Journal of Animal Science, 82, 1091-1099.

Melchior, D., N. Mézière, B. Sève and N. Le Floc'h. 2005. Is tryptophan catabolism increased under indoleamine 2,3 dioxygenase activity during chronic lung inflammation in pigs? Reproduction and Nutrition Development, 45, 175-183.

Moloney, A.P. and M. McGee. 2017. Factors Influencing the Growth of Meat Animals. In Lawrie's Meat Science (Eighth Edition) (pp. 19-47).

Negro, M., S. Giardina, B. Marzani, and F. Marzatico. 2008. Branched-chain amino acid supplementation does not enhance athletic performance but affects muscle recovery and the immune system. Journal of Sports Medicine and Physical Fitness, 48, 347-51.

Newsholme, E.A., and A.R. Leech. 2008. Biochemistry for the medical sciences. John Wiley \& Sons Ltd, UK.

Nicastro, H., C. Ribeiro da Luz, D.F. Seixas Chaves, L.R. Grassmann Bechara, V. Azevedo Voltarelli, M.M. Rogero, and A.H. Lancha. 2012. Does Branched-Chain Amino Acids Supplementation Modulate Skeletal Muscle Remodeling through Inflammation Modulation? Possible Mechanisms of Action. Journal of Nutrition and Metabolism, Article ID 136937, 1-10.

Nie, C., T. He, W. Zhang, G. Zhang and X. Ma. 2018. Branched Chain Amino Acids: Beyond Nutrition Metabolism. Int. J. Mol. Sci. 19, 954; doi:10.3390/ijms19040954.

Noblet, J., B. Sève and C. Jondreville. 2002. Valeurs nutritives pour les porcs. Tables de composition et de valeur nutritive des matières premières destinées aux animaux d'élevage: porcs, volailles, bovins, ovins, caprins, lapins, chevaux, poissons. Sauvant D., Perez JM, Tran G.(Eds), INRA Editions, Versailles, France, pp.25-35.

NRC. 2012. Nutrient Requirements of Swine. Animal Nutrition series. ISBN 978-0-309-22423-9.

Parra, M.D., P. Fuentes, F. Tecles, S. Martínez-Subliela, J.S. Martínez, A. Muñoz, and J.J. Cerón. 2006. Porcine acute phase protein concentrations in different diseases in field conditions. Journal of Veterinary Medicin B, 53, 488-493.

Pastorelli, H., J. van Milgen, P. Lovatto, and L. Montagne. 2012b. Meta-analysis of feed intake and growth responses of growing pigs after a sanitary challenge. Animal 6:952-961. 
Pastorelli, H., N. Le Floc'h, E. Merlot, M. C. Meunier-Salaūn, J. van Milgen, and L. Montagne. 2012a. Sanitary housing conditions modify the performance and behavioural response of weaned pigs to feed- and housing-related stressors. Animal 6:1811-1820.

Patience, J.F., M.C. Rossoni-Serão, and N.A. Gutiérrez. 2015. A review of feed efficiency in swine: biology and application. Journal of animal science and biotechnology, 6,1, 33.

Petersen, H.H., J.P. Nielsen and P.M. Heegaard. 2004. Application of acute phase protein measurements in veterinary clinical chemistry. Veterinary Research, 35, 163-187.

Pluk, P., M. van Krimpen. 2018. Effect of reducing dietary crude protein in hog finisher barrows and gilts on technical performance. Report Wageningen Livestock Research, Report 1111.

Rakhshandeh A., J.K. Htoo and C.F.M. de Lange, 2010. Immune system stimulation of growing pigs does not alter apparent ileal amino acid digestibility but reduces the ratio between whole body nitrogen and sulfur retention. Livestock Science 134, 21-23.

Rakhshandeh, A. 2015. Impact of disease on amino acid requirements of growing pigs. Technical report number NPB 13-082. Texas Tech University.

Rakhshandeh, A. and C.F.M. de Lange. 2011. Immune system stimulation in the pig: effect on performance and implications for amino acid nutrition. https://www.researchgate.net/publication/280533824.

Rakhshandeh, A. and C.F.M. de Lange.2012. Evaluation of chronic immune system stimulation models in growing pigs. Animal, 6, 305-310.

Rakhshandeh, A., J.K. Htoo, N. Karrow, S.P. Miller and C.F.M. de Lange. 2014. Impact of immune system stimulation on the ileal nutrient digestibility and utilisation of methionine plus cysteine intake for whole-body protein deposition in growing pigs. British Journal of Nutrition, 111, 101110.

Randle, P.J., P.B. Garland, C.N. Hales, and E.A. Newsholme. 1963. The glucose fatty-acid cycle. Its role in insulin sensitivity and the metabolic disturbances of diabetes mellitus. Lancet. 13;1 (7285):785-9.

Reeds, P.J., C.R. Fjeld and F. Jahoor. 1994. Do the differences between the amino acid compositions of acute-phase and muscle protein have a bearing on nitrogen loss in traumatic states? Journal of Nutrition, 124, 906-910.

Sakkas, P., C.M.C. van der Peet-Schwering, W.J.J. Gerrits, E. Kampman-Van der Hoek, J.J.G.C. van den Borne and A.J.M. Jansman. 2016. Livestock Research Report 943 [in Dutch], Wageningen Livstock Research, Wageningen.

Sandberg, F.B., G.C. Emmans and I. Kyriazakis. 2006. A model for predicting feed intake of growing animals during exposure to pathogens. Journal of Animal Science, 84, 1552-1566.

Sandberg, F.B., G.C. Emmans and I. Kyriazakis. 2007. The effects of pathogen challenges on the performance of naïve and immune animals: the problem of prediction. Animal, 1, 67-86.

Saris, W.H., and L.J. van Loon. 2004. Nutrition and health: nutrition and performance in sports. Nederlands Tijdschrift voor Geneeskunde; 148, 708-12.

Schinkel, A.P., M.E. Spurlock, R.T. Richert and T.E. Weber. 2003. Modelling health statusenvironmental effects on swine growth. Pages 355 in Book of Abstracts of the 54th Annual Meeting of the EAAP. Wageningen Pers, Wageningen, The Netherlands.

Spurlock, M.E. 1997. Regulation of metabolism and growth during immune challenge: an overview of cytokine function. Journal of Animal Science, 75, 1773-1783.

Stark, K.D.C. 2000. Epidemiological investigation of the influence of environmental risk factors on respiratory diseases in swine - a literature review. Veterinary Journal, 159, 37-56.

Steel, J.W., L.E. A. Symons, and W.O. Jones. 1980. Effects of level of larval intake on the productivity and physiological and metabolic responses of lambs infected with Trichostrongylus colubriformis. Australian Journal of Agricultural Research, 31, 821-838.

Stuart, W.D, T.E. Burkey, N.K. Gabler, K. Schwartz, T. Dinh, C.F.M. de Lange, D. Klein, J.A. Dawson, and $A$. Rakhshandeh. 2015. Infection with porcine reproductive and respiratory syndrome virus (PRRSV) affects body protein deposition and alters amino acid metabolism in growing pigs. Journal of Animal Science, 93, Suppl. s3/Journal of Dairy Science, 98, Suppl. 2, abstract 790.

Stuart, W.D., T.E. Burkey, N K. Gabler, K.J. Schwartz, D. Klein, J.A. Dawson, A.R. Pendleton, C.F.M. de Lange, and A. Rakhshandeh. 2016. Immune system stimulation (ISS) induced by E. coli lipopolysaccharide (LPS) alters amino acid metabolism in growing pigs. doi: 10.2527/msasas2016110.

Symons, L.E. ., J.W. Steel, and W.O. Jones. 1981. Effects of larval intake on the productivity and physiological and metabolic responses of lambs infected with Ostertagia circumcincta. Australina Journal of Agriculture, 32, 139-148.

Tamanna, N., and N. Mahmood. 2014. Emerging Roles of Branched-Chain Amino Acid Supplementation in Human Diseases. International Scholarly Research Notices. Article ID 235619, 8 pages. http://dx.doi.org/10.1155/2014/235619. 
Trevisi, P., D. Melchior, M. Mazzoni, L. Casini, S. De Filippi, L. Minieri, G. Lalatta-Costerbosa and P. Bosi. 2009. A tryptophan-enriched diet improves feed intake and growth performance of susceptible weanling pigs orally challenged with Escherichia coli K88. Journal of Animal Science, $87,148-156$.

Tsien, C., G. Davuluri, D. Singh, A. Allawy, G.A.M. Ten Have, S. Thapaliya, J.M. Schulze, D. Barnes, A.J. McCullough, M.P.K.J. Engelen, N.E.P. Deutz, and S. Dasarathy. 2015. Metabolic and molecular responses to leucine-enriched branched chain amino acid supplementation in the skeletal muscle of alcoholic cirrhosis. Hepatology, 61, 2018-2029.

van der Meer, Y. 2017. Nutrition of pigs kept under low and high sanitary conditions. PhD Dissertation, Wageningen University, Wageningen, the Netherlands.

van der Meer, Y., A. Lammers, A.J.M. Jansman, M.M.J.A. Rijnen, W.H. Hendriks, and W.J.J. Gerrits. 2016. Performance of pigs kept under different sanitary conditions affected by protein intake and amino acid supplementation., Journal of Animal Science, 94, 4704-4719.

van der Peet-Schwering, C.M.C. van der and A.J.M. Jansman. 1997. Nutriëntenbehoefte van varkens onder suboptimale omstandigheden. NL rapport no. 68, Wageningen Livestock Research, Wageningen.

van der Peet-Schwering, C.M.C., H.J.P.M. Vos, G.F.V. van der Peet, M.W.A. Verstegen, E. Kanis, C.H.M. Smits, A.G. de Vries and N.P. Lenis. 1994. Technisch Model Varkensvoeding. Report P1.117. Institute for Pig Husbandry, Rosmalen, The Netherlands.

van der Peet-Schwering, C.M.C., P. Bikker. 2018. Amino acid requirement of growing and finishing pigs. Report Wageningen Livestock Research, Report 1101.

Van Houtert, M.F J., I.A. Barger, J.W. Steel, R.G. Windon, and D.L. Emery. 1995. Effects of dietary protein intake on responses of young sheep to infection with Trichostrongylus colubriformis. Vet. Para. 56, 163-180.

van Milgen, J., A. Valancogne, S. Dubois, J.Y. Dourmad, B. Sève and J. Noblet. 2008. InraPorc: a model and decision support tool for the nutrition of growing pigs. Animal Feed Science and Technology, 143, 387-405.

Wagenmakers, A.J.M. 1999. Tracers to investigate protein and amino acid metabolism in human subjects. Proceedings of the Nutrition Society, 58, 987-1000.

Waterlow, J.C. 2006. Protein turnover. CABI, UK.

Webel, D.M. , R.W. Johnson and D.H. Baker. 1998a. Lipopolysaccharide-induced reduction $\mathrm{s}$ in food intake do not decrease the efficiency of lysine and threonine utilization for protein accretion in chickens. Journal of Nutrition, 128, 1760-1766.

Webel, D.M. , R.W. Johnson and D.H. Baker. 1998b. Lipopolysaccharide-induced reduction s in body weight gain and food intake do not reduce the efficiency of arginine utilization for whole-body protein accretion in the chick. Poultry science, 77, 1893-1898.

William J. Durham, Edgar Lichar Dillon, and Melinda Sheffield-Moore. Inflammatory burden and amino acid metabolism in cancer cachexia. Curr Opin Clin Nutr Metab Care. 2009 Jan; 12, 72-77.

Williams, N.H., T.S. Stahly and D.R. Zimmerman. 1997a. Effect of chronic immune system activation on the rate, efficiency and composition of growth and lysine needs of pigs fed from 6 to $27 \mathrm{~kg}$. Journal of Animal Science, 75, 2463-2471.

Williams, N.H., T.S. Stahly and D.R. Zimmerman. 1997b. Effect of chronic immune system activation on body nitrogen retention, partial efficiency of lysine uitlization, and lysine needs of pigs. Journal of Animal Science, 75, 2472-2480.

Williams, N.H., T.S. Stahly and D.R. Zimmerman. 1997c. Effect of level of chronic immune system activation on the growth and dietary lysine needs of pigs fed from 6 to $112 \mathrm{~kg}$. Journal of Animal Science, 75, 2481-2496.

Williams, P.N., C.T. Collier, J.A. Carroll, T.H. Welsh Jr, and J.C. Laurenz. 2009. Temporal pattern and effect of sex on lipopolysaccharide-induced stress hormone and cytokine response in pigs. Domestci Animal Endocrinology, 37, 139-147.

Wilson, J.M., P.J. Fitschen, and B. Campbell. 2013. International Society of Sports Nutrition Position Stand: beta-hydroxy-beta-methylbutyrate (HMB). Journal of International Society of Sports Nutrition; 20:6. doi: 10.1186/1550-2783-10-6.

Wray-Cahen, D., P.R. Beckett, and H.V. Nguyen. 1997. Insulin-stimulated amino acid utlization during glucose and amino acid clamps decreases with development. American Journal of Physiology, 273, E305-E314.

Yi, G.F., A.M. Gaines, B.W. Ratliff, P. Srichana, G.L. Allee, K.R. Perryman and C.D. Knight. 2006. Estimation of the true ileal digestible lysine and sulfur amino acid requirement and comparison of the bioefficacy of 2-hydroxy-4-(methylthio)butanoic acid and DL-methionine in eleven- to twentysix-kilogram nursery pigs Journal of Animal Science, 84, 1709-1721. 
Yoon, M.S. 2016. The Emerging Role of Branched-Chain Amino Acids in Insulin Resistance and Metabolism. Nutrients 8, 405; doi:10.3390/nu8070405.

Zello, G.A., P.B. Pencharz and R.O. Ball. 1990. Phenylalanine flux, oxidation, and conversion to tyrosine in human studied with L-[1-13 C]phenylalanine. American Journal of Physiology, 259, 835843.

Zhou, H., B. Yu, J. Gao, J.K. Thoo and D. Chen. 2018. Regulation of intestinal health by branchedchain amino acids. Animal Science Journal 89, 3-11. doi:10.1111/asj.12937.

Fuller M.F., R. McWilliam, T.C. Wang, L.R. Giles. 1989. The optimum dietary amino acid pattern for growing pigs. 2. Requirements for maintenance and for tissue protein accretion. Br. J. Nutr., 62:255-267. 


\section{Appendix 1}

\section{Rationale behind the methodology of the clamp technique}

The aim of the clamp technique is to stimulate metabolism at a constant insulin infusion rate and simultaneously $A A$ and glucose are infused at a variable rate so that baseline arterial plasma $A A$ and glucose concentrations are maintained (i.e clamped) at a constant level. To maintain AA and glucose at a constant level, arterial blood samples are collected every 5 to 10 minutes and analyzed for AA and glucose concentration. When arterial $A A$ and/or glucose concentrations decline, the intraportal infusion rate of $A A$ and/or glucose will be increased. When arterial AA and/or glucose concentrations increase, the intraportal infusion rate of $A A$ and/or glucose will be reduced. Depending on the anabolic capacity of the pig, a stable infusion rate for AA and glucose will be reached, generally within 2 hours after the start of the clamp-technique. This is called the steady state phase of the clamp technique and at steady state the NMU is calculated for all individual AA and glucose.

By intraportal infusion, the physiological route of appearance of insulin (secreted from the pancreatic beta-cells during feed intake), glucose and AA (from the intestine after feed intake) is mimicked. Concentrations of insulin, glucose and AA are high in the portal vein during the intraportal clamp studies, and therefore the liver will be exposed to concentrations of insulin, glucose and AA alike the situation during a meal. This allows the liver to fully exert its metabolic control function in the body. For instance, most glucogenic AA (mainly alanine) are metabolized by the liver whereas branchedchain AA (isoleucine, leucine and valine) are metabolized in peripheral tissues. Considering the foregoing argumentation, it is important to impose a correct portal - peripheral gradient for insulin, glucose and all individual AA, resulting in simulation of NMU for glucose and AA alike the situation during a meal.

Two to three hours after the start of the intraportal variable infusion of AA and glucose during the clamp, the activated metabolism reaches a stable phase (steady state) during which the AA and glucose infusion is constant at constant arterial AA and glucose concentrations. During this steady state phase, the amount of AA and glucose infused into the portal vein is equal to the NMU of these AA and glucose at the whole body level. 


\section{Appendix 2}

\section{Trauma, immune system activation and whole body protein turnover}

The effects of general trauma and muscle damage on whole body protein breakdown and synthesis (i.e. protein turnover) has been summarized in the book "Protein turnover" by JC Waterlow, (2006). General trauma was used to describe a multitude of pathological states - burns, soft-tissue (including muscle) injury, fractures, multiple organ failure and generalized sepsis. Trauma is always accompanied by immune system activation (Waterlow, 2006; Durham et al. 2009). Trauma can be considered as severe compromised health, as compared to the LPS and terpentine induced immune system activation in pigs by Dekker et al. (2004) and Kampman-Van de Hoek et al. (2015 thesis, 2015, 2016) which can be considered as more mild. Nevertheless, the body's response with respect to protein turnover seems to be much the same in all the trauma conditions. General trauma (Waterlow JC, 2006) is characterized by an increase in whole body protein breakdown ( $+85 \%$; range from $49 \%$ to $128 \%$ ) which exceeds a simultaneous increase in whole body protein synthesis $(\sim+38 \%$; range from $17 \%$ to $47 \%$ ). The difference between protein breakdown and protein synthesis reflects the increase in AA oxidation ( $\sim 47 \%$; range from $29 \%$ to $81 \%$ ). Whole body protein breakdown largely reflects the breakdown of skeletal muscle whereas whole body protein synthesis largely reflects the synthesis of proteins by the liver related to "general trauma and/or the immune system". It seems therefore that, at the expense of muscle, AA are made available for repair in other parts of the body. The question to be asked could be: how can skeletal muscle degradation be reduced during trauma/immune system activation without inhibiting whole body repair? Before this question can be answered we need to know whether skeletal muscle degradation during trauma/immune system activation can be reduced by nutritional intervention or that it is a given fact because the hormonal and cytokine milieu that accompanies trauma/immune system activation is catabolic and cannot be modulated by feed. During trauma/immune system activation glucocorticoids and glucagon concentrations are increased whereas growth hormone and insulin concentrations are reduced (Newsholme and Leech, 2008). It is possible to increase blood insulin and reduce blood glucagon concentrations by increasing blood glucose concentrations. The latter can be accomplished by feeding glucose and/or starch supplemented feed (Newsholme and Leech, 2008). It is also possible to increase blood insulin concentrations by feeding supplemental branched chain AA, in particular Leu (Manders et al. 2012).This combined feeding approach (extra glucose and BCAA) is feasible. Reducing glucocorticoids can be accomplished by feeding supplemental Trp (Koopmans et al, 2005). This approach seems less feasible related to the costs of supplementing high levels of high L-Trp to induce a reducing effect on cortisol concentrations in blood. So it seems only possible to relieve the catabolic hormonal milieu during trauma and/or immune system activation by feeding extra glucose, starch and BCAA. The latter approach may reduce skeletal muscle degradation during trauma/immune system activation and the achieved reduction in available AA for repair from endogenous sources should be compensated by supplying extra AA via the diet which are needed for whole body repair. The aim of the study of Dekker et al. (2004) was to designate AA which are deficient during immune system activation (Ile, Leu, Val, Trp) and to provide indications for recommendations for changes in amino acid levels in the diets for pigs under immune challenge conditions. 


\section{Appendix 3}

Ingredient and nutrient composition of the starter diet used for model calculations (Pluk and van Krimpen, 2018).

\begin{tabular}{|c|c|c|c|c|c|c|}
\hline Ingredients & & & $\%$ & & & \\
\hline Barley & & & 36.1 & & & \\
\hline Corn & & & 36.8 & & & \\
\hline Soybean meal HP & & & 16.4 & & & \\
\hline Wheat middlings & & & 5.7 & & & \\
\hline Salt & & & 0.4 & & & \\
\hline Limestone & & & 1.15 & & & \\
\hline Palm oil & & & 1.36 & & & \\
\hline Premix & & & 0.75 & & & \\
\hline Monocalcium phosphate & & & 0.64 & & & \\
\hline Sodium bicarbonate & & & 0.07 & & & \\
\hline Potassium bicarbonate & & & 0.09 & & & \\
\hline L-Lysine HCL & & & 0.361 & & & \\
\hline DL-Methionine & & & 0.092 & & & \\
\hline L-Valine & & & 0.035 & & & \\
\hline L-Threonine & & & 0.121 & & & \\
\hline L-Tryptophan & & & 0.014 & & & \\
\hline Dry matter & $\%$ & & 88.6 & & & \\
\hline Moisture & $\%$ & & 11.4 & & & \\
\hline Crude protein & $\%$ & & 16.5 & & & \\
\hline Crude fat & $\%$ & & 3.7 & & & \\
\hline Ash & $\%$ & & 4.7 & & & \\
\hline Starch (Ewers) & $\%$ & & 43.2 & & & \\
\hline Calcium & $\%$ & & 0.61 & & & \\
\hline \multirow[t]{2}{*}{ Phosphorus } & $\%$ & & 0.53 & & & \\
\hline & & & $\begin{array}{l}\text { SID } \\
\text { (\% in } \\
\text { diet) }\end{array}$ & $\begin{array}{c}\text { Rel. to } \\
\text { Lys }\end{array}$ & $\begin{array}{c}\text { Gross } \\
(\%)\end{array}$ & $\begin{array}{l}\text { SID } \\
(\%)^{1}\end{array}$ \\
\hline EW (energy value pigs) & - & CVB & 1.10 & & & \\
\hline Lysine & $\%$ & CVB & 0.93 & 1.00 & 1.05 & 89 \\
\hline Methionine & $\%$ & CVB & 0.32 & 0.34 & 0.35 & 91 \\
\hline Cysteine & $\%$ & CVB & & & 0.29 & \\
\hline Methionine + Cysteine & $\%$ & CVB & 0.56 & 0.60 & 0.64 & 87 \\
\hline Threonine & $\%$ & CVB & 0.60 & 0.65 & 0.71 & 86 \\
\hline Tryptophan & $\%$ & CVB & 0.17 & 0.18 & 0.20 & 85 \\
\hline Isoleucine & $\%$ & CVB & 0.60 & 0.60 & 0.64 & 86 \\
\hline Leucine & $\%$ & CVB & 1.15 & 1.23 & 1.32 & 86 \\
\hline Valine & $\%$ & CVB & 0.69 & 0.74 & 0.80 & 86 \\
\hline Arginine & $\%$ & CVB & 0.91 & 0.98 & 1.00 & 91 \\
\hline Histidine & $\%$ & CVB & 0.37 & 0.40 & 0.42 & 87 \\
\hline Phenylalanine & $\%$ & CVB & 0.70 & 0.75 & 0.80 & 87 \\
\hline Tyrosine & $\%$ & CVB & 0.49 & 0.52 & 0.56 & 87 \\
\hline
\end{tabular}

${ }^{1}$ standardized ileal digestible (SID) 


\section{Appendix 4}

Calculation of the protein deposition in a pig of $50 \mathrm{~kg}$ in the reference (non-challenged) health scenario based on the dietary supply of Lys.

\begin{tabular}{|c|c|c|}
\hline Parameter & Unit & Value \\
\hline BW & $\mathrm{kg}$ & 50 \\
\hline $\mathrm{CP}$ content in the diet & $\mathrm{g} / \mathrm{kg}$ & 165 \\
\hline Feed intake & $g / d$ & 1700 \\
\hline Extra free AA suppl. & $\mathrm{g} / \mathrm{kg}$ & - \\
\hline Total lysine content diet & $\mathrm{g} / \mathrm{kg}$ & 10.50 \\
\hline SID AA & $\%$ & 89 \\
\hline SID diet (formulated) & $\mathrm{g} / \mathrm{kg}$ & 9.3 \\
\hline SID intake & $g / d$ & 15.9 \\
\hline Intake (SID) rel. to Lys & $\%$ & 100 \\
\hline \multicolumn{3}{|l|}{ Maintenance (50 kg BW) } \\
\hline Integument & $\mathrm{mg} / \mathrm{d}$ & 85 \\
\hline Basal turnover & $\mathrm{mg} / \mathrm{d}$ & 449 \\
\hline Basal endogenous & $\mathrm{mg} / \mathrm{d}$ & 532 \\
\hline immune AA profile 1 (APP/Ig) & & 0 \\
\hline Immune AA profile 2 (MUC) & & 0 \\
\hline Immune proteins (APP/Ig) $(50 \mathrm{~kg})$ & $\mathrm{mg} / \mathrm{d}$ & 0 \\
\hline Total, net & $g / d$ & 1.07 \\
\hline Total, gross & $g / d$ & 1.48 \\
\hline Maintenance req. rel. to SID intake & $\%$ & 9.3 \\
\hline \multicolumn{3}{|l|}{ Retention body } \\
\hline Gross available & $g / d$ & 14.4 \\
\hline Max. efficiency factor (per AA) & & 0.72 \\
\hline Change efficiency factor & & 1.00 \\
\hline Net available & $g / d$ & 10.4 \\
\hline AA in body protein ( $\mathrm{g}$ per 100 gram protein) & & 6.96 \\
\hline Protein retention (Ref.) & $g / d$ & 149.0 \\
\hline Protein intake & $\mathrm{g} / \mathrm{d}$ & 280 \\
\hline Protein efficiency & $\%$ & 53 \\
\hline Scenario performance level & $\%$ & 100 \\
\hline
\end{tabular}




\section{Appendix 5}

Maximum efficiency of using standardized ileal digestible protein and amino acids for body protein deposition, calculated from the ideal amino acid profile, maintenance requirements and body composition for AA (van Milgen et al., 2008).

Maximum efficiency of using standardised ileal digestible protein and amino acid for body protein deposition, calculated from the ideal amino acid profile, maintenance requirements and body composition

\begin{tabular}{|c|c|c|c|c|c|c|}
\hline Item & $\begin{array}{l}\text { Ideal amino } \\
\text { acid profile }^{\mathrm{a}}\end{array}$ & $\begin{array}{l}\text { Integument loss } \\
\left(\mathrm{mg} / \mathrm{kg} \mathrm{BW}^{0.75} / \mathrm{d}\right)\end{array}$ & $\begin{array}{l}\text { Losses due to basal } \\
\text { turnover }^{\mathrm{b}}(\mathrm{mg} / \mathrm{kg} \\
\left.\mathrm{BW}^{0.75} / \mathrm{d}\right)\end{array}$ & $\begin{array}{l}\text { Basal endogenous } \\
\operatorname{losses}^{\mathrm{c}}(\mathrm{g} / \mathrm{kg} \text { DMI })\end{array}$ & $\begin{array}{l}\text { Content in body } \\
\text { protein }^{\mathrm{d}}\end{array}$ & $\begin{array}{l}\text { Maximum } \\
\text { efficiency } \\
\left(k_{\mathrm{AA}}\right)^{\mathrm{e}}\end{array}$ \\
\hline Protein & n.a. & 104.4 & 361.1 & 8.517 & 1.0000 & 0.81 \\
\hline Methionine & 0.30 & 1.0 & 7.0 & 0.087 & 0.0188 & 0.64 \\
\hline Cystine & n.a. & 4.7 & 4.7 & 0.140 & 0.0103 & n.a. \\
\hline Methionine + cystine & 0.60 & 5.7 & 11.7 & 0.227 & 0.0291 & 0.51 \\
\hline Isoleucine & 0.60 & 2.5 & 12.4 & 0.257 & 0.0346 & 0.60 \\
\hline Leucine & 1.00 & 5.3 & 27.1 & 0.427 & 0.0717 & 0.76 \\
\hline Valine & 0.70 & 3.8 & 16.4 & 0.357 & 0.0467 & 0.71 \\
\hline Phenylalanine & 0.50 & 3.0 & 13.7 & 0.273 & 0.0378 & 0.82 \\
\hline Tyrosine & n.a. & 1.9 & 9.0 & 0.223 & 0.0286 & n.a. \\
\hline Phenylalanine + tyrosine & 0.95 & 4.9 & 22.7 & 0.497 & 0.0664 & 0.75 \\
\hline Histidine & 0.32 & 1.3 & 10.2 & 0.130 & 0.0279 & 0.93 \\
\hline
\end{tabular}

a From Sève (1994).

b From Moughan (1998).

'From Noblet et al. (2002).

d From Le Bellego and Noblet (2002).

${ }^{\mathrm{e}}$ The maximum efficiencies are calculated from the hypothesis that the ideal amino acid profile is correct for a pig weight $55 \mathrm{~kg}$, consuming $1625 \mathrm{~g}$ of feed per day and with an average daily gain of $650 \mathrm{~g} / \mathrm{d}$. The efficiency for lysine was fixed at 0.72 , from which the $k_{\mathrm{AA}}$ values of the other amino acids were calculated. 


\section{Appendix 6}

Calculated effects of health scenario (reference vs. LSC; scenario 1 and $5 a$ ) and dietary energy density adjustment on calculated protein and fat deposition in the body of pigs $(50 \mathrm{~kg})$.

\begin{tabular}{|c|c|c|c|c|}
\hline & Units & Ref. & LSC & LSC adj. $^{3}$ \\
\hline NE in diet & $\mathrm{MJ} / \mathrm{kg}$ & 9.68 & 9.68 & 10.70 \\
\hline EW diet & & 1.10 & 1.10 & 1.22 \\
\hline Feed intake & $g / d$ & 1700 & 1632 & 1632 \\
\hline NE intake & $\mathrm{MJ} / \mathrm{d}$ & 16.5 & 15.2 & 16.8 \\
\hline $\mathrm{NE}$ requirement for maintenance & $\mathrm{MJ} / \mathrm{d}$ & 5.45 & 5.89 & 5.89 \\
\hline NE for protein and fat retention & $\mathrm{MJ} / \mathrm{d}$ & 11.0 & 9.28 & 10.9 \\
\hline Marginal ratio & $\mathrm{g} / \mathrm{g}$ & 1.28 & 1.28 & 1.28 \\
\hline Protein deposition (basal) ${ }^{1}$ & $\mathrm{~g} / \mathrm{d}$ & 42.4 & 45.8 & 45.8 \\
\hline Protein deposition (additional) ${ }^{2}$ & $\mathrm{~g} / \mathrm{d}$ & 106.4 & 85.3 & 103.4 \\
\hline Protein deposition (total) & $g / d$ & 149 & 131 & 149 \\
\hline Fat deposition & $g / d$ & 149 & 119 & 144 \\
\hline
\end{tabular}

${ }^{1}$ Protein deposition below a feeding level of $1.3 \times \mathrm{M}$, below which only protein is deposited and no fat. ${ }^{2}$ When the feeding level is above $1.3 \times \mathrm{M}$, protein and fat are deposited in proportion equal to the marginal ratio till the maximum protein deposition capacity is reached ( $P D_{\max }$ ).

${ }^{3}$ LSC (low sanitary condition) scenario in which a diet is fed with an increased energy density and increased levels of dietary (SID) Trp, Thr, Val, Lys, Met + Cys and Ile to compensate for the assumed increased requirements for these amino acids to allow a body protein deposition equal to the reference scenario. 

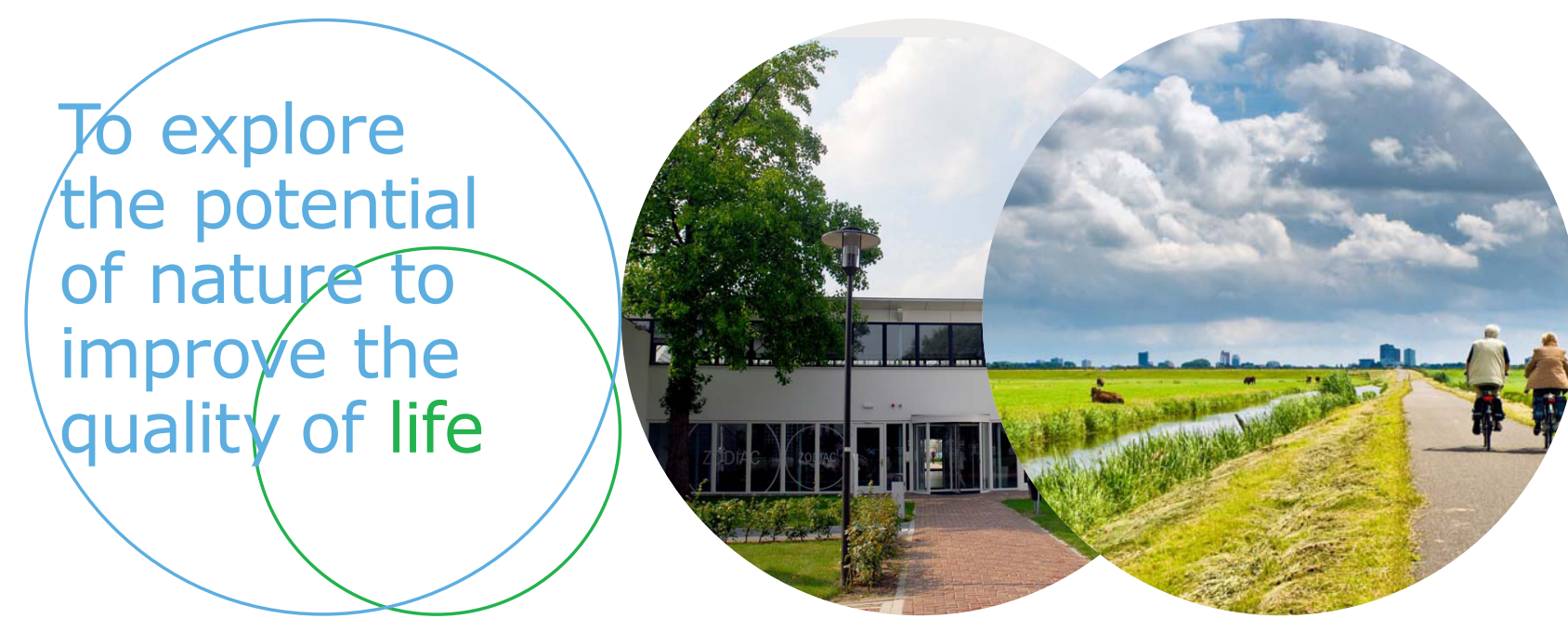

Wageningen Livestock Research P.O. Box 338

$6700 \mathrm{AH}$ Wageningen

The Netherlands

T +31 (0)31748 3953

E info.livestockresearch@wur.nl

www.wur.nl/livestock-research

Wageningen Livestock Research creates science based solutions for a sustainable and profitable livestock sector. Together with our clients, we integrate scientific knowledge and practical experience to develop livestock concepts for future generations.

Wageningen Livestock Research is part of Wageningen University \& Research. Together we work on the mission: 'To explore the potential of nature to improve the quality of life'. A staff of 6,500 and 10,000 students from over 100 countries are working worldwide in the domain of healthy food and living environment for governments and the business community-at-large. The strength of Wageningen University \& Research lies in its ability to join the forces of specialised research institutes and the university. It also lies in the combined efforts of the various fields of natural and social sciences. This union of expertise leads to scientific breakthroughs that can quickly be put into practice and be incorporated into education. This is the Wageningen Approach. 